\title{
AN EVALUATION OF ENVIRONMENTAL IMPACT ASSESSMENT IN ERITREA
}

\author{
by \\ TEDROS KUBROM ZEREMARIAM
}

Submitted in partial fulfilment of the academic requirements

for the degree of

Masters of Environment and Development

in the

Centre for Environment and Development,

School of Applied Environmental Sciences,

University of Natal

\section{Pietermaritzburg}

2003 


\begin{abstract}
This paper reviews environmental impact assessment (EIA) policy and practice in Eritrea against a set of evaluation criteria. These include: institutional aspects of the ELA system (policy development, legal basis for EIA, institutional strength and responsibilities for EIA administration, and resources adequacy); the EIA process (screening, scoping, EIA study, documentation, review, decision-making, and monitoring and auditing); and other features of the EIA system (coverage, consideration of alternatives, public consultation and participation, system monitoring, the cost and benefit of EIA system and strategic environmental assessment (SEA)).
\end{abstract}

To assess the extent of ELA practice, the EIA report review criteria developed by the Impact Assessment Unit (IAU) of Oxford Brookes University were used to review case studies of two sectoral EIA reports: the Massawa International Airport Project and the Keren Water Supply Project. Additionally, a literature review was undertaken and interviews with different stakeholders were conducted to collect the required information.

The review indicated that, in principle and at a policy level, the current EIA system in Eritrea meets ten of the 17 evaluation criteria, partially meets three and fails to meet four. The major weakness relates to the legal provisions for EIA; adequacy of resources (human and environmental data/information); centrality of EIA findings in decision making; and the formal provision for SEA for programmes, plans and policies. In practice, however, the overall EIA system in the country is weakly established. Thus, to strengthen the current EIA system in the country increased environmental awareness, continuous training in EIA for government officials, consultants, and research and educational institutions is required. Most importantly, revision and subsequent proclamation of the draft legislation is required to provide a sound legal basis for EIA in Eritrea. 


\section{PREFACE}

The research described in this mini-dissertation was carried out at the Centre for Environment and Development, University of Natal, Pietermaritzburg, under the supervision of Dr Nevil Quinn.

The mini-dissertation represents the original work of the author and has not otherwise been submitted in any form for any other degree or diploma at any university. Where use has been made of the work of others it is duly acknowledged in the text.

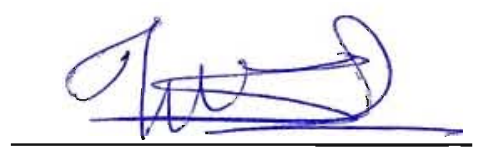

Tedros Kubrom Zeremariam

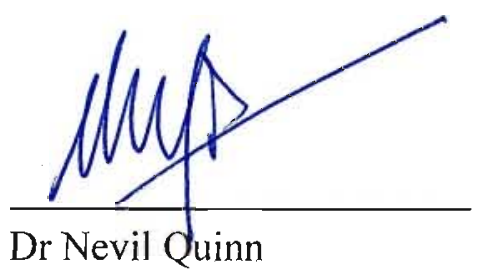




\section{ACKNOWLEDGEMENTS}

I am very grateful to Dr Nevil Quinn, my supervisor, whose support and guidance has been of tremendous assistance in driving the dissertation to its conclusion. I am also grateful to all those who gave of their precious time to provide me with information: Gezae Kibreab, Leake Woldegiorgis, Marilou Bradley, Mebrahtu Ogbazgi, Mogos Welde-Yowhannis, Petros Tsegay, Semereab Habtetsion, Sengal Weldetensae, Simon Ghebregziabher, Teclemariam Berhane, Teclemarian Zego and Yohannes Debresion. Thanks also to Estifonos Bein, Filmon Tsegay, Habteab Tesfasion, Kidane Brhane, Mebrahtu Eyasu, Mihret Girmay, Resene Abraha, Simon Araya, Sofia Weldu, and Tekleab Mesghena, for their assistance and readiness to provide documents and materials for this paper. Finally thanks to EHRD for funding all my studies and to Nyambe Nyambe for his support and encouragement during the writing of the paper. Any error of fact or judgment is mine, and should not be attributed to any respondent. 


\section{TABLE OF CONTENTS}

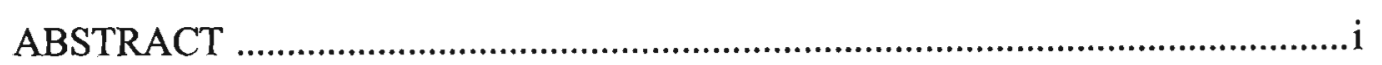

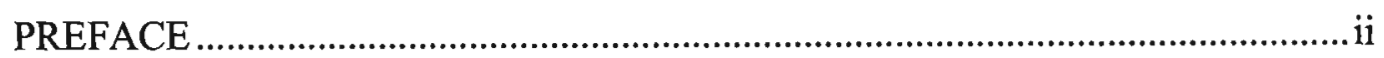

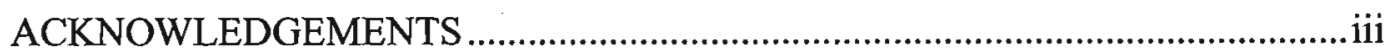

ABBREVIATIONS AND ACRONYMS …........................................................

TABLE OF CONTENTS FOR COMPONENT A ............................................... vii

LIST OF TABLES, FIGURES, BOXES AND APPENDICES FOR

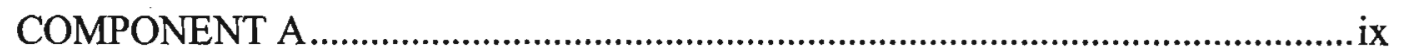

TABLE OF CONTENTS FOR COMPONENT B .................................................

LIST OF TABLES, FIGURES AND APPENDICES FOR COMPONENT B .........xii 


\section{ABBREVATIONS AND ACRONYMS}

$\begin{array}{ll}\text { AfDB } & \text { African Development Bank } \\ \text { CBD } & \text { Convention on Biological Diversity } \\ \text { CCC } & \text { Convention on Climate Change } \\ \text { CCD } & \text { Convention to Combat Desertification } \\ \text { CEC } & \text { Council of European Communities } \\ \text { CITES } & \text { Convention on International Trade in Endangered Species of Animals } \\ & \text { and Plants } \\ \text { DEAT } & \text { Department of Environmental Affairs and Tourism } \\ \text { DEP } & \text { Draft Environmental Proclamation } \\ \text { DoE } & \text { Department of Environment } \\ \text { EA } & \text { Environmental Assessment } \\ \text { EE } & \text { Environmental Evaluation } \\ \text { EER } & \text { Environmental Evaluation Report } \\ \text { EEQ } & \text { Environmental Evaluation Questionnaire } \\ \text { EIA } & \text { Environmental Impact Assessment } \\ \text { EIS } & \text { Environmental Impact Statement } \\ \text { EMP } & \text { Environmental Management Plan } \\ \text { ESA } & \text { Environmentally Sensitive Area } \\ \text { FINNIDA } & \text { Finish International Development Agency } \\ \text { GoE } & \text { Government of Eritrea } \\ \text { IAIA } & \text { International Association for Impact Assessment } \\ \text { IAU } & \text { Impact Assessment Unit } \\ \text { IEE } & \text { Initial Environmental Examination } \\ \text { IRC } & \text { Impact Review Committee } \\ \text { MARPOL } & \text { International Convention for Prevention of Pollution from Ships } \\ \text { MENA } & \text { Middle East and North Africa } \\ \text { NAP } & \text { National Action Program to Combat Desertification and Mitigate the } \\ & \text { Effect of Draught } \\ & \text { National Biodiversity Strategy and Action Plan } \\ & \end{array}$


NEAP National Environmental Action Plans

NEAPG National Environmental Assessment Procedures and Guidelines

NEMP-E National Environmental Management Plan for Eritrea

NEPA National Environmental Policy Act

NGO Non-Governmental Organisation

NORAD Norwegian Agency for International Development

NRCE Natural Resource Consulting Engineers

OECD Organisation for Economic Cooperation and Development

PRA Participatory Rural Appraisal

PRS Economic Growth and Poverty Reduction Strategy

SEA Strategic Environmental Assessment

TOR Terms of Reference

UNEP United Nations Environment Program

UNCLOS United Nations Convention on the Law of Sea

USAID United States Agency for International Development

WSSD World Summit on Sustainable Development 


\section{TABLE OF CONTENTS FOR COMPONENT A}

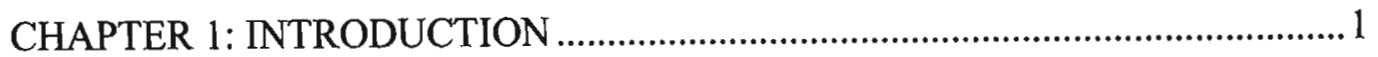

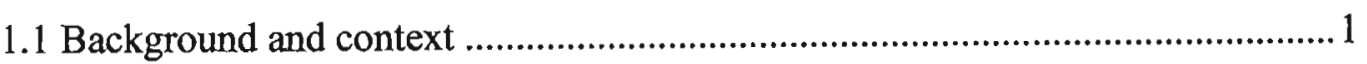

1.1.1 Historical development of environmental impact assessment ................... 1

1.1.2 Environmental impact assessment and sustainable development ............... 3

1.2 Eritrea's response to the global environmental concern .....................................4

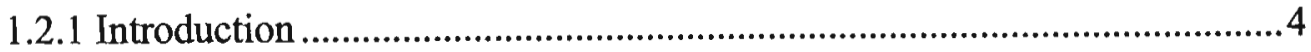

1.2.2 International environmental conventions signed by Eritrea........................6

1.3 Introduction to environmental impact assessment in Eritrea............................... 7

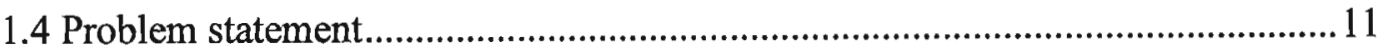

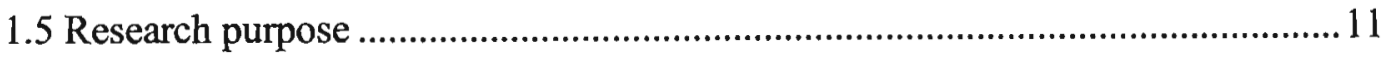

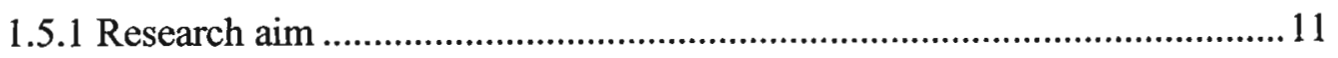

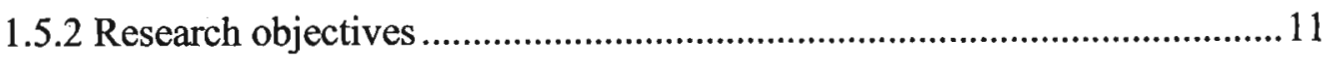

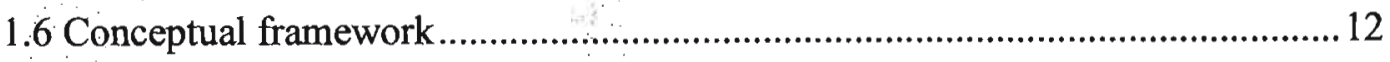

CHAPTER 2: ENVIRONMENTAL IMPACT ASESSMENT: SCOPE, DEFINITION, OBJECTIVE AND PRINCIPLES.............................................. 14

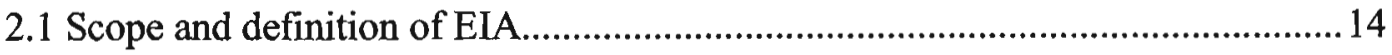

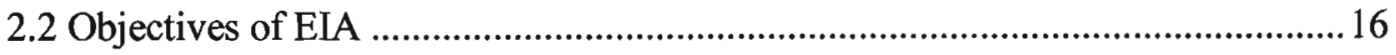

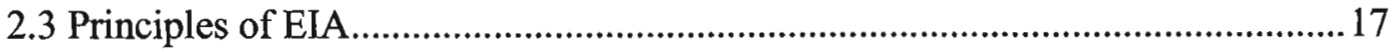

CHAPTER 3: ENVIRONMENTAL IMPACT ASSESSMENT SYSTEMS:

EVALUATION CRITERIA, PROCESS AND ENSTITUTIONAL ASPECTS.......21

3.1 Evaluating effectiveness of the ELA systems.....................................................21

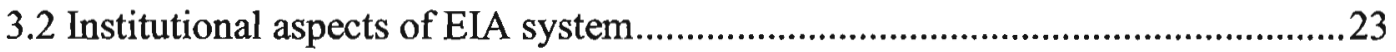

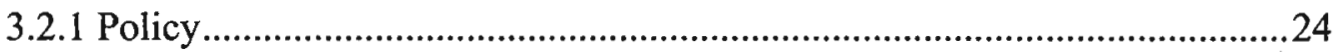

3.2.2 Establishment of an environmental institution.......................................25

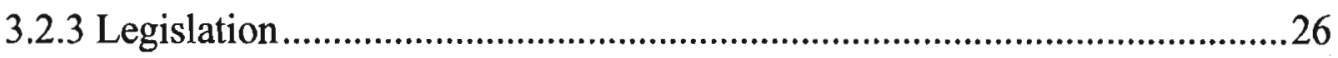

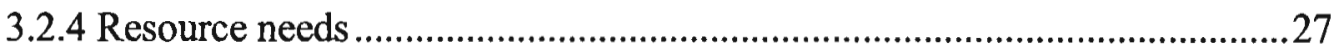

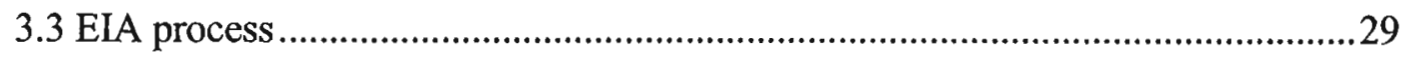




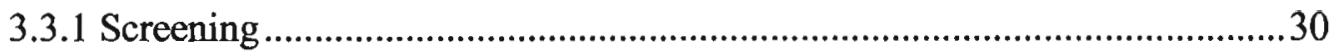

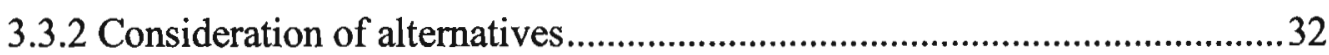

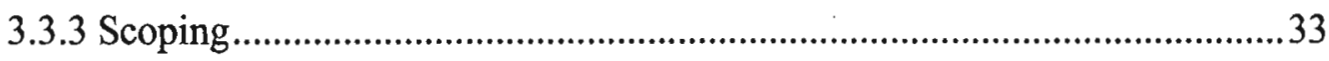

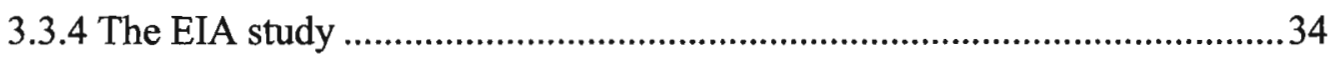

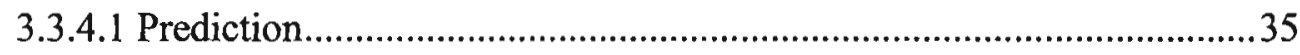

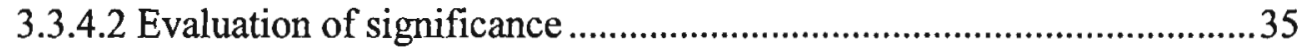

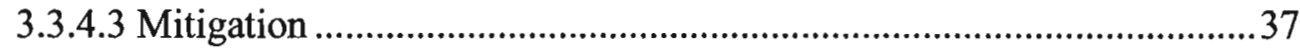

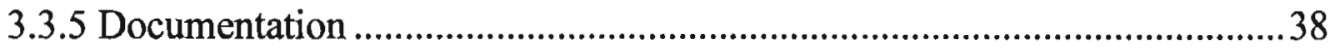

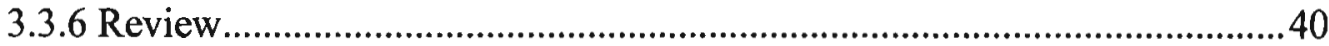

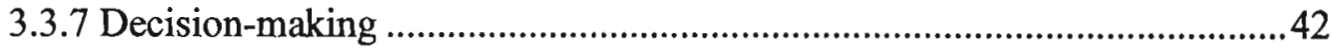

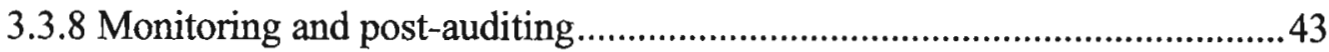

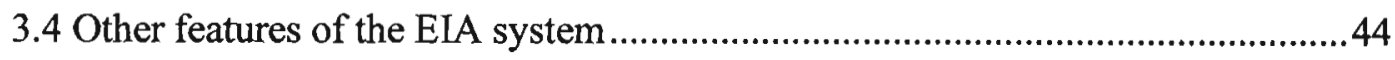

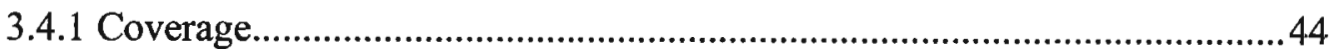

3.4.2 Public consultation and participation ....................................................45

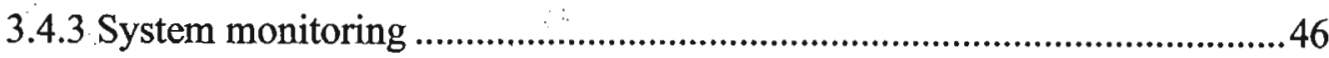

3.4.4 Cost and benefit of the EIA system........................................................4

3.4.5 Project EIA sustained by SEA............................................................ 48

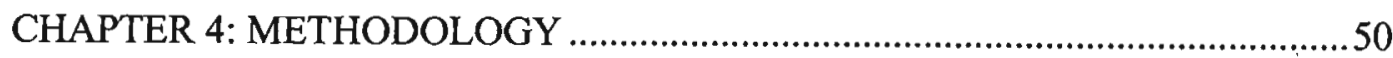

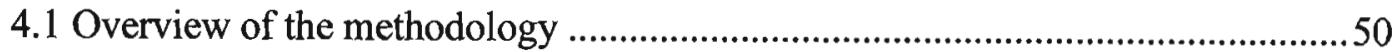

4.2 Evaluation of the national ELA system ….......................................................5.

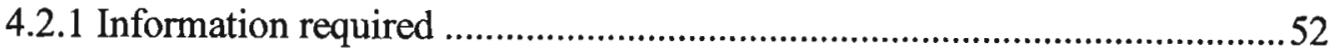

4.2.2 Methods of information gathering.........................................................5

4.2.3 Criteria for reviewing the EIA system ...............................................5

4.3 Evaluation of two sectoral EIA case studies....................................................5

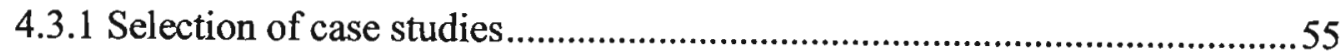

4.3.2 Criteria for reviewing the quality of EISs ............................................56

4.4 Assumptions and anticipated problems ........................................................5

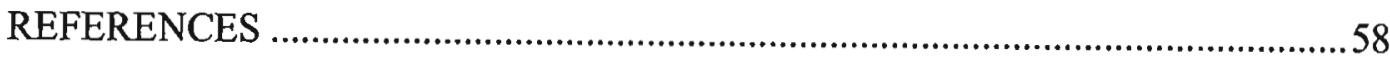




\section{LIST OF TABLES, FIGURES, BOXES AND APPENDICES FOR COMPONENT A}

\section{TABLES}

Table 1.1: International agencies involved with EIA ………….............................

Table 2.1: Environmental assessment- the evolving paradigm...................................15

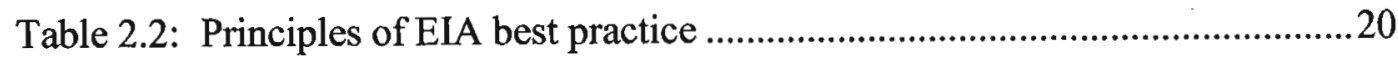

Table 4.1: Interviewees for the study ..................................................................53

\section{FIGURES}

Figure 1.1: The geographical location of Eritrea ………………..............................

Figure 1.2: Flowchart of environmental assessment process in Eritrea.....................9

Figure 1.3: Flowchart of full EIA process in Eritrea …………................................ 10

Figure 1.4: EIA as a tool for sustainable decision making ...................................... 12

Figure 1.5: Schematic illustration of the contextual framework of the focus of the

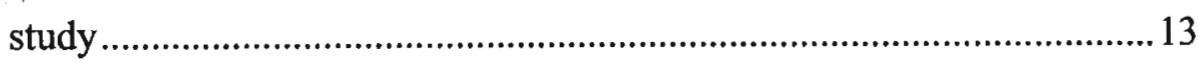

Figure 3.1: The environment impact assessment process .............................................30

Figure 4.1: The methodology adopted for the study ..................................................51

\section{BOXES}

Box 1.1: International environmental conventions signed by Eritrea..........................

Box 2.1: Emerging areas of impact assessment-definition........................................... 16

Box 2.2: Enforcement of public participation, one of principal features of EIA,

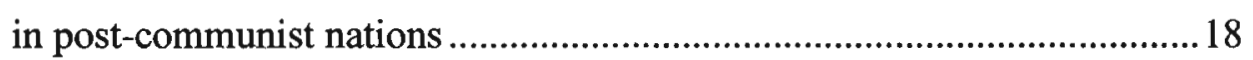

Box 3.1: EIA system evaluation criteria .............................................................23

Box 3.2: Recognition of environmental and economic goals in the WSSD agenda.. 24

Box 3.3: The role of NGOs and international aid agencies in supporting institutional strengthening of developing countries: an example of Middle East and North Africa (MENA) ...............................................26

Box 3.4: Time and cost effective environmental assessment: a lesson from Greater Cairo Wastewater Project.............................................................28 
Box 3.5: World Bank Category A, B and C projects/Components ........................... 31

Box 3.6: Determination of environmental significance ...........................................36

Box 3.7: Alternative means of mitigation.............................................................. 37

Box 3.8: Examples of Findings of EIS quality reviews ...........................................39

Box 3.9: Requirements for preparing an effective EIA report.................................40

Box 3.10: The World Bank's environmental assessment review criteria ..................4 41

Box 3.11: Examples of weak links between EIA and decision-making ....................42

Box 3.12: Examples of positive consequences of public participation.......................46

Box 3.13: Monitoring of EIA systems in South Africa ............................................4 47

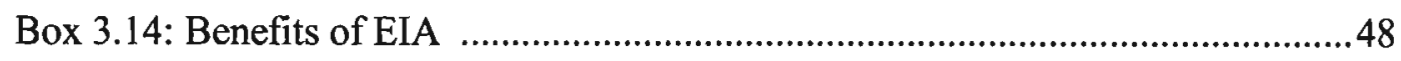

Box 3.15: Courses of action for making SEA effective...........................................49

Box 4.1: EIA system evaluation criteria adopted for this study ..............................55

\section{APPENDICES}

Appendix 1: EIS review criteria (IAU, Oxford Brookes University)

Appendix 2: Documents requested and interview questions 


\section{TABLE OF CONTENTS FOR COMPONENT B}

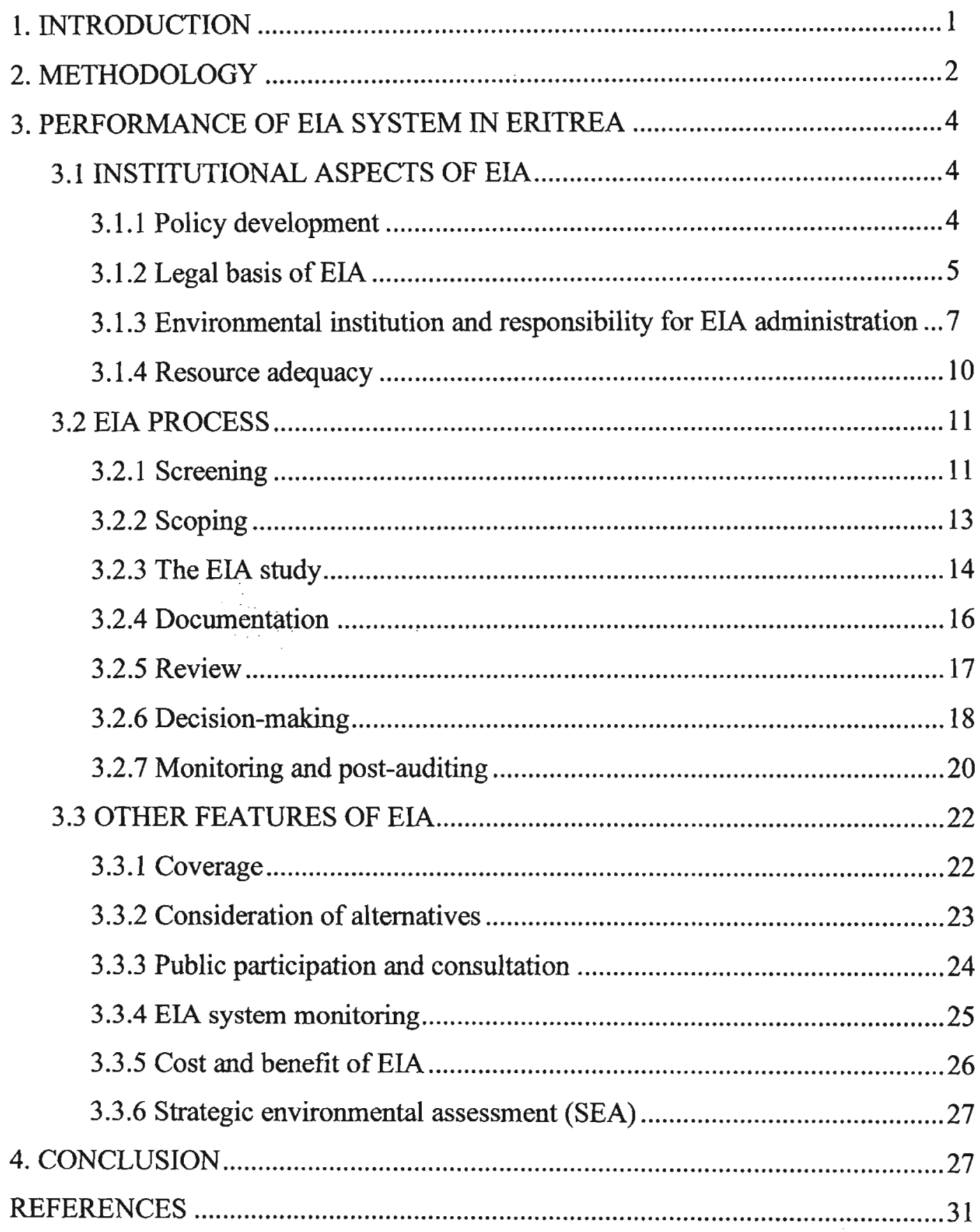




\section{LIST OF TABLES, FIGURES AND APPENDICES FOR COMPONENT B}

\section{TABLES}

Table 1: National policy documents for sustainable development ............................. 4

Table 2: Annual trend of project screening (1999-mid 2002) ................................. 12

Table 3: Annual trend of decisions for environmental clearance (1999-mid 2002) .. 19

Table 4: Performance of the Eritrea EIA system .....................................................22

Table 5: Summary of the EIA report review for the two sectoral case studies...........30

\section{FIGURE}

Figure 1: Organizational structure of Department of Environment, Ministry of and, Water and Environment 9

\section{APPENDICES}

Appendix 1: List of interviewees

Appendix 2: EIA report review for sectoral case studies

Appendix 3: Annual report on EIA of projects for environmental clearance (1999-mid 2002) 
COMPONENT A 


\section{CHAPTER 1 \\ INTRODUCTION}

\subsection{Background and context}

Since the time of earliest civilization, human beings have been causing deterioration to the environment. The main global environmental concerns include: land degradation, forest loss and degradation, loss of biological diversity and habitat fragmentation, access to fresh water and water pollution, degradation in marine and coastal zones, atmospheric pollution and global warming, Ozone layer depletion and acid rain (Pearce 1995; United Nations Environment Program 1997). Many of these environmental problems initially manifested at local levels, but are now an international concern (Mannion \& Bowlby 1992). Localized problems (such as deforestation and atmospheric pollution) are increasingly seen as a cause for global problems through their cumulative effects (Middleton 1999). These problems, therefore, require an international response that needs to start at a local scale, if global sustainability is to be achieved.

\subsubsection{Historical development of environmental impact assessment}

In the 1960s environmental awareness resulted in promulgation of a law in United States, the National Environmental Policy Act (NEPA) of 1969, that represented a landmark in environmental management (Modac \& Biswas 1999). NEPA introduced environmental impact assessment (EIA) for first time, which required consideration of possible impacts prior to decision-making on whether or not a proposal should be given approval to proceed (Wood 1995; Modac \& Biswas 1999). Since then the concept of EIA has spread to cover most of the developed world. In developing countries, however, it was introduced later and is less firmly established, although a few countries such as Malaysia and the Philippines adopted it at early stage (1974 and 1978 respectively) (Lee \& George 2000). African countries in general are lagging behind in the adoption of EIA. Barrow (1997), however, noticed that a few countries such as South Africa, Egypt, Nigeria and Ghana have made some progress with the implementation of EIA in their development programmes.

The method of adoption of EIA has varied from country to country. Some use law and specific regulations, others respond initially by using existing environmental planning legislation with emphasis on the assessment of environmental impact. Cabinet resolutions 
and advisory procedures are also used as a way of implementing EIA policies and procedures in some countries (Gilpin 1995; Wood 1995). Since its initial introduction EIA has evolved and spread considerably. Roe et al. (1995) mention that by the end of 1970s more attention was required to assess the effectiveness, efficiency and relevance of EIA which resulted in emergence of new techniques such as social and cumulative impact assessment and risk analysis. In addition there was also a trend of moving ELA from project-level scope to the level of plans and policies (Roe et al. 1995; Modac \& Biswas 1999).

The globalization of the world economies through trade, financial markets and information flows, is complemented by negotiations on global and regional environmental issues. These negotiations are leading to the management of key resources such as water and forests (National Strategies for Sustainable Development 2000), which require the use of environmental management tools such as EIA. Many international agencies have adopted some form of EIA policy (Table 1.1). Furthermore the number of individual countries that have adopted EIA as an environmental management tool have increased rapidly. There are possibly more than 100 countries having some type of national system or equivalent international requirement (e.g. as a requirement for granting aid). This diffusion of EIA has been driven and accompanied by innovation in law, procedure and method (Canter 1996; Sadler 1996).

Table 1.1: International agencies involved with ELA (Wood 1995; Barrow 1997; Modac \& Biswas 1999)

\begin{tabular}{|l|l|}
\hline \multicolumn{1}{|c|}{ Agency } & Year \\
\hline Organisation for Economic Cooperation and Development (OECD) & 1974 \\
\hline US Agency for International Development (USAID) & 1975 \\
\hline Council of European Communities (CEC) & 1985 \\
\hline Norwegian Agency for International Development (NORAD) & 1988 \\
\hline United Nations Environment Program (UNEP) & 1988 \\
\hline Finish International Development Agency (FINNIDA) & 1989 \\
\hline World Bank & 1989 \\
\hline African Development Bank (AfDB) & 1992 \\
\hline
\end{tabular}




\subsubsection{Environmental impact assessment and sustainable development}

A global change in perception in matters of development and environment occurred in the 1970 s as a result of the rise in environmental awareness (World Commission on Environment and Development 1987; Welford 1998). Sustainable development is defined as "development that meets the needs of the present without compromising the ability of future generations to meet their own needs" (World Commission on Environment and Development 1987:4), and is the prevailing paradigm that emerged out of this global environmental awareness. Sustainable development recognises that economic growth alone is insufficient for the purpose of development. The central idea is that development can occur only if and when there is recognition of the need to sustain and expand the environmental resource base (Smith 1993). This, therefore, indicates the need for certain management tools that reconcile environment and development and help to achieve sustainable development.

EIA is one of the management tools that are intended to achieve sustainable development. The World Commission on Environment and Development recognises EIA as an essential component in the promotion of sustainable development. Moreover, principle 17 of the 1992 Rio Declaration of Environment and Development stipulates the adoption of EIA as a national instrument to achieve sustainable development (Gilpin 1995). EIA addresses the challenges of traditional decision-making which are only based on technical feasibility, financial viability and legal permissibility (Smith 1993). EIA improves decision-making by ensuring that project options under consideration are environmentally sound and sustainable (Roe et al. 1995).

Geping (1987) identified three roles of EIA in sustainable development, which also have direct benefit to developing countries. Firstly, the introduction of EIA will change the traditional patterns of economic development, by bringing about a coordinated development of the economy and the environment through reconciling economic considerations and environmental concerns. Secondly, EIA provides a basis for determining the direction and scale for development for a given region. That is, when EIA is applied to policies, plans and programs, it can provide information on the environmental conditions and environmental carrying capacity of a given region and this will help to formulate appropriate social and economic development plans accordingly. Thirdly, EIA provides a basis for formulating appropriate environmental protection policies and 
implementing sound management. It will tell us what limits to impose on pollution and damage caused by a particular construction project in order to meet the requirement of an environmental standard. Also, EIA provides a basis for introducing other environmental management systems. These, therefore, show that there is a great opportunity in EIA as a tool for sustainable development where developing countries can derive a benefit.

\subsection{Eritrea's response to the global environmental concern}

\subsubsection{Introduction}

Eritrea is a country in the north-east of Africa (Figure 1.1) bordering Ethiopia to the south and the Red Sea between Djibouti and Sudan, with a total land area of $124320 \mathrm{~km}^{2}$ (Lonely Planet 2002). The country has a varied terrain and climate which includes: savannah, temperate highlands, and a desert coastal plain (Pool 1982). Based on the 1999 estimate, the population size of Eritrea is 3719000 with a growth rate of $4.57 \%$ (FAO/GIEWS 2001). Agriculture contributes $80 \%$ of the country's economy, while the balance is contributed by industry and services. 


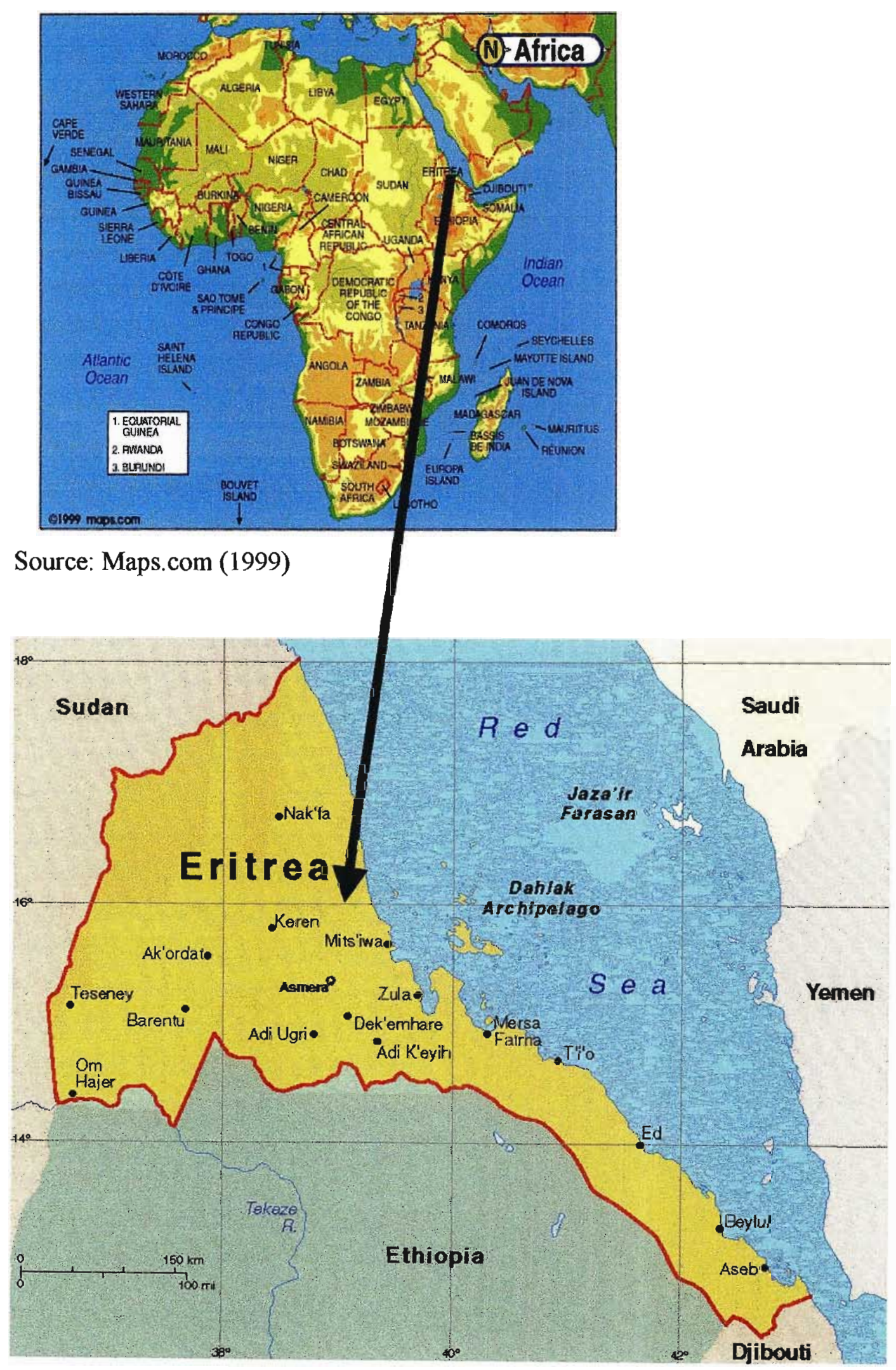

Source: GeographyIQ (2002)

Figure 1.1: The geographical location of Eritrea 


\subsubsection{International environmental conventions signed by Eritrea}

While many countries were taking action to tackle the global environmental problems through international conventions, Eritrea was fighting for independence and selfdetermination from 1960 to 1991 . This thirty years war has had severe consequences for the people and the environment of the nation. However, soon after their independence Eritreans joined the global community and committed themselves to sustainable development and to the principles of Agenda 21. Moreover, the Government of Eritrea (GoE) firmly subscribes to the wisdom behind the traditional African saying: "the environment is not ours to do as we wish, rather, it is what we borrowed from future generation" (Government of Eritrea 1995:1).

Eritrea is currently party to several international conventions. These conventions are given in Box 1.1. Furthermore, Eritrea has recognised that "complete self-sufficiency is a myth and that many environmental resources are shared with neighboring countries, and therefore the People and the Government must promote global and regional alliance for environmental sustainable development" (Government of Eritrea 1995: 2).

Box 1.1: International environmental conventions signed by Eritrea (Filmon 2002 pers. comm.)

- Convention on International Trade in Endangered Species of Animals and Plants (CITES)

- Convention on Climate Change (CCC)

- Convention to Combat Desertification (CCD)

- Convention on Biological Diversity (CBD)

- International Convention for Prevention of Pollution from Ships (MARPOL)

- The Convention on Prevention of Marine Pollution by dumping waste and other matter (London Convention)

- UN Convention on the Law of Sea (UNCLOS)

- Convention concerning the protection of World Cultural and National Heritage (World Heritage Convention)

- African Convention on the Conservation of Nature and Natural Resources

- Regional Convention for the Conservation of Red Sea and Gulf of Aden 


\subsection{Introduction to environmental impact assessment in Eritrea}

The thirty years war for independence and self-determination coupled with drought, and past colonial administration that lacked sound management of natural resource has resulted in environmental degradation in Eritrea. One typical example is the failure of the plan to increase domestic food production drastically through extensification and intensification of agriculture. Advisors have noted that,

"although some increase was recorded, mainly through extensification, the overall increase in food production was not only insignificant but also of wide fluctuations between years. It was recognised that besides lack of soil moisture, the severe degradation of natural resources base for agriculture was one of the main limiting factors for the result" T. Consult (2001:2).

To address environmental problems and head towards sustainable development, the GoE has given attention to the incorporation of environmental issues into its macro-policy. To strengthen the environmental dimension of the macro-policy the National Environmental Management Plan for Eritrea (NEMP-E) was developed by an interministerial committee (Government of Eritrea 1995). Besides these, the Constitution of Eritrea was ratified in 1997 with a provision that the state shall be responsible for land, water, air and natural resource management to ensure sustainable development (Government of Eritrea 1997).

Moreover, section 16 (a) of the macro-policy indicates the need for EIA by stipulating that "environmental consequence of every intended investment will be studied as a necessary component of the overall feasibility of the venture" (Government of Eritrea 1994:49). The NEMP-E also put implementation of environmental assessment as one of the priority plans to be achieved, next to the establishment of the Eritrean Agency for Environment (which later became Department of Environment (DoE)). In response to this, the National Environmental Assessment Guidelines and Procedures (NEAGP) manual come to effect in 1999. It contains procedures and guidelines for environmental clearance of projects and monitoring and evaluation of projects. NEAGP is recognised as a landmark in the implementation of a system of environmental assessment in Eritrea, although there had been some environmental assessment of individual projects in the past (DoE 1999). 
The NEAGP developed in a way to suit Eritrea's current and future condition of economic growth (DoE 1999). Nevertheless it is prepared on the basis of the World Bank environmental assessment principles and more or less corresponds with procedures and guidelines of the Bank (T.Consult 2001). It is also accepted by international institutions and organisations which are involved in development projects in Eritrea. However, the legal and technical instruments which are very important to translate this policy document into specific requirements are still under development.

According to the NEAGP projects are categorised into category A, B and C. Category C projects are those projects which do not involve major physical changes to the natural environment, and as a result they are approved without environmental assessment. Whereas Category B projects are large projects but with a less adverse environmental impact and need to pass through an environmental evaluation questionnaire (which is the final environmental evaluation report for Category B projects). Category A projects on the other hand are large-scale projects with potentially major impact on the environment. They are the only projects that need to pass through full impact assessment (DoE 1999). The overall environmental assessment process in Eritrea is given in Figure 1.2 and the flow chart for full EIA (in Eritrea) is given in Figure 1.3. The content of the NEAPG and the overall application of EIA in Eritrea will be discussed in component B of the dissertation, whilst evaluating the performance of the EIA system in the country. 


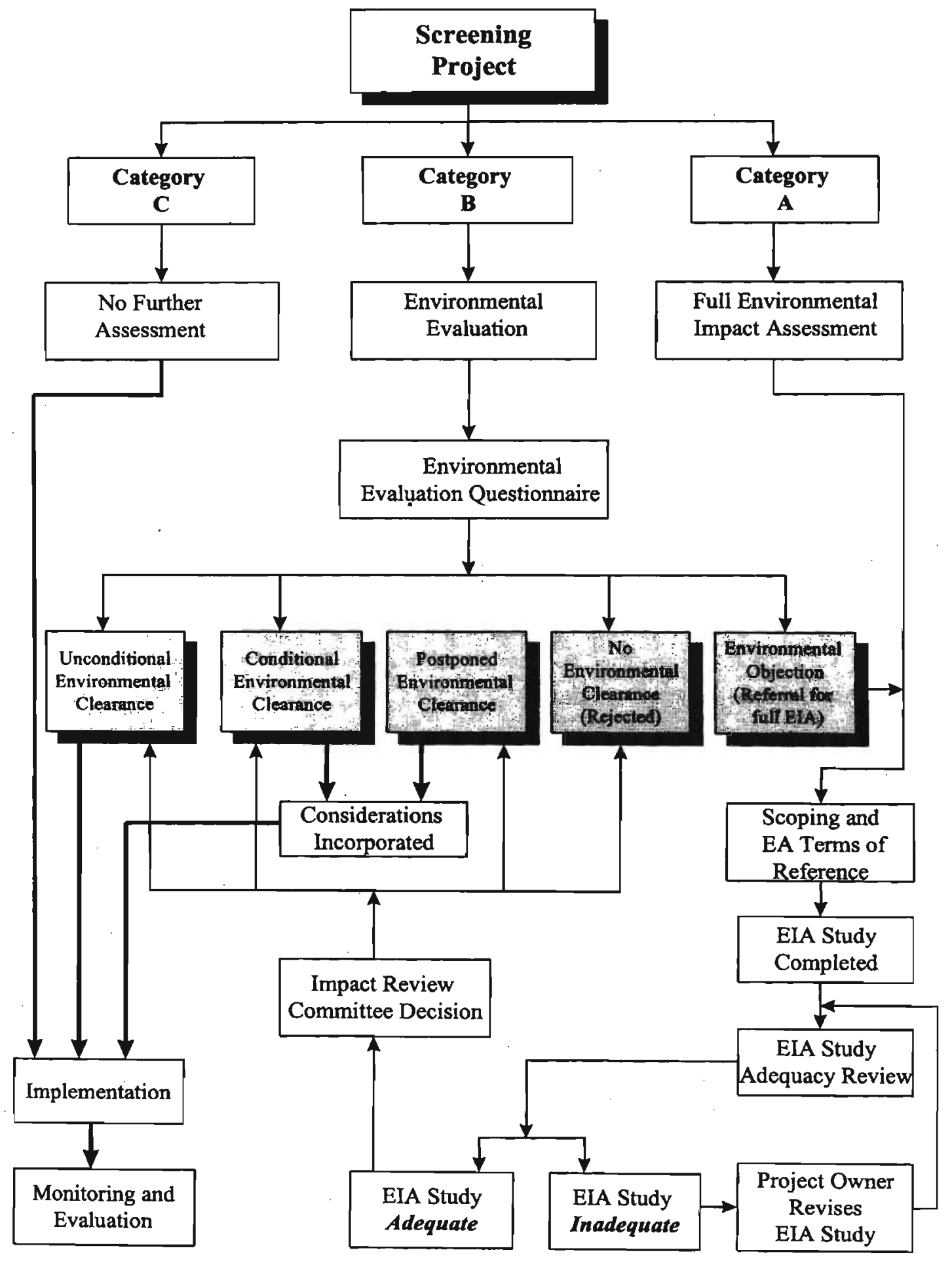

Figure 1.2: Flowchart of the environmental assessment process in Eritrea (DoE 1999) 


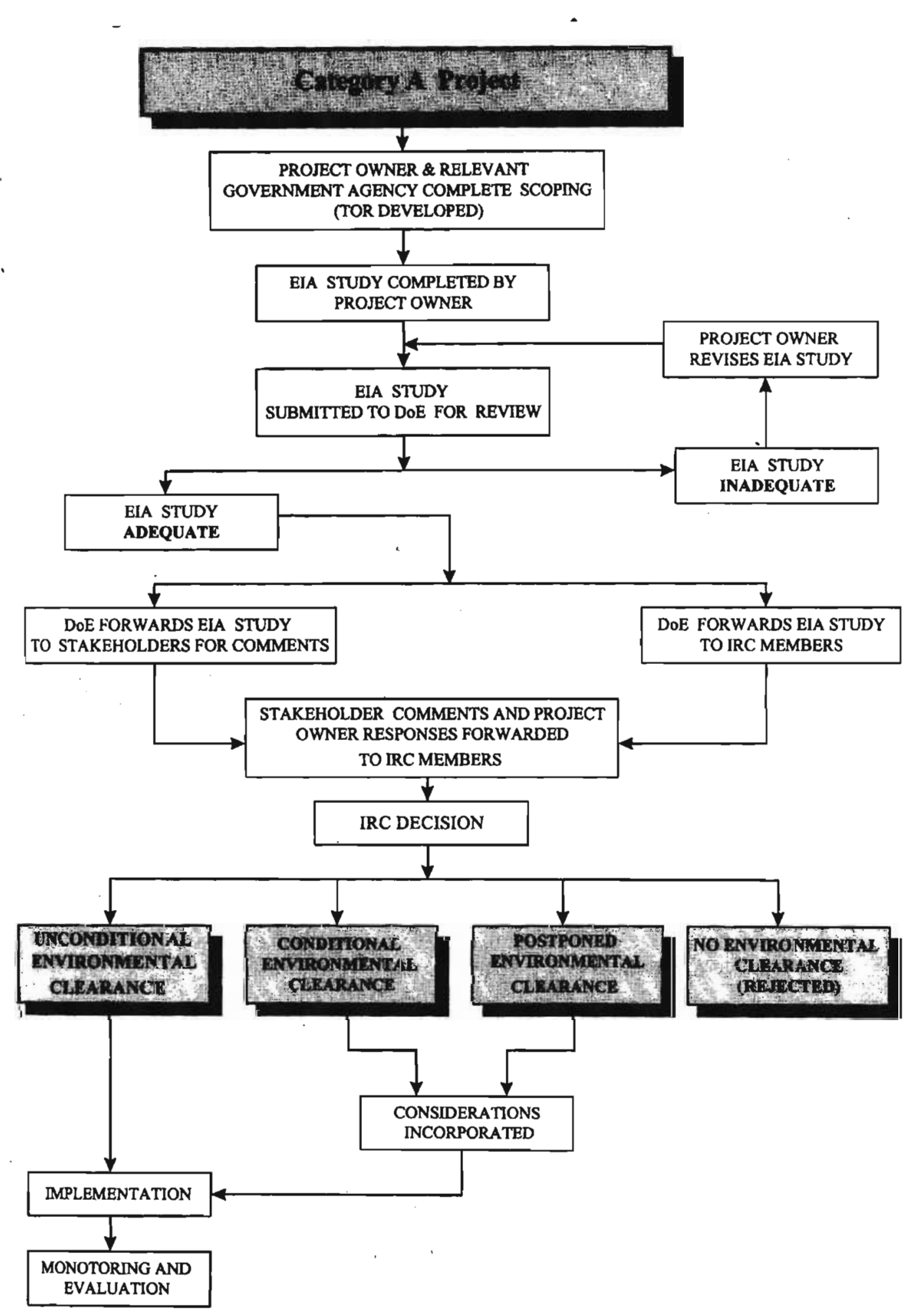

Figure 1.3: Flowchart of full EIA process in Eritrea (DoE 1999) 


\subsection{Problem statement}

Like many other poor countries in the world, economic growth in Eritrea is imperative. However, experience from other countries in the world shows that development that does not consider environmental impact is not long-lasting (Fahrenhorst 1996). It is acknowledged that environment and development are inseparable and EIA is widely used as a policy tool for reducing the negative environmental consequences of development activities, and for promoting sustainable development (Lee \& George 2000). Economic, infrastructure and industrial reconstruction in Eritrea is starting from scratch and one can see this as an opportunity for the country not to begin development at the expense of the environment as has happened in many other countries (Fahrenhorst 1996). Worldwide EIA has been used for more than three decades. In Eritrea on the other hand, ELA was only introduced in 1999. Potentially, Eritrea has much to learn from international experience.

A review of national EIAs against international principles and procedures has been adopted as a way of improving EIA application in many countries. But until now there has been no such review of the EIA system in Eritrea. Therefore, it is useful to evaluate the effectiveness of EIA application in Eritrea if the development projects are going to be sustainable and the country is to remain committed to the international conventions that the country is party to. This leads to the central research question that this study addresses: To what extent are international principles and procedures of EIA being incorporated into the EIA policy and practice in Eritrea?

\subsection{Research purpose}

\subsubsection{Research aim}

The aim of the research project is to review EIA policy and practice in Eritrea with respect to international principles and procedures, with an intention to identify some recommendations for better application and institutional administration.

\subsubsection{Research objectives}

In achieving the above stated aim, the following objectives are identified:

- To review literature on existing international principles and procedures of EIA in order to establish criteria for review;

- to review the current Eritrean EIA policy; 
- to assess current EIA practice in Eritrea through two sectoral case studies;

- to assess the current institutional arrangements with respect to EIA administration and implementation; and

- to make recommendations regarding the application of EIA in Eritrea based on the above objectives.

\subsection{Conceptual framework}

EIA is based on understanding how the natural environment functions, and how social, technological, and economic forces interact with the environment and resource issues (Modac \& Biswas 1999). This understanding will allow promotion of the positive impacts of development while minimising negative impacts on the environment. The goal of EIA as an environmental management tool is to promote decision-making that leads to sustainable development (Figure 1.4).

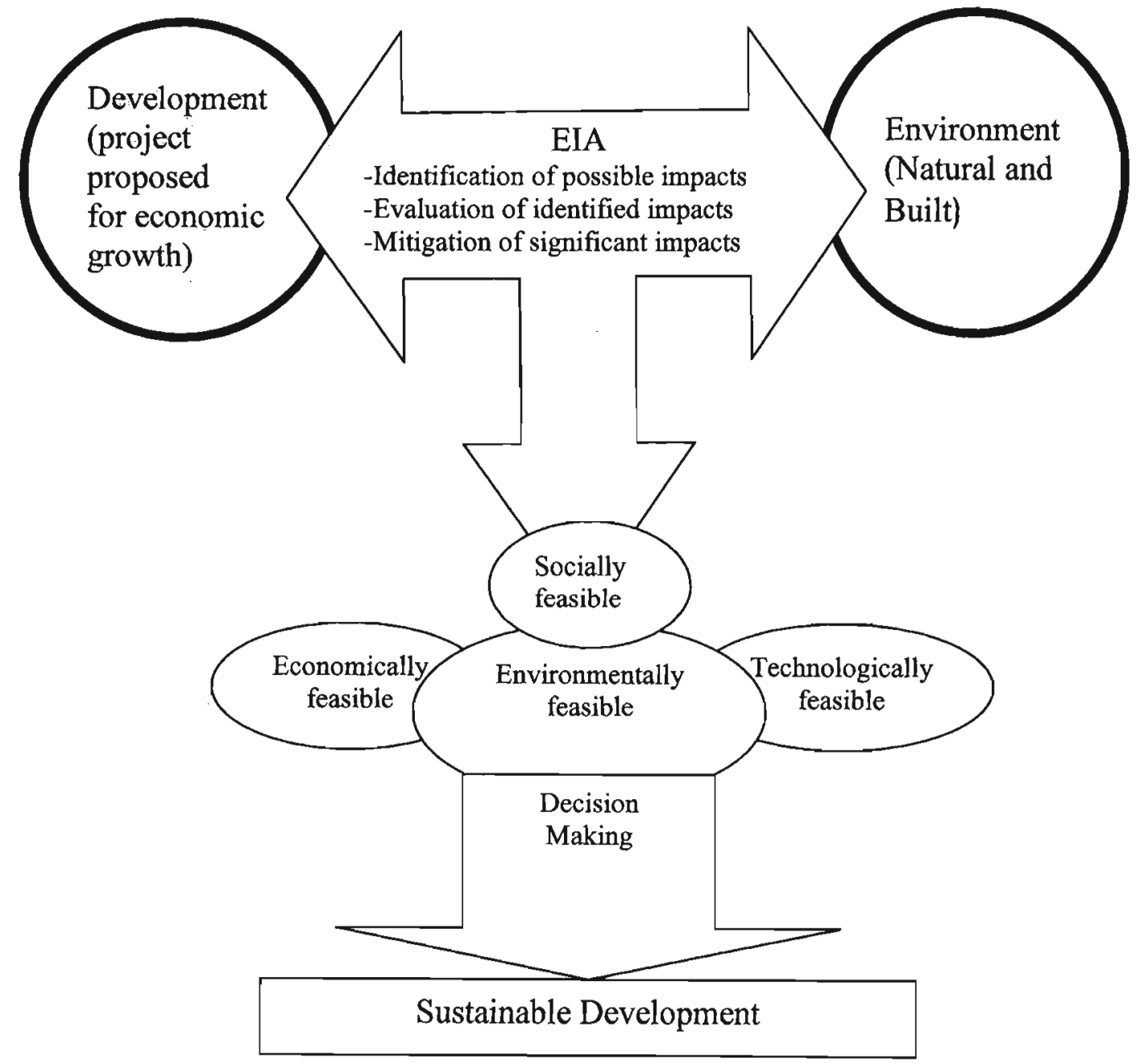

Figure 1.4: EIA as a tool for sustainable decision-making 
The macroeconomic policy together with national legislation and international agreements provides an overall framework for development in Eritrea (Government of Eritrea 1995). As a contribution to the environmental dimension of that policy, this study examines the quality of the national EIA system, and identifies those international principles and procedures that are not included. Figure 1.5 presents the framework for the study.

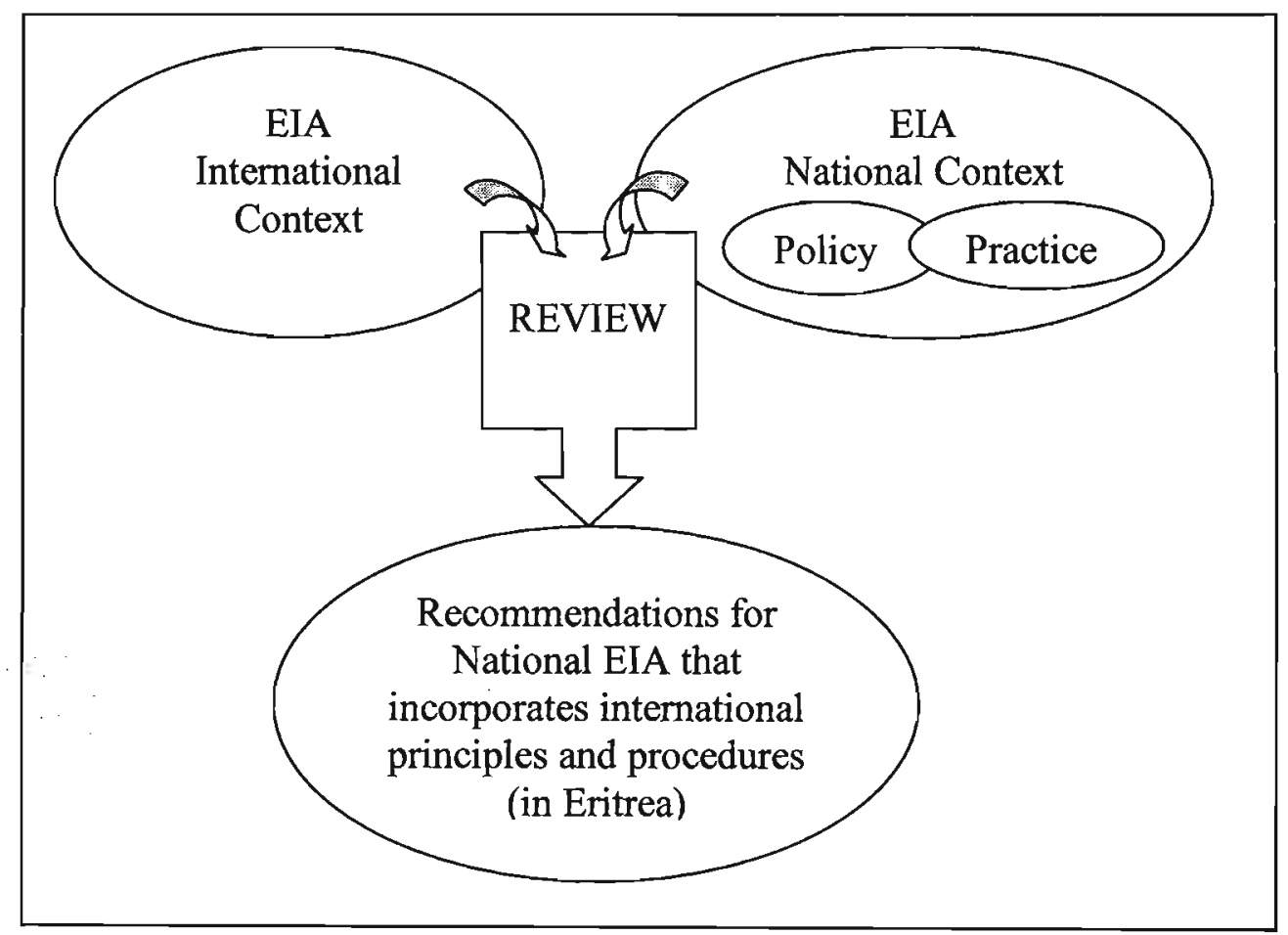

Figure 1.5: Schematic illustration of the contextual framework of the focus of the study 


\section{CHAPTER 2}

\section{ENVIRONMENTAL IMPACT ASESSMENT: SCOPE, DEFINITION, OBJECTIVE AND PRINCIPLES}

\subsection{The Scope and definition of EIA}

Since its first development in 1969 in the United States of America, EIA has been adopted by many countries. This has resulted in diverse terms and definitions. For example, in some countries such as United Kingdom and Canada EIA is known as environmental assessment (EA) and in Netherlands it is known as Milieu-effectrapportage (MER) (Wood 1995). Similarly, the definition of EIA differs from author to author and from country to country.

In its broadest scope, (Gilpin 1995:4) defines EIA as " the official appraisal of the likely effects of a proposed policy, program, or project on the environment; alternatives to the proposal; and measures to be adopted to protect the environment". However, many authors define EIA as a project-level method while the environmental assessment of policies, plans and programs is referred to as strategic environmental assessment (SEA).

Wood (1995:1) defines ELA as "the evaluation of the effects likely to arise from a major project (or other action) significantly affecting the natural and man made environment." In a simple form, South Africa has defined EIA as "a process of examining the environmental effects of a development" (Department of Environmental Affairs and Tourism 1998:6). According to the FINNIDA, EIA in developing countries is defined as "a planning tool which is used, together with the project feasibility study, to ensure that the project plan is the optimal economic-cum-environmental plan, that is, the plan is environmentally as well as economically sound, and thus represents the best approach to planning for developing projects in order that continuing economic development will be sustainable" (Modac \& Biswas 1999:13). In the words of the Eritrean DoE, EIA is defined as "the process by which the potential impact of a project on the environment is determined through an indepth study involving project scoping and using both existing information and the collection of new data to produce an integrated EIA report and environmental management plan (EMP)" (DoE 1999:3). 
Despite the diversity of definitions, most acknowledge that EIA is a process (that includes identification, prediction, evaluation and mitigation) rather than a specific action and is used in avoiding or mitigating the negative impact of development on both the human and biophysical environment.

Sadler (2002a) argue that since its inception, the scope of impact assessment, has evolved from project level EIA (first generation paradigm) to SEA (second generation paradigm), and now toward integrated, sustainability-oriented approaches (third generation paradigm). Looking towards the future, he predictes that environmental assessment will evolve towards sustainable appraisal (SA) and integrated environmental management (IEM) (Table 2.1).

Table 2.1: Environmental assessment- the evolving paradigm (Sadler 1996; 1999 cited in Sadler 2002a:146)

\begin{tabular}{|l|l|}
\hline \multicolumn{1}{|c|}{ Paradigm/level/stage } & \multicolumn{1}{|c|}{ Key characteristic-post Rio } \\
\hline $\begin{array}{l}\text { First generation-project level } \\
\text { ELA }\end{array}$ & $\begin{array}{l}\text { Include social, health and other impacts, cumulative effects and } \\
\text { biodiversity. }\end{array}$ \\
\hline Second generation-SEA & Applies to policy, plans, programmes and legislation. \\
\hline $\begin{array}{l}\text { Third generation-toward } \\
\text { environmental sustainability } \\
\text { assurance (ESA) }\end{array}$ & $\begin{array}{l}\text { Use of EIA and SEA to safeguard critical resource and ecological } \\
\text { functions and offset residual damage; plus environmental accounting } \\
\text { and auditing of natural capital loss and change. }\end{array}$ \\
\hline $\begin{array}{l}\text { Next generation-toward } \\
\text { sustainability appraisal (SA) } \\
\text { and integrated environmental } \\
\text { management (IEM) }\end{array}$ & $\begin{array}{l}\text { Integrated or full cost assessment of the economic, environmental } \\
\text { and social impacts of proposals. Comprehensive or full cycle } \\
\text { assessment and control of all impacts of existing and proposed } \\
\text { actions. }\end{array}$ \\
\hline
\end{tabular}

Among the emerging developments in impact assessment are cumulative effect assessment (CEA), social impact assessment (SIA), risk assessment (RA), health impact assessment (HIA), and ecological impact assessment (EcIA) (see Box 2.1 for definitions). These aspects have been considered as components of an EIA, but are now emerging as specific areas in their own right (Modac \& Biswas 1999). Impact assessment should, therefore, be viewed as a generic process that includes EIA of projects, SEA of policies, plans and programmes, and their relationships to a larger set of impact assessment and planningrelated tools (Sadler 1996). 
Box 2.1: Emerging areas of impact assessment-definition

Cumulative effect assessment (CEA): is the process of systematically analysing and assessing cumulative environmental change (the accumulation of changes in environmental systems over and across space in an additive or interactive manner) (Modac \& Biswas 1999: 197).

\section{Social impact assessment (SIA)}

- In western countries: SIA can be stated as the process of assessing or estimating, in advance, the social consequences that are likely to follow from specific policy actions or project development, particularly in the context of appropriate national, state or provincial environmental policy legislation (Burdge \& Vanclay 1995:32).

- In developing countries: SIA can be considered as a framework for incorporating participation and social analysis into the design and delivery of development projects (World Bank 1995). Or as a process for research, planning and management of change arising from policies and projects (Taylor et al. 1995:1).

Health impact assessment (HLA): can be stated as an assessment of the health effects (income and social states, social support networks, education, employment and working conditions, heath services, physical environments, personal health practice and coping skills, healthy child development, biological and genetic endowment) of development projects, programs and policies in decision-making (Kwiatkowski 2002:35).

Risk Assessment (RA): can be stated as an approach developed to the analysis of risks associated with various typed of developments (Glasson et al. 1999: 8). It adopts a structured and iterative process with similar features to EIA: i.e. hazard identification, hazard assessment, risk estimation, and risk evaluation (Petts 2002:38).

Ecological Impact Assessment (EcLA): is an approach used to predict and evaluate the impact of development on ecosystems and their components, thereby providing the information needed to ensure that ecological issues are given full and proper consideration in development planning (Treweek 1999).

\subsection{Objectives of EIA}

Although there are many different definitions of ELA, they do have a generally shared objective; providing insight to decision makers, with an indication of the likely consequences of their actions (Erickson 1994; Wood 1995). Thus, EIA helps in avoiding environmentally unacceptable actions, and mitigating to the point of acceptability of the environmental effects of proposals (Wood 1995).

Many developers and even some organs of state may consider EIA as an administrative exercise, a process that must be involved to bring about minor changes to a development 
that would probably have happened anyway, or alternatively as costly and time-consuming activity (Glasson et al. 1999). However, as Lee and George (2000) state, the overall purpose of EIA is not to prevent development from taking place but rather to assist in shaping the development process. That is, reading the outcome of the EIA, the project planners and engineers can then shape the project to achieve and sustain the expected benefits without causing irreversible environmental impacts (Modac \& Biswas 1999). Moreover, wise developers can use the EIA process to negotiate "green gain" solutions, which may eliminate or offset environmental impacts, reduce local opposition and avoid costly public inquires (Glasson et al. 1999).

Furthermore, the objectives of EIA can be stated as (Erickson 1994; Wood 1995; International Association for Impact Assessment 1999):

- To ensure that environmental considerations are integrated into the development decision-making at the early stages of planning an activity;

- to predict and avoid, minimize or compensate the adverse environmental, social, economic and cultural effect of a proposed activity;

- to protect the productivity and capacity of natural systems and the ecological processes which maintain their function;

- to ensure the involvement of the public and inter-agency coordination; and

- to promote sustainable development and enhance the use of resource and management opportunities.

\subsection{Principles of EIA}

Like many other environmental management tools, the effective management of EIA is based on a number of basic principles (Modac \& Biswas 1999). Countries such as Canada and Australia, for example, have produced a national statement of principles for conducting EIA. As mentioned in Gilpin (1995) the Canadian EIA principles emphasize cost-effective process, early stage assessment, public participation and encouragement, scoping, consistent application of EIA through out the country, and cooperation between different levels of government. Likewise, the Australian national EIA principles give emphasis to: provision for public participation and post-project analysis; policy and planning frameworks, consistent approaches and integrity; consultation with public and 
decision makers, taking the opportunity to improve projects; and advising the public on how to become effectively involved (Gilpin 1995).

One of the principal features of EIA in developed countries (e.g. Canada and Australia) is well-developed public consultation and participation. In many developing countries and countries in transition, particularly those of post-communist nations (Box 2.2), public participation requirements are far from being specific and enforceable (Czerp 2001).

Box 2.2: Enforcement of public participation, one of the principal features of EIA, in postcommunist nations (Czerp 2001:26).

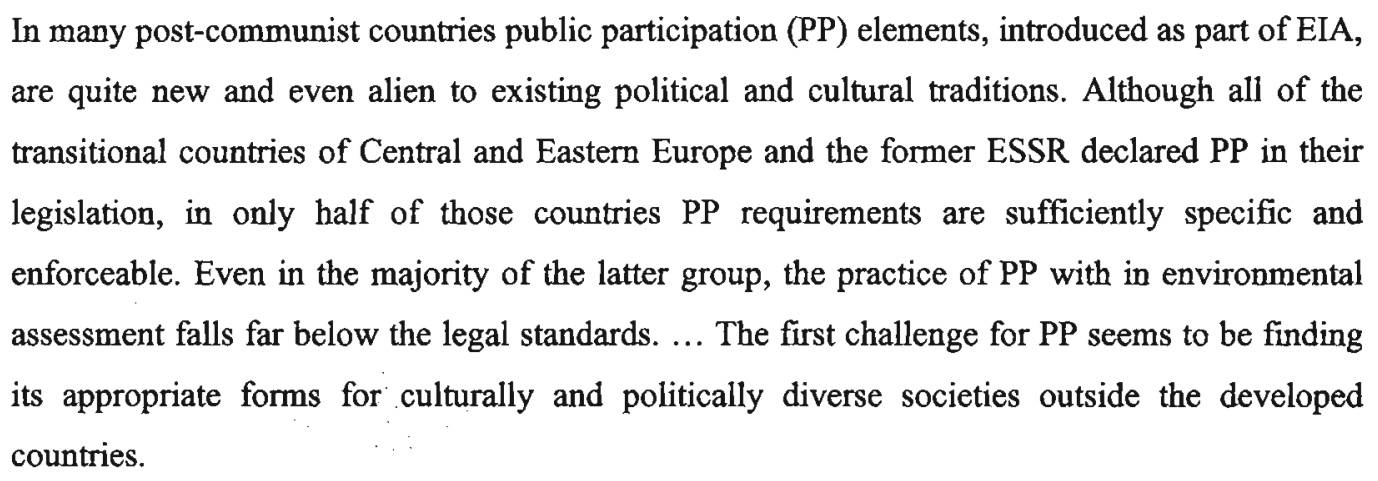

Sadler (1996) sets out certain principles that need to be considered for use as a basis for EIA. These include: apply EIA consistently with criteria appropriate for the purpose; undertake the process in accordance with procedural (or best practice) guidelines; address the issues that really matter; and provide sound consequential information for decision making. Similarly United Nations Environment Program (1988) states certain general, but simple and most important principles for good ELA practice (Wood 1995); good EIA must thus:

- Focus on the main issues;

- involve the appropriate persons and groups;

- link information to decisions about the project;

- present clear options for the mitigation of impacts and for sound environmental management; and

- provide information in a form useful to the decision makers. 
The same principles are also mentioned in Modac and Biswas (1999) as important principles in managing EIA in developing countries. Moreover, the International Association for Impact Assessment (IAIA), in cooperation with Institute of Environmental Assessment, UK has developed a set of comprehensive principles of Environmental Impact Assessment Best Practice (Table 2.2). The principles were formulated based on the results of the International Study of the Effectiveness of Environmental Assessment; the UNEP document on issues, trends and practice in EIA; other guidance materials on best practice in EIA; and the expertise and experience of IAIA. They are primarily designed for reference and use by professionals and aim to promote effective practice of EIA consistent with the institutional and process arrangements that are enforced in different countries (International Association for Impact Assessment 1999).

The IAIA principles have two tiers; basic and operating. The basic principles apply to all stages of EIA, while the operating principles describe how the basic principles should be applied to the main steps and the specific activity of assessment of alternatives. Generally, the principles are broad, generic, and non-prescriptive. They emphasize EIA as a process, and are intended to be applicable to all levels and types of proposals, having regard to the limits of available time, information and resources (International Association for Impact Assessment 1999). 
Table 2.2: Principles of EIA best practice (International Association for Impact Assessment 1999:4-5)

\section{EIA Should be:}

\section{Basic Principles}

Purposive-the process should inform decision-making and result in appropriate levels of environmental protection and community well being.

Rigorous-the process should apply "best practicable" science, employing methodologies and techniques appropriate to address the problems being investigated.

Practical-the process should result in information and outputs which assist with problem solving and are acceptable to and able to be implemented by proponents.

Relevant-the process should provide sufficient, reliable and usable information for development planning and decisionmaking.

Cost-effective- the process should achieve the objectives of EIA within the limits of available information, time, resource and methodology.

Efficient- the process should impose the minimum cost burdens in terms of time and finance on proponents and participants consistent with meeting accepted requirements and objectives of ELA

Focused- the process should concentrate on significant environmental effects and key issues; i.e., the matters that need to be taken into account in making decisions.

Adoptive- the process should be adjusted to the realities, issues and circumstances of the proposals under review without compromising the integrity of the process, and be iterative, incorporating lessons learned throughout the proposal's life cycle.

Participative- the process should provide appropriate opportunities to inform and involve the interested and affected publics, and their inputs and concerns should be addressed explicitly in the documentation and decision-making.

Interdisciplinary-the process should ensure that the appropriate techniques and experts in the relevant biophysical and socio-economic disciplines are employed, including use of traditional knowledge as relevant.

Credible-the process should be carried out with professionalism, rigor, fairness, objectivity, impartiality and balance, and be subject to independent checks and verification

Integrated-the process should address the interrelationships of social, economic and biophysical aspects.

Transparent-the process should have clear, easily understood requirements for EIA content; ensure public access to information; identify the factors that are to be taken into account in decision making; and acknowledge limitations and difficulties.

Systematic-the process should result in full consideration of all relevant information on the affected environment, of proposed alternatives and their impacts, and of the measures necessary to monitor and investigate residual effects.

\section{Operating principles \\ ELA process should be applied:}

*As early as possible in decision-making and throughout the life cycle of the proposed activity;

*To all development proposals that may cause potentially significant effects;

*To biophysical impacts and relevant socio-economic factors, including health, culture, gender lifestyle, age, and cumulative effects consistent with the concept and principles of sustainable development;

* To provide for the involvement and input of communities and industries affected by a proposal, as well as the interested public;

*In accordance with internationally agreed measures and activities.

Specifically the ELA process should provide for:

Screening-to determine whether or not a proposal should be subject to ELA and, if so, at what level of detail.

Scoping-to identify the issues and impacts that are likely to be important and to establish terms of reference for ELA

Examination of alternatives-to establish the preferred or most environmentally sound and benign option for achieving proposal objectives.

Impact analysis-to identify and predict the likely environmental, social and other related effects of the proposal.

Mitigation and Impact management-to establish the measures that are necessary to avoid, minimize, or offset predicted adverse impacts and, where appropriate, to incorporate these into an environmental management plan or system.

Evaluation of significance- to determine the relative importance and acceptability of residual impacts (i.e. impacts that can not be mitigated)

Preparation of environmental impact statement (EIS) or report-to document clearly and impartially impacts of the proposal, the proposed measures for mitigation, the significance of effects, and the concerns of the interested public and communities affected by the proposal.

Review of EIS-to determine whether the report meets its terms of reference, provides a satisfactory assessment of the proposal(s) and contains the information required for decision making.

Decision making-to approve or reject the proposal and to establish the terms and conditions for its implementation.

Follow-up-to ensure that the terms and conditions of approval are met; to monitor the impact of development and effectiveness of mitigation measures; to strengthen future EIA applications and mitigation measures; and where required, to undertake environmental audit and process evaluation to optimize environmental management.

"It is desirable, whenever possible, if monitoring, evaluation and management plan indicators are designed so they also contribute to local, national and global monitoring of the state of the environment and sustainable development. 


\section{CHAPTER 3}

\section{ENVIRONMENTAL IMPACT ASSESSMENT SYSTEMS:}

\section{EVALUATION CRITERIA, PROCESS AND INSTITUTIONAL}

\section{ASPECTS}

\subsection{Evaluating effectiveness of the EIA systems}

To ensure that EIA is maximizing its potential as an environmental management tool, measuring its effectiveness is important. Effectiveness is a measure of something which works as intended and meets the purpose for which it was designed (Sadler 1996). The effectiveness of an EIA system depends on the social, political and economic context in which it has to be operated (Wood 1995). For this reason there is no single effective EIA system. Nevertheless, it is possible that principles for a good EIA system can be set and can act as a template for the enhancement of EIA processes and practice (Fuller 1999). In the past, based on these principles which constitute good practice, many criteria have been developed to enhance the quality of EIA. Some of the criteria are focused on the quality of the EIA report (Lee \& Colley 1990; Glasson et al. 1994) and others on the quality of the EIA process (Lee et al. 1994; World Bank 1996a). The success of EIA as a decisionmaking tool, however, depends on the effectiveness of the whole EIA system. Thus, both the EIA process which determines the quality of the EIA report and the institutional arrangements for EIA that facilitate the process need to be effective (Biswas \& Geping 1987).

EIA effectiveness can be measured at different levels. Petts (1999) has considered three levels: (i) internationally, in terms of a comparative assessment of the achievement of international environmental objectives; (ii) nationally, in terms of the performance of a system by reference to the policy and institutional functions which EIA is designed to serve; and (iii) at the micro or process-specific level, in terms of the contribution of EIA to the decision being made. She also states certain points where typical evaluation criteria for EIA systems can be related. These include: clarity of legal provisions; comprehensiveness in terms of coverage of significant environmental actions and impacts; transparency of decision making; openness in terms of opportunity for public participation and review and understanding of the decision; efficiency in terms of cost and time; and robustness of assessment and quality of the EIA report. 
Fuller (1999) classified EIA quality control measures into two categories, mainly as systematic and foundation measures. Systematic measures are those "features of ELA systems that are designed to deliver quality assurance in the practice and administration EIA" (Fuller 1999:56). The foundation measures on the other hand are those "features which promote good practice and underpin the successful application of the systemic approaches" (Fuller 1999: 56). Fuller identifies a number of systematic quality control mechanisms which could be applied to various stages of EIA process, namely screening, scoping, impact assessment, mitigation, follow up and EIA report review. Under the foundation measures, guidelines; capacity building, training and learning exchange; professional recognition and process review are included. However, Fuller's focus is on reviewing the quality of EIA report; what he calls it "the most important quality control mechanism" (Fuller 1999:66), rather than providing a set of evaluation criteria for the whole EIA system.

There are few examples of comprehensive EIA reviews, but as Fuller (1999) states, the most notably independent EIA system evaluations are those of the International Study of the Effectiveness of Environmental Assessment (Sadler 1996) and Environmental Impact Assessment: A Comparative Review (Wood 1995). These evaluations are undertaken to further the development of EIA as an environmental management tool and a tool to be used to promote sustainable development. Sadler (1996) provides a long checklist for review of environmental assessment process effectiveness. The proposed set of criteria deals with appropriateness of institutional controls, adequacy of operational performance for main stages and components of environmental assessment, and relevance to decision-making.

Wood's (1995) evaluation criteria (Box 3.1) are also a comprehensive set developed to see EIA system in its international context. They are based upon the representation of the stages of the EIA process and the aim of EIA. They focus on the requirements and operation of the EIA process (Wood 1995). 
Box 3.1: EIA system evaluation criteria (Wood 1995:12)

1. Is the EIA system based on clear and specific legal provisions?

2. Must the relevant environmental impacts of all significant actions be assessed?

3. Must evidence of the consideration, by the proponent, of the environmental impacts of reasonable alternative actions be demonstrated in the EIA process?

4. Must screening of actions for environmental significance take place?

5. Must scoping of the environmental impacts of actions take place and specific guidelines be produced?

6. Must EIA reports meet prescribed content requirements and do checks to prevent the release of inadequate ELA reports exist?

7. Must EIA reports be publicly reviewed and the proponent respond to the points raised?

8. Must the findings of EIA reports and the review be a central determinant of the decision on the action?

9. Must monitoring of action impacts be undertaken and is it linked to the earlier stages of the EIA process?

10. Must the mitigation of action impacts be considered at the various stages of the EIA process?

11. Must consultation and participation take place prior to, and following, EIA report publication?

12. Must the EIA system be monitored and, if necessary, be amended to incorporate feedback from experience?

13. Are the financial costs and time requirements of EIA system acceptable to those involved and are they believed to be outweighed by discernible environmental benefits?

14. Does the EIA system apply to significant programmes, plans and policies, as well as to projects?

Each evaluation criterion that will be adopted in this study will be discussed systematically in the next section.

\subsection{Institutional aspects of EIA system}

Institutional arrangements are necessary in facilitating the use of EIA as a decision-making tool. They are as important as the techniques for carrying out EIA (Biswas \& Geping 1987). According to Smith (1984) and Mitchell (1989) the focus of institutional arrangements is on the interaction of several variables, most importantly:

- Legislation and regulations, policies, guidelines and activities;

- administrative structures, economic and financial arrangements;

- political structures and decision processes;

- historical and traditional customs and values; and

- stakeholders. 
Sadler (1996) has suggested several key aspects of institutional arrangements for effective EIA. These include:

- Whether the process is based on law or administrative provision;

- whether compliance with the process is voluntary or mandatory; and

- the scope of application, including type of decisions and activities that are subject to assessment.

The key important institutional aspects in developing countries are briefly discussed below.

\subsubsection{Policy}

With the increase in global environmental awareness a considerable number of developing countries have prepared and approved environmental policies in the form of national environmental action plans (NEAP) (Lee \& George 2000). The World Bank (1996b), for example, reported that countries such as Benin, Cote d' Ívoire, Burkina Faso, Ghana, Niger, Nigeria and Togo have completed their NEAP. Yet, there are many developing countries without clear documented policies. This could be due to the priority that these countries give to economic development. However development that ignores environmental consequences is not sustainable (Biswas \& Geping 1987). For these reasons national policies must reflect the twin goals of development and environment. It is within this policy that EIA processes can be carried out. This has also been recognized in the World Summit on Sustainable Development (WSSD) agenda, which Sadler (2002b) describes as a welcoming approach to environmental assessment and management (Box 3.2).

Box 3.2: Recognition of environmental and economic goals in the WSSD agenda (Sadler 2002b: 11).

\footnotetext{
... environmental and economic goals have been adopted for WSSD. The overarching environmental goal is sustainable management of natural resource for development, which is seen as requiring a 'holistic ecological approach'. The overarching economic goal is changing unsustainable patterns of consumption and production. It emphasizes securing greater eco-efficiencies, giving prominence to lowering resource inputs and reducing environmental impacts. Both approaches, pushed seriously, would be welcome to environmental assessment and management practitioners.
}

As mentioned by Ahmad and Sammy (1985) such a national policy should be: 
- Achievable: set realistic goals for both development needs and environmental quality through sound environmental management;

- specific: areas of national concerns on both environment (e.g. land degradation, water pollution or natural resource conservation) and development (e.g. housing, food production or industrial development) should be clearly spelled out so that the developer can plan his action in accordance with the national programme;

- flexible: circumstances will change with time and new information will come to hand, so policy makers should be open to suggestion and comments all the time; and

- responsive: adaptable to the social and cultural traditions of the people of the country which is vital to the success of environmental programmes.

\subsubsection{Establishment of environmental institution}

Lee and George (2000) mention that in developing countries, there is a need for establishment of a strong institutional body mandated with environmental issues, if the implementation of EIA is to be effective. This institutional body (an environmental minister or a department within a ministry) can prepare legislation, set standards, provide policy and play a role in co-operation of different ministries or departments in order to ensure that environmental concerns are respected in all areas (Ahmad \& Sammy 1985). However, Lee (2000) noticed that the environmental ministries, and agencies in many developing countries are new, lack sufficient status and possess few properly trained staff. Moreover, Ahmad and Sammy (1985) and Wood (1995) argue that the success of achieving the goal of establishing such an environmental institution is highly dependent on the adequacy of the local experts and political will of the country.

With the help of local NGOs and international aid agencies such as the World Bank, there is a potential where by the capacity of the environmental institutions in developing countries can be strengthened (see example in Box 3.3). NGOs can involve, for example, in training of the local staff in order to strengthen the human resource requirement; in provision of technical, advisory and financial assistance to the public institution in preparation and implementation of environmental policies; and in coordination of the involvement of the public in meeting and discussion for projects or plans or policy related issues (Rees 2000). 
Box 3.3: The role of NGOs and international aid agencies in supporting institutional strengthening of developing countries: an example of Middle East and North Africa (MENA) (Ahmad 2002:109).

Multilateral and bilateral donor agencies played an important in the development of EIA in the Middle East and North Africa (MENA) region by funding programmes to introduce EIA frameworks and/or to strengthen ELA practice. For example, the World Conservation Union (IUCN) and the European Union funded programmes to draft an environmental law and ELA decree and set up an ELA unit in Syria. The World Bank through the Mediterranean Environmental Technical Assistance Programme (METAP) has supported institutional strengthening and capacity building activities in several MENA countries.

\subsubsection{Legislation}

One of the mechanisms whereby environmental policy implemented, is through legislation. EIA, therefore, must be promulgated by law in unambiguous regulations, leaving no potential for misunderstanding about the interpretation of the obligation to carry out EIA (Modac \& Biswas 1999). Though EIA systems based upon clear specific legal provisions are common in developed countries, the legal basis for EIA in many developing countries is weak, non-mandatory or nonexistent (Wood 1995). Kenya, for example, has developed an important body of environmental legislation but it has not yet enacted a statute on EIA and is still in the process of developing a comprehensive environmental law, which has been in draft form since 1998. Benin is another developing country which drafted set of EIA guidelines for various categories of projects without any legal basis, making the implementation of the of these guidelines a voluntary exercise by project proponent (Bekhechi \& Mercier 2002).

The influence of EIA depends not only on the content of procedures but also on the effectiveness of the regulatory systems of which they form a part (Lee \& George 2000). Experience in developed countries such as Canada and New Zealand shows that there is a need for a shift from the use of discretionary EIA procedures to a legally specified EIA system (Wood 1995). In many developing countries, however, the most important thing is to put in place the appropriate institutional framework and only then the regulatory requirements for EIA (Biswas 1992). Moreover, establishing a legal requirement, though an essential first step, cannot ensure that EIA will actually be conducted properly and used within the decision-making framework. For these reasons, in developing countries both legal and institutional mechanisms need to be simultaneously developed so that EIA procedures can be implemented effectively (Biswas \& Geping 1987). 
Nevertheless, there is an argument that EIA can only be integrated into decision-making when EIA requirements are codified in legislation or regulation; an EIA report must be prepared; and authorities are accountable for considering EIA. In other words, when it is applied in a formal way (Kennedy 1988a). The advantage of legally specified EIAs are performance and evidence of commitment, the avoidance of uncertainty, the provision of a firm basis for public participation, and the enforcement of acceptance of EIA (Fowler 1985; Buckley 1991). On the other hand, only enshrining the broad details of EIA in law or regulation may also have some advantages which include, the desirability of voluntary compliance, the avoidance of judicial involvement, and the retention of discretion (Fowler 1985). Some degree of discretion, therefore, must remain in the application of any EIA system to meet particular circumstances (Wood 1995).

To avoid confusion between different processes or other types of actions and decisionmaking procedures, the legal requirement for EIA should be clearly distinguishable. In addition, to ensure that the various obligations in the EIA process are properly discharged, it is necessary that there should be adequate opportunities for the various participants to appeal administratively, or to the courts (Wood 1995). Furthermore, existence of clear outlines of all the procedures involved in the EIA process, including the time allocated to each stage and any changes involved in it are important. These prevent EIAs from becoming over-lengthy or too scant and help all the EIA participants to get an overview of the process (Wood 1995). In addition, the legislation should also include sanctions for noncompliance if EIA is to be implemented effectively (Ahmad \& Sammy 1985).

\subsubsection{Resource needs}

To carry out the ElA process and to implement the recommendations, certain resources are needed. The first necessary resource for many developing countries is qualified multidisciplinary local staff or experts which include skilled managers (coordinator), trained specialists and communication experts (Modac \& Biswas 1999). Training for government officials, environmental consultancies and research institutions and educational institutions, therefore, could be a major factor for determining the quality of EIAs produced (Ahmad \& Sammy 1985; Biswas \& Geping 1987). Another important resource for EIA could be environmental data or information. The lack of environmental information is common in many developing countries. However, information sharing between different sectors or ministries within the country and data synthesis from similar 
projects within the country or other countries with similar climate and other conditions could be a solution to some extent (Ahmad \& Sammy 1985; Wood 1995; Lee \& George 2000). In building such an effective EIA system in developing countries, NGOs and international aid agencies can be a major contributors through their training and institutional strengthening programmes.

Beside experts and information, time and financial cost are another important resource for performing EIA. According to Modac and Biswas (1999) the time that initial environmental examination (IEE) takes is between two to ten weeks while the detailed EIAs may last between three months and two years. Concerning the cost, in many developing countries it would be in a range of $0.5 \%-1 \%$ of the project cost (Ahmad \& Sammy 1985; Wood 1995). These again will depend on the nature and type of the project, magnitude of the project, quality of the EIA, methodology and techniques, data availability, scope, location, and status number and the caliber of the experts (Biswas \& Geping 1987). In general, there is consensus that such a price is a relatively small price to pay to prevent costly unforeseen problems, to promote development that can be sustained, to help prevent potentially ruinous environmental catastrophes, and to obtain approval and acceptance (Wood 1995; Modac \& Biswas 1999).

Nevertheless, if implementation of environmental assessment is to be effective it needs to be prepared in a cost-effective and timely manner. An example of time and cost-effective environmental assessment for large development projects is indicated in Box 3.4.

Box 3.4: Time and cost effective environmental assessment: a lesson from Greater Cairo Wastewater Project (Modac \& Biswas 1999:345-346).

The experience of Greater Cairo Wastewater Project demonstrates the environmental assessment (EA) for major capital development projects can be prepared in a cost-effective and timely manner when they are prepared at an appropriate point in the course of project development. Cairo Wastewater Organisation (CWO) and USAID believed that the fund spent to prepare the EA represent an effective expenditure of $\$ 270,000$ to support the approximately $\$ 1.4$ billion of new construction for the West Bank section of the Greater Cairo Wastewater Project. USAID experience is that EA for major capital projects are best done following the preparation of preliminary feasibility study, which allows for a clear identification of the proposed projects and alternatives. The EA, to be an effective tool in decision-making, should be available for concurrent review with the feasibility study. ... The costs of EA can be minimized if selected data collection needs are identified early and are included in the basic data collection programme for engineering feasibility study. Saving can also be achieved by requiring the engineering consultants to allow the EA team to use base maps, system plans, technical data and cartographic drafting bases. 


\subsection{EIA process}

EIA is generally conducted in a systematic manner. The process involves a number of steps with feedback interaction between various steps in cyclical fashion (Wood 1995). As Roe et al. (1995) mention, EIA processes vary according to the context and type of the proposed project and EIAs for major projects may take considerable time, human resource and finance. EIA has been adopted in many countries with different degrees of interest where it has evolved to varying degree of competence. This section, however, describes the main elements of a typical EIA process. The interaction between the various steps is expressed in Figure 3.1. 


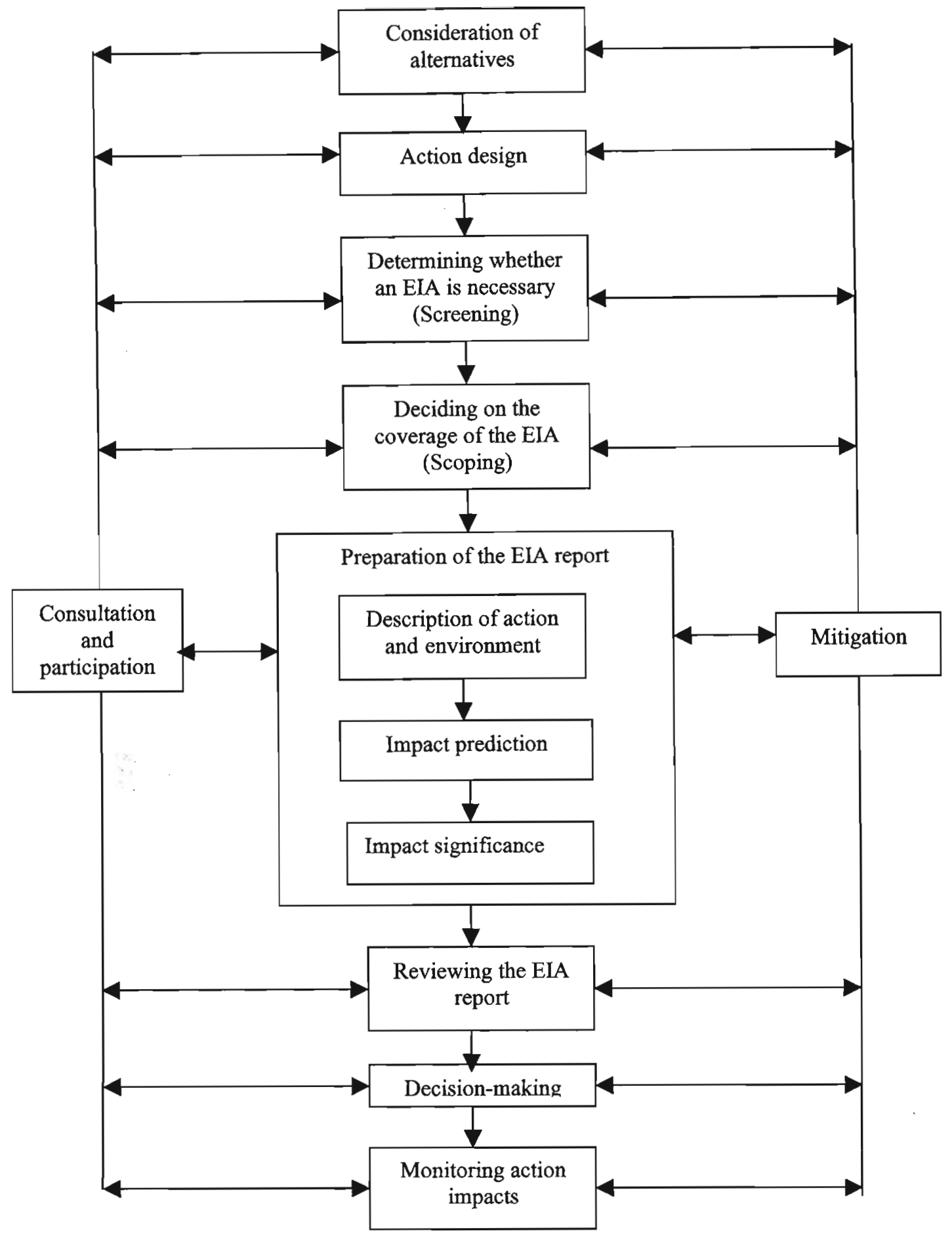

Figure 3.1: The environment impact assessment process (Wood 1995).

\subsubsection{Screening}

Screening is a process of deciding on whether an EIA is required and the level of assessment that is necessary (Roe et al. 1995). Thus, screening clears all those projects with no major negative impacts. The guidelines for whether or not an EIA is required are country specific. However, the general approach involves screening criteria such as size, 
cost or location of project; lists of projects which do or do not require an EIA; and check lists of projects and environments that require further investigation (Roe et al. 1995). In practice, many developing countries use a mixed approach for screening actions (Wood 2000). The World Bank (1999) for example, categorizes projects in to: Category Aprojects with diverse and significant environmental impacts which require full environmental assessment (EA); Category B-projects with few and site specific impacts and require environmental analysis but no full EA, and Category $\mathrm{C}$ - projects unlikely to have significant environmental impacts so do not require environmental analysis. The screening criteria used by the World Bank include: type, location, sensitivity and scale of the project as well as the nature and the magnitude of its potential environmental and social impacts. The list of Category A and examples of Category B and C projects are given in Box 3.5.

Box 3.5: World Bank Category A, B and C projects/Components (World Bank 1999a)

\begin{tabular}{|l|l|l|}
\hline \multicolumn{1}{|c|}{ Category A } & \multicolumn{1}{|c|}{ Category B (examples) } & \multicolumn{1}{|c|}{ Category C (examples) } \\
\hline * Dams and reservoirs & * Agro-industries (small-scale) & * Education \\
* Forestry production projects & * Electrical transmission & * Family planning \\
* Industrial plants (large-scale) and industrial & * Aquaculture and mariculture & * Health \\
estates including major expansion, & (small scale) & * Nutrition \\
rehabilitation, or modification & * Irrigation and drainage (small- & * Institutional development \\
* Irrigation, drainage, and flood control (large- & scale) & * Technical assistance \\
scale) & * Renewable energy & * Most human resource projects \\
* Aquaculture and mariculture (large scale) & * Rural electrification & \\
* Land clearance and levelling & * Tourism & \\
* Mineral development (including oil and gas) & * Rural water supply and sanitation \\
* Port and harbour development & * Watershed projects (management & \\
* Reclamation and new land development & or rehabilitation) & \\
* Resettlement & * Rehabilitation, maintenance, and & \\
* River basin development & upgrading projects (small-scale) & \\
* Thermal power and hydropower & & \\
development or expansion & & \\
* Manufacture, transportation, and use of & & \\
pesticides or other hazardous and/or toxic & & \\
materials & & \\
* New construction or major upgrading of & & \\
highways or rural roads & & \\
* Hazardous waste management and disposal & & \\
\hline
\end{tabular}

With the exception of few countries, such as South Africa, screening of actions in developing countries is not satisfactory and it tends to be based on the requirement of funding agencies (George 2000; Wood 2000). Nonetheless, effective screening of actions should take place in all EIA systems in order to avoid the assessment of unnecessary large number of actions. Thus, a legal test of whether the action is to affect the environment significantly is necessary (Lee \& George 2000). Developing countries, therefore, need to have a sufficiently simple and effective screening approach that contains a list of projects 
and actions with accompanying criteria and thresholds to determine the need for EIA (Kennedy 1988b).

To resolve occasional difficulties of assignment and differences of opinion, some form of discretionary procedure is necessary (Wood 2000). In addition, Modac and Biswas (1999) suggest that some small projects may have more adverse effects than larger projects and placing a quantitative limit on some measures below which no EIA is ever required, might provide an unreviewable exemption that could be taken advantage of by some careless developers. So commonsense and discretion must be exercised in deciding whether or not a proposal needs an EIA (Modac \& Biswas 1999). Moreover, for screening to be effective, Wood $(1995,2000)$ makes the following points:

- Appropriate information is required from the proponent in order to assist the relevant authority and the environmental authority in decision-making for the need of EIA in any particular case;

- whatever approach is adopted, it needs to be specified and precise information about actions, criteria, thresholds and screening procedures should be available for the proponent and other participants in order to ascertain whether assessment is needed; and

- the screening decision should be made by a publicly accountable body and the reasons for that decision should be publicly recorded in order to instil confidence in the process.

\subsubsection{Consideration of alternatives}

If EIA is to perform best there should be sufficient provision for considering alternatives. It is even argued that consideration of alternatives is the heart of EIA report (Council of Environmental Quality 1992). Thus, evidence of consideration by the proponent of environmental impacts of reasonable alternative action must be demonstrated in the EIA process (Wood 1995). These can include alternative sites, alternative techniques, alternative timing and the no-action alternative. In many developing countries the practice of consideration of alternatives to a proposal is weak and the no-action alternative hardly occur (Wood 1995). In South Africa, for example; although regulations that require a description of feasible alternatives (Regulation 7 (1) (b) and Regulation 8 (a) \& (b)) has now (since 1997) developed, a survey done by Mafune et al. (1997) indicate that out of 28 early EIA reports only 9 consider alternatives to a proposal and that 8 of these deal with the no action alternative. 
EIA Projects funded by international development agencies, however, demand consideration of alternatives. The World Bank (1999) for example, requires the comparison of the proposed investment design, site, technology and operational alternatives in terms of their potential environmental impacts and feasibility of their mitigation, capital and current costs, suitability under local conditions, and institutional, training and monitoring requirements. In addition the environmental costs and benefits of each alternative needs to be quantified, and, where possible, economic values should also be attached and the basis for the selected alternative should be stated.

Furthermore, the consideration of such alternatives has to be done at the design stage, which is easiest and cheapest (Wood 1995). They also need to be demonstrated in the preliminary document produced prior to the EIA report in order to encourage analysts to focus on differences between real choices and to show evidence of mitigation (Glasson $e t$ al. 1994; Wood 1995). In case of many alternatives a case-by-case tiered approach can be used to reduce the duration and cost of comparing a large number of alternatives (Ahmad \& Sammy 1985).

Another issue concerning alternatives is that the EIA report should contain evidence that the environmental consequences of alternative approaches, locations and designs have been considered. Furthermore, published guidelines on the treatment of the impacts of reasonable alternatives should exist in order to benefit developers, consultants, decision makers, environmental authorities, consultees and the public (Wood 1995).

\subsubsection{Scoping}

If the screening decision indicates that a particular project needs an EIA, a scoping will be undertaken to identify and narrow-down the potential environmental impacts of the project. This will ensure that the assessment focuses on the key issues for the decision-making (Roe et al. 1995). Scoping involves decision-makers, the local population and the scientific community in identifying the issues which should be considered (Wathern 1988). The scoping process begins early in the project cycle and minimizes inefficiencies by setting the boundaries of the assessment (Erickson 1994). However, care is needed in setting the boundaries. Too narrow a scope will possibly omit important factors or effects and too broad a scope may make the analysis too lengthy. In addition, the scoping team should 
agree on the alternatives and major issues to be addressed. Discussion between the different stakeholders who are involve in the scoping helps to ensure that the different issues and concerns raised by the various groups are considered (Roe et al. 1995). Moreover, public participation helps to eliminate those issues generally agreed as being of a little or no significance. This also avoids misunderstanding and costly mistakes if it is done at the early stage of project planning (Roe et al. 1995).

In many developing countries scoping is fully practiced in situations where there is a requirement by aid agencies. Nigeria, for example, has applied its detailed EIA system to projects funded by development agencies or international oil companies (George 2000). In certain other countries such as India, there is a limited form of scoping where the discussion is between the proponent and the relevant environmental authority without public involvement, though the provisions for public participation have been strengthened recently (Banham \& Brew 1996). In South Africa, on the other hand, scoping is mandatory and a plan of the scoping report has to be reviewed by the relevant authority. In addition, the proponent needs to ensure that the public is given an opportunity for participation in the scoping process and once the decision is made the documents are placed in the public domain (Republic of South Africa 1997).

Ahmad and Sammy (1985) have highlighted that strengthening of scoping could be important for improving EIA in developing countries. Furthermore, the African Development Bank (1992) recommends the combined use of checklist and supporting questions to assist scoping. The World Bank (1999) has emphasized consultation of local affected communities and NGOs to focus the EIA on issues of concern at a local level and take local views into account. Wood (1995) argues that making a reference to published guidance documents and provision for an appeal against the scoping decision could strengthen the effectiveness of scoping.

\subsubsection{The EIA study}

Modac and Biswas (1999) divide the EIA study into two steps, the initial environmental examination (IEE) and the detailed EIA study. According to these authors, IEE is a process that examines the issues that have been identified in the scoping process in more detail by carrying out an exercise of prediction and assessment to identify required mitigation measures. Each alternative (site, design and operational process) is assessed and analysed 
to rank them and find the alternative which may be either cleared or taken to the detailed EIA stage.

In the detailed EIA all the significant issues previously dealt within the IEE are reassessed for adequacy in a formal framework of identification, prediction and assessment. This is because new issues will possibly be identified from the improved understanding of issues due to the IEE, project modification and suggested mitigation measures (Modac \& Biswas 1999). The main processes involved in the detailed EIA are described below in brief.

\subsubsection{Prediction}

Prediction is an attempt to determine the cause and effect of the impacts based on data and analysis from a variety of sources: physical, biological and sociological (Roe et al. 1995). In quantifying impacts, mathematical models, photomontages, physical models, sociocultural models, economic models, experience or expert judgments may be employed. However, the sophistication of the methods should be kept in proportion to the scope of the EIA in order to prevent unnecessary expense (Modac \& Biswas 1999).

In many developing countries, prediction practice is one of the weakest areas of EIA (George 2000). George (2000:92) indicates that “...EIA reports often contain voluminous descriptions of the baseline environment and the project, which may bear little relation to the report's much briefer sections on impact identification and prediction." This is mainly due to the fact that in these countries EIA is relatively new and experience in assessment is limited. However, data needs can be defined clearly and the whole EIA process can be made efficient and effective if a rigorous approach of impact prediction is adopted. In addition, the prediction of impacts will be improved as the number of experts with technical skills and thorough understanding of the receiving environment grows.

\subsubsection{Evaluation of significance}

Once the adverse impacts are predicted it is necessary to evaluate their significance. This task is often subjective and value-laden. The context of the evaluation must, therefore, be considered at various stages (e.g. national and local) (Roe et al. 1995). As mentioned by various authors (Roe et al. 1995; Modac \& Biswas 1999), the judgment of significance can be based on one or more of the following:

- Comparison with existing legislation, regulation or accepted standards; 
- consultation with the relevant decision makers;

- reference to the protected status of particular areas or ecosystems, landscape and species;

- consistency with government policy objectives; and

- acceptability to potentially affected people and the general public.

The adoption of significance criteria varies according to countries' political culture and socio-economic frameworks (George 2000). In countries without strong democratic traditions, for example, technical recognition is given more attention than public recognition. For aid agencies and development banks and countries like Australia (see Box 3.6), on the other hand, public interest or perception is an important consideration (Glasson et al 1999; George 2000).

Box 3.6: Determination of environmental significance (West Australian Environmental Authority 1993).

Environmental significance is a judgment made by the West Australian Environmental Authority and is based upon the following factors:

(a) character of the receiving environment and the use and value which society has assigned to it;

(b) magnitude, spatial extent and duration of anticipated change;

(c) resilience of the environment to cope with change;

(d) confidence of prediction of change;

(e) existence of policies, programmes, plans and procedures against which the need for applying the

EIA proposal to a process can be determined;

(f) existence of environmental standards against which a proposal can be assessed; and

(g) degree of public interest in environmental issue likely to be associated with a proposal.

However, the choice of appropriate significance criteria depends on the nature and significance of the impact. For example, if the nature of the impact is widely understood and agreed, institutional recognition such as consistency with policy and regulations will be used as a form of criterion. If the nature of the impact is not agreed to be significant in an institutional norm but concerns at least some section of the public, acceptability to potentially affected people and the general public need to be used as form of criterion. On the other hand if the nature of the impact is not widely understood to cause public concern but of concern to technical specialists, technical understanding of the impact's consequence could be used (Canter 1996). 


\subsubsection{Mitigation}

Mitigation involves the introduction of measures to avoid, reduce, remedy or compensate for all adverse impacts (Roe et al. 1995; Wood 1995) (Box 3.7).

Box 3.7: Alternative means of mitigation (George 2000:90)

\begin{tabular}{|ll|}
\hline $\begin{array}{l}\text { Approach } \\
\text { Avoid }\end{array}$ & $\begin{array}{l}\text { Examples } \\
\text { Change of route or site details, to avoid important ecological or } \\
\text { archaeological features. }\end{array}$ \\
Replace & $\begin{array}{l}\text { Regenerate similar habitat of equivalent ecological value in a } \\
\text { different location. }\end{array}$ \\
Reduce & $\begin{array}{l}\text { Filters, precipitators, wastewater treatment, noise barriers, dust } \\
\text { enclosures, visual screening, wildlife corridors, change timing of } \\
\text { activities. }\end{array}$ \\
Restore & $\begin{array}{l}\text { Site restoration after mineral extraction. } \\
\text { Relocation of displaced communities, facilities for affected } \\
\text { compensate }\end{array}$ \\
& communities, financial compensation for affected individuals, \\
& recreational vark or other compensating environmental benefits. \\
\hline
\end{tabular}

In some developing countries such as South Africa, there is an emphasis on mitigation of impacts. Wood (1999:56) stated that " mitigation is a great strength of ElA in South Africa. Because there have been so few refusals of authorization, almost the whole emphasis of integrated environmental management was on avoiding, reducing or remedying the negative environmental impacts of developments and enhancing the positive impacts at each stage in EIA process." However, a survey of the early EIAs in South Africa (1971-1986) indicates that mitigation of social impacts was given far less attention than mitigation of biophysical impacts (Mafune et al. 1997). Similarly George (2000) mentions that in countries with weak democratic process compensation arrangements (for projects which involve relocation of large number of people such as large dams) may not be considered satisfactory by the affected people. This however, can be addressed by having a social impact assessment and stakeholder participation.

Some of the mitigation may involve considerable costs, so there is a need to quantify the costs and compare all the alternative measures in order to assist decision-makers in their choice of options (Roe et al. 1995). To ensure that mitigation of impacts is considered at various stages of the EIA process, there should be clear records in the statement that indicate the developer's commitment to mitigation measures (Wood 1995). Modac and Biswas (1999) and George (2000) also highlight the need for details of how the mitigation measures will be implemented and function over the time span for which they are necessary. 
Furthermore, existence of published advice on mitigation and modification of actions also will be helpful to all participants of the EIA process. Provision of public consultation and participation would assist in getting mitigation measures and in determining which residual impacts are tolerable and which cannot be accepted (Wood 1995). Finally, the mitigation measures should actually ameliorate impacts (function effectively) and should not involve the expenditure of unnecessary time, human or financial resources (function efficiently) (Wood 1995).

\subsubsection{Documentation}

Documentation is a vital step in the EIA exercise, and is at the heart of EIA process. If there is no proper preparation of a report documenting the findings relating to the predicted impacts of the proposal on the environment, there can be no meaningful EIA (Wood 1995). The EIA document, which is normally called an EIA report or environmental impact statement (EIS) ${ }^{1}$, communicates the finding of EIA study to a wide range of professionals, decision makers, administrators, interest groups and the general public (Roe et al. 1995; Modac \& Biswas 1999).

An EIA document can be divided into a reference document and a working document (Ahmad \& Sammy 1985). According to these authors the reference document contains the detailed record of the EIA study including charts, graphs and technical calculations. This document is written by a technical specialist who undertakes the quantification of impacts. It is intended for use by a technical audience such as people working on the EIA report and people working with the project after it has been implemented. The working document on the other hand is a simple and clear record that communicates the technical information (the reference document) to the decision-maker. It is prepared by a coordinator and presents the conclusions and recommendations in a summary form (Ahmad \& Sammy 1985).

\footnotetext{
${ }^{1}$ For the sake of consistency, an EIA report would be used throughout the paper rather than using it interchangeably with the EIS.
} 
The content of an EIA report may differ from country to country, however, Wood (1995) and Lee (2000) argue that, the content of the EIA report must:

- Describe the proposed actions and the environment affected;

- predict the magnitude and significance of expected changes to the environmental conditions;

- identify and assess the impacts of alternatives which have been investigated and of any mitigation measures which are proposed for inclusion in the project; and

- present the findings in an appropriate form for the intended users of the statement (i.e. it should contain a non-technical summary).

An EIA report is prepared to assist decision-making. In many countries particularly in developing countries (see examples in Box 3.8), however, such a use of EIA reports is limited. As Lee (2000) stated this is because:

- They are not completed and made available at early stages for consultation and authorization purposes;

- there is lack of appropriate form of analysis used and content of the finding in the EIA report for decision-making; and

- they are presented in a way which is not useful for consultation and decision-making.

Box 3.8: Examples of findings of EIA report quality reviews

Ibrahim (1992): Analysed the quality of 13 ELA reports submitted to the Department of Environmen in Malaysia between 1988 and 1991. Of these, $8 \%$ were assessed as good quality (A or $\mathrm{B}$ rating), $77 \%$ were bordering ( $\mathrm{C}$ or $\mathrm{D}$ rating) and 155 were poor ( $\mathrm{E}$ or $\mathrm{F}$ rating).

Rout (1994): $\quad$ Reviewed the quality of 7 EIA reports submitted to the state authority in Orissa India. Approximately 30\% were satisfactory (all in Category $\mathrm{C}$ ) and $70 \%$ were unsatisfactory (in D, E or F Categories).

Where: $A=$ Generally well performed, no important tasks left incomplete; $B=$ Generally satisfactory and complete, only minor omissions and inadequacies; $\mathrm{C}=\mathrm{Can}$ be considered just satisfactory, despite omissions and inadequacies; $\mathrm{D}=\mathrm{Parts}$ are well attended but must as a whole, be considered just unsatisfactory because of omissions and/or inadequacies; $E=N o t$ satisfactory, sienificant omissions or inadequacies: and $\mathrm{F}=$ Verv unsatisfactorv. important tasks poorlv done or not attempted.

If EIA is to be meaningful these problems need to be addressed. Furthermore, to prepare an effective EIA report Wood (1995) has identified several requirements summarised in the Box 3.9. 
Box 3.9: Requirements for preparing an effective EIA report (Wood 1995).

- The information held by the authority about the environment or type of action needs to be available to the proponent.

- Published guidelines on ELA preparation, content and form which are helpful to the proponents, consultants, decision makers, environmental authorities, interest groups and the public, should exist.

- The methods employed in EIA report preparation need to be specified.

- To avoid the danger of consultancies being selected by price or suffering from bias, some form of accreditation of EIA consultants or code of practice should be introduced.

- Checks on the content, form, objectivity and accuracy of information presented should occur before publication of EIA report.

- As in the other stags of EIA process, there should be a requirement for consultation and participation in EIA report preparation.

\subsubsection{Review}

An EIA review process involves the systematic assessment of the quality and completeness of the EIA report for decision-making and consideration of its implications for project implementation (Roe et al. 1995; Modac \& Biswas 1999). The fundamental requirement of a review process is that the responsible authorities, expertise and the public should be able to comment upon the EIA report and the action it describes before a decision on the action is made (Wood 1995). Ensuring objectivity is a necessary task in EIA review. Wood (1995) has identified methods such as; use of review criteria, the accreditation of EIA report body, the publication of the results of review, and the involvement of consultees and the public for promoting objectivity of EIA reviewing.

In some developing countries EIA review is undertaken by the environmental agency, but normally review is done by planners and other interested parties who have knowledge of the regulations and an understanding of EIA methodology and current ideas of best practice in EIA (Modac \& Biswas 1999). For projects funded by the World Bank, the EIA needs to be reviewed by the borrower, to ensure that the consultants or agency staff followed the terms of reference (TOR) and met both the Bank and country requirements. The Bank's staff must also ensure the adequacy of the EIA report by checking against the Bank's review criteria which are given in Box 3.10 (World Bank 1999a). For further strengthening of the EIA review there should be a provision that the proponent can be asked for more information in case of inadequate EIA reports, and there should also be a provision for a right to appeal against review decisions (Wood 1995). 
Box 3.10: The World Bank's environmental assessment review criteria (World Bank 1999a:5-6)

- Were the TORs followed?

- Are the items required by the EA Operations Division (OD) included?

- Is the Executive Summary adequate?

- Decision-makers may read only the summary, therefore it must present the significant impacts (in order of importance), clarifying which are unavoidable and which are irreversible; the measures which can be taken to mitigate them; the cumulative effect of impacts; and the requirements for monitoring and supervision.

- Are recommendations clearly stated in the Executive Summary?

- Is the project outline description complete, insofar as the aspects which can affect the environment are concerned?

- Are project alternatives described?

- Is the baseline study section in the main report concise and useful to readers who are not specialists in the scientific disciplines covered?

- Does the section give an overall picture of present conditions and trends, and include ongoing and proposed development activities in the study area?

- Does it provide comments on the quality of the data and the completeness of the database?

- Is there consideration of probability in the section in which impacts are predicted and evaluated?

- Are potential impacts mentioned that were expected a priori but not found?

- Are significant impacts analyzed in more detail than less significant ones?

- Is sufficient justification provided for dropping topics from further consideration?

- Do mitigating measures both control adverse impacts and enhance project benefits?

- Are the institutional arrangements for implementing the measures defined?

- Are the costs of implementing all its recommendations adequately budgeted in the cost tables?

- Where monitoring programs are described, are the reasons for and costs of the monitoring activities covered?

- Is there a description of the institutional arrangements for carrying out the work, evaluating the results, and initiating any necessary action to limit adverse impacts disclosed by monitoring?

- Will the project be in compliance with Bank directives and policies on environmental matters, such as involuntary resettlement properties and wildlands?

- Are proposals for institutional strengthening and training adequate?

- Is there documentation of community involvement, including an overview of the issues raised and their disposition?

- In general, is the report free of jargon, and are technical terms defined where they occur or in a glossary?

- Where existing databases, planning studies, other EAs, scientific papers, etc., are used as information sources, are the references given? 


\subsubsection{Decision-making}

Decision-making takes place throughout the EIA process. However, the main decision in the EIA process, whether or not to allow the proposal to proceed is taken in the public domain (Wood 1995). Decisions are influenced by a number of things. These include social, political, and economic circumstances and the regulatory, procedural and institutional constraints within which the decisions are taken (Lee 2000).

Decision-making in many developing countries is not open to external observation and besides the economic and social factors they could be influenced by corruption (Wood 1995). In South Africa, for example, refusal is very uncommon because of the overwhelming pressure for development and the decisions are made on the basis of narrow nature conservation or other bases, rather than on consideration of internationally recognized good EIA practice (Wood 1999a). Lee (2000) also mentions certain factors that lead to weak decision-making practice of EIA in developing countries (see Box 3.11). These include:

- Starting the EIA too late in the project cycle;

- lack of coordination between EIA and project planning;

- limitations within EIA reports;

- deficiencies in consultation arrangements;

- inadequate linkages between EIA reports, other appraisals, consultations and decision making; and

- weak links between the EIA process and project implementation.

Therefore, if the goal of EIA is to be achieved, the above weaknesses need to be addressed. In addition, the findings of the EIA report and review need to be a central determinant of the decision of the action (Wood 1995). According to Modac and Biswas (1999), EIA performs best in a model of rational decision making, in which one designated authority makes a crucial decision based on factual information and rational arguments. It is also argued that, the decision made by the decision-making body should be publicly released, noting the avenue of appeal that are available to the proponents and members of the public (Gilpin 1995). Furthermore, Wood (1995) highlights the need for published guidance on the factors to be considered in the decision and the public release of decision documents that include an examination of how the EIA report and review influenced the decision. 
Box 3.11: Examples of weak links between EIA and decision-making

Sri Lanka: As far as national economic and local development planning and implementation process are
concerned, the EIA process fits very poorly as of now. There appear to be great resistance within planning
agencies to use it as a planning tool and it can hardly be said to be integrated into their process at all (Smith \&
van der Wansem 1995:19-22).
Philippines: Recent experiences encountered in the implementation of major projects in the country show that,
despite the conduct of EIAs, serious difficulties are still faced by project implementers because environmental
consequences are not sufficiently considered in the early stages of project cycle. As a result, the entry point of
environmental point assessment in project cycle is not early enough to be useful in decision making and EIA is
oftentimes seen as merely another bureaucratic requirement to hurdle (Smith \& van der Wansem 1995:19-22).
Graphite Mining Project in Tanzania: AfDB prepared ToR for the EIA and the company sub-contracted
its preparation, both taking place after the design of the plant and mining operation had been finalized. The
environmental impact study was undertaken principally as a stand-alone exercise. The proponents provided the
background information required for the consultants to prepare the EIS, but there was no further integration
between the EIA process project design. The EIS focused tightly on the design prepared during the feasibility
study, and did not explore alternative options for design, plant siting and mine waste disposal plans. In a more
general sense, the EIS would appear to have had no impact on the siting, design and operation of the project
(Mwalyosi \& Hughes 1998:51-52).

\subsubsection{Monitoring and post-auditing}

Monitoring is required to ensure that the action is implemented as described in the assessment and its impacts are no greater than predicted in the assessment. It provides valuable feedback for use in future assessments (Lee \& George 2000). Monitoring measures may involve physical inspection measurement using various instruments, combined with professional judgment (Wood 1995).

Though the requirement for a monitoring plan or environmental management plan is increasing (George 2000), in many developing countries, even in those with a relatively long EIA experience such as South Africa, monitoring is absent or poorly developed (Wood 1999a). For example, Mwalyosi and Hughes (1998:69), based on the review of the performance of EIA in Tanzania, state that " in most of the case studies reviewed, the EIA process ended with the submission of the EIS. In no case did EIA practitioner involvement continue during the implementation or post completion stages of the project. Postcompletion monitoring seems to be particularly poor in this respect." Many of the monitoring procedures of developing countries are similar to those of the funding agencies such as the World Bank (George 2000).

Once the EIAs of existing projects are completed, the post-auditing can begin. Auditing an EIA provides an opportunity and mechanism to learn from experience, and to refine project 
design and implementation procedures (Roe et al. 1995). In addition, it helps to find empirical evidence for cause-and-effect relationships that will be useful in ongoing and future EIAs (Modac \& Biswas 1999). Moreover, post-auditing provides regulatory agencies with a framework for checking compliance with and performance against an environmental management plan (Roe et al. 1995). In some developing countries there may be a provision for post-auditing or follow-up monitoring but they often lack sufficient detail to be fully effective (George 2000). For projects funded by World Bank, the Bank supervises the implementation of environmental aspects and the borrower needs to report on compliance with measures agreed with the Bank on the basis of the findings of the EIA, including implementation of EMP, the status of mitigation measures, and the findings from monitoring progress in project implementation (World Bank 1999a).

To strengthen the EIA process, all the different types of monitoring (implementation monitoring, impact monitoring and impact auditing) must be specifically given in the EIA report and need to be linked to the earlier stages of the EIA process (Wood 1995). It is essential that good, detailed published guidelines on monitoring and auditing action implementation and impact exist, and that regular monitoring reports be submitted to environmental agencies (Wood 1995; Modac \& Biswas 1999). Moreover, for the monitoring and auditing of actions to be effective, Wood (1995) has stated that the results of such monitoring must be compared with the predictions in the EIA report and the proponent must take ameliorative action if there is a need for it. As in the other stages of EIA process monitoring and auditing, results should be published and there should be a public right of appeal if the results are unsatisfactory.

\subsection{Other features of EIA system}

\subsubsection{Coverage}

Since the objective of EIA is to ensure that the environmental impacts of significant actions should be assessed, there is a need to have an explicit requirement to cover all (public and private) environmentally significant proposals (Sadler 1996). Though some times certain projects are exempt from EIA for overwhelming reasons (e.g. national security conditions), care is needed that the unjustified use of such legislation should not by-pass EIA requirements (Wood 1995). EIA should be implemented at different stages of the project and should address significant environmental issues, social, economic and 
health factors, examination and comparison of alternatives, cumulative effects and ecosystem level changes, as well as sustainability considerations (Sadler 1996). However project EIAs have limited capacity to deal with global and regional scale changes and other broader environmental sustainability considerations. These are addressed by higher levels of decision-making tools such as SEA. Therefore, if EIA is to fulfill its role as a decisionmaking tool, its coverage need to be expanded to include all significant environmental problems of projects, programs, plans, and policies.

\subsubsection{Public consultation and participation}

The general public is the ultimate recipient of the economic benefits and environmental damages. Therefore, every EIA should involve the public as part of the decision-making process of project development (Modac \& Biswas 1999). It can be even said that, "an EIA is not an EIA without consultation and public participation" (Wood 1995: 225). As Ahmad and Sammy (1985) and Modac and Biswas (1999) mention, local residents and NGOs can be a good source of information for EIA, and in some cases they may provide insights for new alternatives. However, besides the acknowledgement of these advantages, public consultation and participation in many developing countries is low (see examples in Box 2.2). If there is any, it is very general and lacks detail, resulting in difficulties in its implementation (Lee \& George 2000). Among the reasons for poor public consultation and participation are lack of knowledge about EIA, the confidentiality of EIA reports, the lack of a culture of participation and a low level of literacy (Wood 1995).

For projects funded by development agencies such as the World Bank, however, consultation with affected parties during the EIA process is part of the requirement for the project to be financed. The World Bank (1999) requires consultation with affected communities and local NGOs at least during the scoping stage, and once the draft EIA is prepared. For projects that affect peoples' livelihood and for community based projects, the Bank requires active public participation in the environmental assessment process, development process and the analysis of social and environmental issues. Box 3.12 provides examples from World Bank funded projects in which public consultation has contributed substantial added value. 
Box 3.12: Examples of positive consequences of public participation (World Bank 1999b:3)

In a Solid Waste Management Project for the Organization of Eastern Caribbean States, negative environmental impact of a proposed landfill site in Grenada which the EA team had missed were identified through public consultation, leading to the protection of an endangered species.

Consultation with groups affected by a flood control project in the Ecuador Lower Guayas Flood Control Project results in changes to the alignment of flood evacuation canals, despite higher costs, to save an important wetland area.

Public consultation on a Water Management Project in Espirito Santo, Brazil, served to identify adverse social impacts and helped in the development of appropriate mitigation measures to promote an artisan community's access to clay deposits and prevent a decline in the living standards of a nearby urban neighborhood.

To strengthen the effectiveness of public consultation and participation the methods employed need to be appropriate to the stages of EIA process and suit the culture, language, literacy level, social consideration and structure of the community likely to be affected by the proposed development (Lee \& George 2000). In addition, there is an argument that copies of EIA documents should be made public at each stage of the EIA process and easy access to the documents needs to be facilitated (Glasson et al. 1994; Gilpin 1995; Wood 1995; Lee \& George 2000). Furthermore, Wood (1995) argues that there is a need to specify obligatory consultees at various stages in the EIA process and funding should be provided to encourage public participation. He also states the need for consultation and participation with adjoining authorities, states and countries if proposals are made which could affect their environment. The existence of published guidelines on consultation and participation, and the right to appeal against the published results of consultation and participation are other necessary elements for effectiveness of the EIA process (Wood 1995).

\subsubsection{System monitoring}

Monitoring and auditing of impact actions alone will not make EIA effective. There must be some form of EIA system monitoring which permits the amendment of EIA system to incorporate feedback from experience and remedy any weakness identified (Wood 1995). In developing countries, however, there is little experience in EIA system monitoring. Information about EIA is limited and EIA reports are not easily available. In addition, there is scant interest in reviewing the operation of the system (Wood 1995). Ahmad and Sammy (1985) state that this condition will however change with expansion of EIA organizational 
capacity and regulatory requirements. Box 3.13 provides an assessment of state of EIA system monitoring in South Africa.

Box 3.13: Monitoring of EIA systems in South Africa (Wood 1999a: 56-57).

There is no provision in either the Environmental Conservation Act or the ELA regulations for any review of the EIA system or for the keeping of documents relating to EIA. Department of Environmental Affairs and Tourism (DEAT) appear not to keep any records of EIA documents or copies of EIA reports or other documents. DEAT sees this as the responsibly of the provincial government or, where EIA responsibilities are delegated, of the appropriate local government. However, this view is not shared by these bodies. At present, the keeping both of records and EIA reports is often rudimental. No annual reports on EIA activities are required or are likely to be prepared. Equally, no records of the financial costs or time requirements of EIA are kept, though anecdotal evidence exists. The fragmentation of responsibilities, the understaffing of relevant authorities and the unaccountable bureaucratic culture in South Africa all militate against adequate EIA system monitoring. Documents are, however, generally publicly available to persistent enquires and it is intended to make use of Internet to afford greater accessible in the future.

The EIA system can be strengthened by appointing an independent body mandated with keeping records of EIA reports for various types of actions and other EIA documents, the financial costs and time required as well as making them publicly available at specificied locations. This body could function as a central EIA information desk, with a complete EIA library. Moreover, the body could carryout a review to improve the EIA system (Wood 1995; Modac \& Biswas 1999). Finally, monitoring of the EIA system requires public consultation and participation and it needs to function efficiently and effectively as in all other stages of the EIA system (Wood 1995).

\subsubsection{Cost and benefit of the EIA system}

The value of EIA as an appraisal tool depends on the relationship between the benefits and costs of its application. In developing countries the opinions on this issue vary from country to country. Wood (1995) states that the cost of the EIA system exceeds the benefits because of delays in financial resources, lack of expertise, data and confidentiality. Gilpin (1995) on the other hand notes that EIA systems have invariably permitted significant advances in economic growth which is reflected in improved material well-being and health of an entire society, for example, improved life expectancy between 7 and 15 in developing countries such as China, India, Bangladesh and Indonesia.

As a principle, as Lee and George (2000) state, EIA should result in certain benefits which are given in Box 3.14 . 
Box 3.14: Benefits of EIA (Lee \& George 2000:9).

- Environmental and other sustainable benefits, attributable to the environmental assessment system resulting from modifications to actions prior to their approval and implementation;

- saving in the mitigation costs due to earlier detection of potential environmental problems and better designed corrective measures to deal with these problems; and

- saving in time in obtaining approval for new developments, also due to the earlier detection and correction of environmental problems which reduce controversy and conflict during the authorization process.

These benefits assist in avoiding the extra cost to the developer and the authorities in complying with EIA system and procedural requirements, losses of time where the system does not work efficiently and unjustified delays occur, and additional mitigation expenditures due to the EIA process commencing too late in the planning and project cycle or where it is used to impose insufficiently substantiated mitigation requirements on developers (Lee \& George 2000).

Furthermore, as a measure of the efficiency of the EIA process, Wood (1995) mentions that participants in the EIA process should believe that it has altered the behavior of proponents, consultants, consultees, the public and the decision-making authorities. $\mathrm{He}$ also states that empirical evidence that the EIA process has significantly altered the outcome of the decisions should exist so that those who are involved in the EIA process believe that the environmental quality and acceptability of decisions are improved by it.

\subsubsection{Project EIA sustained by SEA}

EIA for projects may not work effectively if the room for decisions is restricted by earlier decisions at national level. For example, the policy of industrial development in rural area, needs to be initially subjected to SEA rather than assessing each industrial project separately (Modac \& Biswas 1999). In such cases, there should be a provision for the EIA system to be applied to the significant programmes, plans, and policies (strategic decisions) as well. This ensures that all the alternatives and impacts relevant to sustainability goals are adequately considered (Wood 1995; Modac \& Biswas 1999). 
Like project EIA, SEA also involves screening, scoping, prediction, consultation, public participation, mitigation of impacts and monitoring, and dealing with alternatives and significant impacts not covered adequately at project level (Wood 1995).

In general the experience of SEA in developing countries is weak. In Africa for example, with the exception of some ad hoc SEA, as in South Africa, and part of the planning process for national parks, as in Tanzania, SEA is not well developed (George 2000). However, Wood (1995) notes that there is a considerable interest in the application of SEA in developing countries for matters such as regional development plans and land use plans for developing areas. According to Wood (1995), the work on the World Bank's national environmental action plans, regional and sectoral environmental assessments indicate that there are more potential advantages in using SEA in developing countries than in the developed world, although the challenges related to the use of SEA in developing countries are more acute than in developed countries. To make SEA effective, consideration of the points listed in Box 3.15 is necessary.

Box 3.15: Courses of action for making SEA effective (Wood 1995:272-273 and Modac \& Biswas 1999:214)

- Increase the general understanding of SEA, for example the types of actions to which SEA could usefully be applied and its relation to existing ELA and sustainable development policies;

- clarifying the procedural issues, for example, at which decision points in a planning process should SEA be applied, how should SEA findings be integrated with other policy and planning considerations in decision making;

- clarifying methodological issues by adapting existing methods (including ELA methods) for SEA use;

- strengthening the capacity for the practical application of appropriate SEA methods: for example, understanding 'trial runs', diffusing examples of good SEA practice, preparing SEA guidance and providing training in its use;

- reviewing existing environmental data source to assess their potential use in SEA and prioritising measures for correcting any deficiencies; and

- it should be established as a cost-effective tool of environmental management.

The understanding and implementation of the above-stated courses of action, therefore, would address the regional and global scale changes, and other environmental sustainable considerations. 


\section{CHAPTER 4 \\ METHODOLOGY}

\subsection{Overview of the methodology}

To review the application of EIA in Eritrea, a review of both the performance of the EIA system and the quality of EIA reports (case studies) will be undertaken. The methodology for the research will be predominantly qualitative, though some quantitative data are also going to be collected. To achieve the objectives of the study, initially the international application of the subject matter (EIA) will be reviewed. Thus, international principles, concepts, procedures and experiences of EIA will be identified with a view to establish evaluation criteria for both the performance of the EIA system and the quality of the EIA reports. Thereafter, the national EIA policy and practice will be reviewed against these established evaluation criteria to examine the overall effectiveness of the national EIA application. Finally, from the analysis of evaluation, recommendations which result in better national EIA application (if there is a need) will be provided. The methodology adopted for this study is illustrated in Figure 4.1. 
Literature review on ELA for international organizations (e.g. World Bank) and other developing countries.

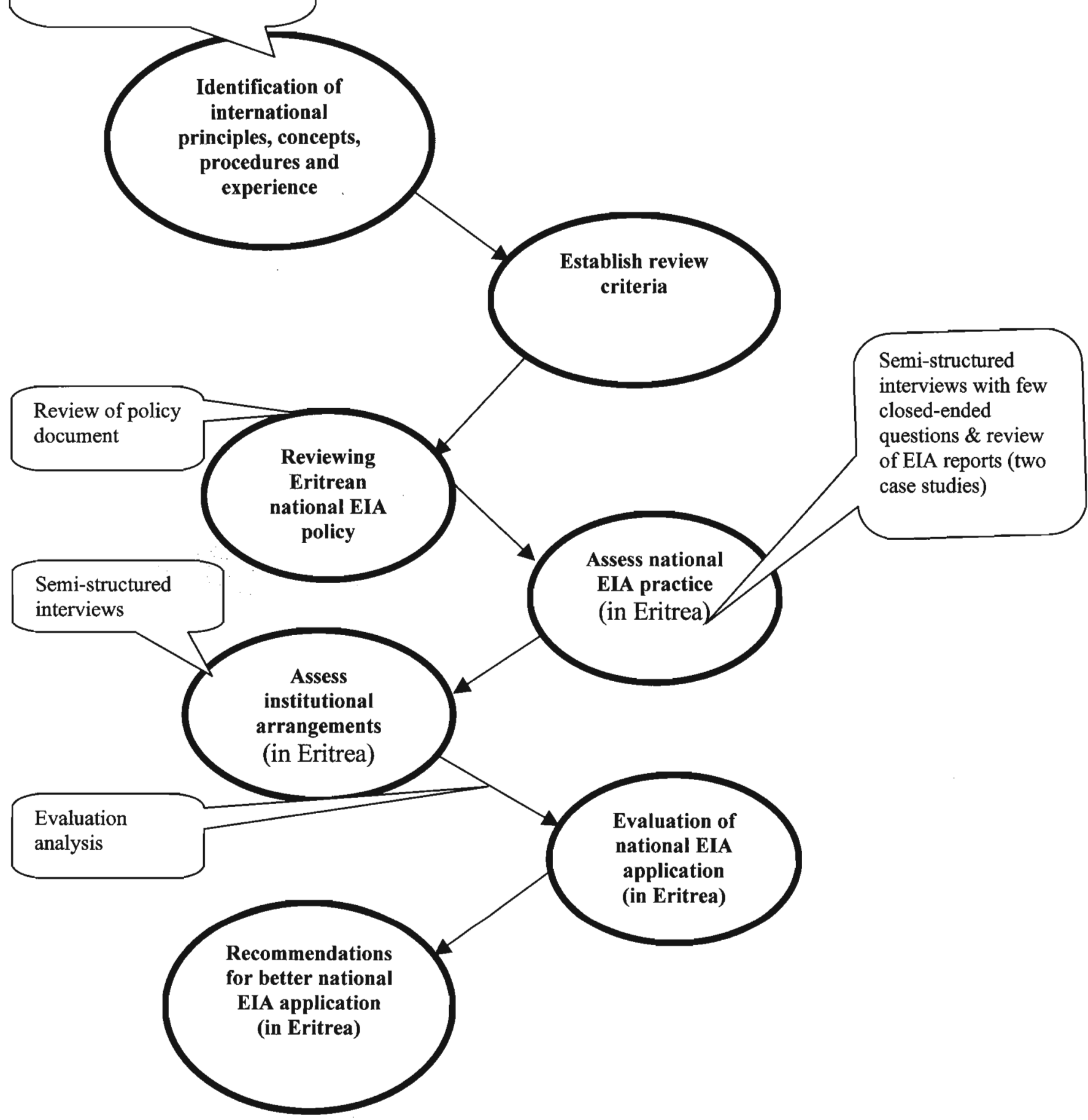

Figure 4.1: The methodology adopted for the study 


\subsection{Evaluation of the national EIA system}

\subsubsection{Information required}

To review the performance of the EIA system in Eritrea, information on the following issues will be gathered.

- Institutional aspects of EIA system (policy, environmental institution and responsibilities for EIA administration, ELA legislation, and availability of resources);

- EIA process (screening, scoping, EIA study, documentation, review, decision-making, monitoring and auditing); and

- other features of EIA system (coverage, consideration of alternatives, public consultation and participation, system monitoring, cost and benefit of the EIA system and SEA).

\subsubsection{Methods of information gathering}

The method for collecting and analyzing the information will be a critical review of literature, reports, and other relevant documents. That is, as far as possible, the NEAPG document, Draft Environmental Proclamation (DEP), EIA reports, annual reports on EIA, and other EIA related documents will be reviewed. However, anticipating limited literature on the national EIA system and scarcity of documents, interviews with different stakeholders (Table 4.1) will be held. The focus of these interviews will be to assess the institutional arrangements with respect to EIA administration and implementation. Aid agencies such as World Bank and other environmental NGOs (if they exist) will also be interviewed for their experience in the application and implementation of the EIA process in the country.

The interviews will be semi-structured and open-ended in order to help the researcher get more information and insight on the national experience of the subject matter. The interviews will be personal (one to one) and will be recorded using a tape recorder. In addition a few closed-ended questions will be used to collect some quantitative data (e.g. the number of projects that have gone through full EIA since 1995, the number of projected rejected, etc.). This quantitative information will provide figurative data for evaluating the extent to which EIA is practiced in the country. The details of the documents required and interview questions are given in Appendix 2. 
Table 4.1: Interviewees for the study

\begin{tabular}{|l|l|l|}
\multicolumn{1}{|c|}{ (institution Eritrea) } & \multicolumn{1}{|c|}{$\begin{array}{c}\text { Number of } \\
\text { interviewee(s) }\end{array}$} & \multicolumn{1}{|c|}{ Position of interviewee(s) } \\
\hline $\begin{array}{l}\text { DoE, Ministry of Land Water and } \\
\text { Environment }\end{array}$ & 1 or 2 & $\begin{array}{l}\text { Director General and/or EIA unit director, or Senior } \\
\text { expert in EIA/Environmental management. }\end{array}$ \\
\hline $\begin{array}{l}\text { Department of Infrastructure, } \\
\text { Ministry of Public Works }\end{array}$ & 1 or 2 & Director General or Unit director(s) \\
\hline Ministry of Energy and Mines & 1 or 2 & Head of department(s) \\
\hline $\begin{array}{l}\text { Ministry of Agriculture } \\
\text { Department of Industry, Ministry } \\
\text { of Trade and Industry }\end{array}$ & 1 & Division/Unit directors \\
\hline $\begin{array}{l}\text { Ministry of Transport and } 3 \\
\text { Communication }\end{array}$ & 1 or 2 & Division/section director \\
\hline $\begin{array}{l}\text { World Bank (other NGOs) } \\
\text { T. Consult. }\end{array}$ & 1 & Department head/Division head(s) \\
\hline $\begin{array}{l}\text { Natural Resource Consulting } \\
\text { Engineering (NRCE) }\end{array}$ & 1 & Private Consultant \\
\hline
\end{tabular}

\subsubsection{Criteria for reviewing the EIA system}

A review of national EIAs against international principles and procedures has been adopted as a way of improving EIA application in many countries. As Fuller (1999) indicates the two notably comprehensive and independent EIA system evaluation criteria are those adopted by Wood (1995) and Sadler (1996). Some of the criteria in Sadler (1996), however, are proposed to check the performance of activities that have already been undertaken. That is, to check if the activities are completed fully and successfully rather than determining the existence of requirements as to what constitutes effectiveness. For example, the criteria set for screening checks if a proposal was classified correctly as to level and requirement for assessment, as opposed to establishing whether screening of actions for environmental significance must take place? In addition questions set for measuring the overall results of effectiveness are not independent. This means they can be used as evaluation criteria only if there is enough information, mainly on evidence from monitoring and auditing.

Unlike the criteria set by Sadler (1996) which deal with performance of activities that have already been undertaken, Wood's (1995) criteria deal with the quality of activities that need to take place. In contrast to Sadler's (1996) criteria which are based on a scale 
measurement, Wood's (1995) criteria are open-ended and allow one to make a descriptive evaluation. They have been employed to make an international comparison on the effectiveness of at least eight EIA systems, including those of the US, California, the UK, the Netherlands, Canada, the Commonwealth of Australia, Western Australia, and New Zealand (Wood 1995; Wood 1999b). In addition they were used to assess the extent to which the South African EIA system meets internationally recognized good EIA practice (Wood 1999a). With some modification, Wood's (1995) criteria have also been used to undertake a comparative review of the EIA systems of three developing counties; Egypt, Turkey and Tunisia (Ahmad \& Wood 2002).

Considering the scope and the aim of the study, therefore, the evaluation criteria developed by Wood (1995) are preferred as the basis for the evaluating the effectiveness of the application of EIA in Eritrea. To meet the aim and objectives of this study, the author has slightly modified Wood's (1995) criteria and incorporated the experience of developing countries on what constitutes effective EIA. These are mainly the institutional aspects of EIA system such as: existence of clear environmental policy; establishment and strength of environmental institution; and availability and accessibility of resources. They are based on different literature sources among which include: Ahmad and Sammy (1985); Biswas and Geping (1987); Roe et al. (1995); Modac and Biswas (1999); World Bank (1999); George (2000); Lee (2000); Lee and George (2000). The criteria are descriptive in nature and are presented in Box 4.1. 
Box 4.1: EIA system evaluation criteria adopted for this study (after Wood 1995)

1. Institutional aspect of EIA system

1.1 Does a clearly documented environmental policy at national, regional and local levels exist?

1.2 Is there institution body mandated with environmental matters and does responsibilities for EIA administration clearly specified?

1.3 Is the EIA system based on clear and specific legal provisions?

1.4 Are there adequate resource to carry out meaningful EIA?

\section{EIA Process}

2.1 Must screening of actions for environmental significance take place?

2.2 Must scoping of the environmental impacts of actions take place and specific guidelines be produced?

2.3 Are there enough guidelines prepared to assist during the EIA study (prediction and evaluation) and is mitigation of action impacts be considered at the various stages of the ELA process?

2.4 Must EIA reports meet prescribed content requirements and do checks to prevent the release of inadequate EIA reports exist?

2.5 Must EIA reports be publicly reviewed and the proponent respond to the points raised?

2.6 Must the findings of EIA reports and the review be a central determinant of the decision on the action?

2.7 Must monitoring of action and post-auditing take place?

3. Other features of EIA system

3.1 Must the relevant environmental impacts of all significant actions be assessed?

3.2 Must evidence of the consideration, by the proponent, of the environmental impacts of reasonable alternative actions be demonstrated in the EIA process?

3.3 Must consultation and participation take place prior to, and following, EIA report publication?

3.4 Must the EIA system be monitored and, if necessary, be amended to incorporate feedback from experience?

3.5 Are the financial costs and time requirements of EIA system acceptable to those involved and are they believed to be outweighed by discernible environmental benefits?

3.6 Does the EIA system apply to significant programmes, plans and policies, as well as to projects?

\subsection{Evaluation of two sectoral EIA reports: case studies}

\subsubsection{Selection of case studies}

A review of all or as many as possible of the existing EIA reports would have been the best approach to adopt in order to see the broad picture of the status quo of EIA practice in Eritrea. However, time and financial constrains makes this approach impossible. Considering these limitations, therefore, two EIA reports will be used as a case study for evaluating the practice of EIA in the country. To minimise this limitation, the review will be thorough and (as stated earlier) the reports will be from different sectors. 
The reports will be requested from DoE, if not available, they will be requested from the World Bank or other sector ministries. In selecting the EIA reports certain criteria will be used. These include:

- The reports need to be full EIA documents. That is, the reports should be for Category A projects;

- the reports need to be from two different sectors; and

- the reports should reflect the current EIA practice. That is, they need to be recently published or released.

\subsubsection{Criteria for reviewing the quality of the EIA reports}

To evaluate the quality of EIA reports or EIA reports certain review criteria have been developed, among which include: Lee and Colley's (1990) review checklist; the Netherlands Environmental Impact Assessment Commission operating criteria (Fuller 1999); and the World Bank environment assessment review criteria (World Bank 1999a). Initially each of these criteria were developed with the requirement of specific country or institution. With time, however, they have been used (particularly the Lee and Colley's review package) either directly or in a modified form in other countries or institutions (e.g. by Institute of Environmental Assessment) (Glasson et al 1999; Lee \& George 2000). In 1994 the European Communion published review criteria similar to Lee and Colley's, but with some details and longer list of specific questions.

For the case studies of this particular study, the EIA report review criteria developed by Impact Assessment Unit (IAU), Oxford Brookes University (Appendix 1) will be used. The criteria are an amalgamation and extension of the Lee and Colley's (1990) and the European Commission's EIA report review criteria. The criteria are comprehensive and set in-depth requirements for: description of development; description of the environment; scoping, consultation and impact identification; prediction and evaluation of impacts; alternatives; mitigation and monitoring; non-technical summary; and organization and presentation of information (Glasson et al. 1999).

The criteria (the EIA system evaluation criteria and EIA report review criteria) used in this study will provide a comprehensive framework for the evaluation of the EIA system in Eritrea both at policy and practice levels. 


\subsection{Assumptions and anticipated problems}

The research is based on the assumption that there will be cooperation from the Eritrean DoE and all other interviewees. Nevertheless, problems such as lack of enough literature on national EIA and a shortage of documents is anticipated. However, as mentioned in the methodology, the interview with experts and/or relevant government authorities will be used to fill the information gaps in literature and documentation. 


\section{REFERENCES}

African Development Bank. 1992. Environmental Assessment Guidelines. Abidjan: African Development Bank.

Ahmad, B. S. 2002. The Middle East and North Africa. In: Environmental Assessment Yearbook. Lincoln: Institute of Environmental Management \& Assessment and Manchester: EIA Centre.

Ahmad, B. and C. Wood. 2002. A comparative evaluation of the EIA systems in Egypt, Turkey and Tunisia. Environmental Impact Assessment Review 22: 213-234.

Ahmad, J.Y. and G.K. Sammy. 1985. Guidelines to Environmental Impact Assessment in Developing Countries. London: Hodder and Stoughton.

Banham, W. and D. Brew. 1996. A review of the development of environmental impact assessment in India. Project Appraisal 11: 195-202.

Barrow, C.J. 1997. Environmental and Social Impact Assessment: An Introduction. London: Edward Arnold.

Bekhechi, M. A. and J. Mercier. 2002. The Legal and Regulatory Framework for Environmental Impact Assessment. Washington, D.C: The World Bank.

Biswas, A.K. 1992. Summary and recommendations. In: Biswas, A.K. and Agarwala, S. B.C. (eds). Environmental Impact Assessment for Developing Countries. Oxford: Butterworth-Heimann.

Biswas, A.K. and Q. Geping. (eds). 1987. Environmental Impact Assessment for Developing Countries. London: Tycooly International.

Buckley, R. 1991. Environmental planning legislation: court back up better than Ministerial discretion. Environmental and Planning Law Journal 8:250-7. 
Burdge, RJ and F. Vanclay. 1995. Social impact assessment. In: Vanclay, F and Bronstein, DA (eds.). Environmental and Social Impact Assessment. Chichester: John Wiley.

Canter, L.W. 1996. Environmental Impact Assessment. $2^{\text {nd }}$ ed. New York: McGraw-Hill International Editions.

Council of Environmental Quality. 1992. Environmental Quality 1991: Twenty second Annual Report. Washington DC: USGPO.

Czerp, A. 2001. Public participation in Environmental Assessment. In: Environmental Assessment Yearbook. Lincoln: Institute of Environmental Management \& Assessment and Manchester: EIA Centre.

Department of Environment. 1999. National Environmental Assessment Procedures and Guidelines. Asmara: Government Printing.

Department of Environmental Affairs and Tourism. 1998. Environmental Impact Management: Guideline Document, EIA Regulations Implementation Of Sections 2122 And 26 Of The Environment Conservation Act, April 1998. Pretoria: Government Printers.

Erickson, P.A. 1994. A Practical Guide to Environmental Impact Assessment: Academic. California: San Diego Press.

Fahrenhorst, B. (ed). 1996. National Environmental Management Plan for Eritrea. Berlin: Heinrich-Boll Foundation.

FAO/GIEWS. 2001. Eritrea: Population [Online]. FAO. Available at: http://www.fao.org/giews/english/basedocs/eri/eripople.stm [Accessed 2 January 2003].

Fowler, R.J. 1985. Legislative bases of environmental impact assessment. Environmental and Planning Law Journal 2:200-5. 
Fuller, K. 1999. Quality and Quality Control in EIA. In: Petts, J. (ed). Handbook of Environmental Assessment: Environmental Impact Assessment in Practice, Impact and Limitations. Vol. 2. Oxford: Blackwell Science.

GeographyIQ. 2002. Eritrea [Online]. GeographyIQ.com. Available at: http://www.geographyiq.com/countries/er/Eritrea_map flag_geography.htm [Accessed 9 September 2002].

George, C. 2000. Environmental Impact Prediction and Evaluation In: Lee, N. and George, C. (eds). Environmental Assessment in Developing and Transition Countries: Principles, Methods and Practice. Chichester: John Wiley and Sons, Ltd

Geping, Q. 1987. The Role of Environmental Impact Assessment in Economic Development. In: Biswas, A.K. and Q. Geping. (eds). Environmental Impact Assessment for Developing Countries. London: Tycooly International.

Gilpin, A. 1995. Environmental Impact Assessment: Cutting Edge for Twenty First Century. United Kingdom: Cambridge University Press.

Glasson, J., R. Therivel and A. Chadwick. 1994. Introduction to Environmental Impact Assessment. London: UCL Press.

Glasson, J., R. Therivel and A. Chadwick. 1999. Introduction to Environmental Impact Assessment. $2^{\text {nd }}$ ed. London: UCL Press.

Government of Eritrea. 1994. Macro Policy. Asmara: Government Printers.

Government of Eritrea. 1995. National Environmental Management Plan for Eritrea. Asmara: Eritrean Agency for Environment.

Government of Eritrea. 1997. The Constitution of Eritrea. Asmara. Government printers. 
Ibrahim, A.K.C. 1992. An Analysis of Quality Control in the Malaysian Environmental Impact Assessment Process. Unpublished MSc dissertation. Manchester: University of Manchester.

International Association for Impact Assessment. 1999. Principles of Environmental Impact Assessment Best Practice [Online]. USA: IAIA. Available at:

http://www.iaia.org [Accessed 16 July 2002].

Kennedy, W. V. 1988a. Environmental Impact Assessment in North America, Western Europe: what has worked where, how and why? International Environmental Reporter 11(4): 257-62.

Kennedy, W.V. 1988b. Environmental Impact Assessment and bilateral development aid: an overview. In: Wathern, P. (ed). Environmental Impact Assessment: Theory and practice, London: Unwin Hyman.

Kwiatkowski, R. 2002. Health Impact Assessment: Miles to go before we sleep. In: Environmental Assessment Yearbook: The EA agenda for Johannesburg and beyond. Lincoln: Institute of Environmental Management \& Assessment and Manchester: EIA Centre.

Lee, N. 2000. Reviewing the Quality of Environmental Assessments. In: Lee, N. and George, C. (eds). Environmental Assessment in Developing and Transition Countries: Principles, Methods and Practice. Chichester: John Wiley and Sons, Ltd.

Lee, N. and C. George. (eds). 2000. Environmental Assessment in Developing and Transition Countries: Principles, Methods and Practice. Chichester: John Wiley and Sons, Ltd.

Lee, N., F. Walsh and G. Reeder. 1994. Assessing the performance of EA process. Project Appraisal 9(3): 161-172.

Lee, N. and R. Colley. 1990. Reviewing the Quality of Environmental Statements. Occasional Paper. No. 24. Manchester UK: EIA Centre, University of Manchester. 
Lonely Planet. 2002. Africa: Eritrea, Environment [Online]. lonelyplanet.com. Available at: http://www.lonelyplanet.com/destinations/africa/eritrea/environment.htm [Accessed 2 January 2003].

Mannion, A.m. and S.R. Bowlby. (eds). 1992. Environmental Issues in the 1990s.

Chichester: Reed Wood Books.

Maps.com. 1999. Africa physical map [Online]. Maps.com. Available at: http://www.maps.com/explore/atlas/phy/africa.html [Accessed 9 September 2002].

Middleton, N. 1999. The Global Casino: An Introduction to Environmental Issues. $2^{\text {nd }}$ ed. London: Arnold Publishers.

Mitchell, B. 1989. Geography and Resource Analysis. $2^{\text {nd }}$ ed. London: Longman.

Modac, P. and A. K. Biswas. 1999. Conduction Environmental Impact Assessment for Developing Countries. Tokyo: United Nations University Press.

Mafune, I., B. McLean, H. Rodkin and R. C. Hill. 1997. The early years of EA in South Africa: a review of case studies form 1971 to 1986. Paper to International Association for Impact Assessment (South Africa Chapter) Conference. KwaMaritane: IAIA-SA.

Mwalysi, R and R. Hughes. 1998. The performance of EIA in Tanzania: an Assessment. London: International Institute for Environment and Development.

National strategies for Sustainable Development. 2000. Pakistan's National Conservation Strategy: Renewing Commitment To Action Report Of The Mid-Term Review, November 2000. [Online] nnsd knowledge management system. Available at: http://www.nssd.net/country/pakistan/mtrch5.htm [Accessed 29 March 2003].

Pearce, D. 1995. Blueprint 4: Capturing global environmental value. London: Earthscan Publication Ltd.

Petts, J. (ed). 1999. Handbook of Environmental Assessment: Environmental Impact Assessment in Practice, Impact and Limitations. Vol. 2. Oxford: Blackwell Science. 
Petts, J. 2002. Risk Assessment and Environmental Impact Assessment, Post Rio. In: Environmental Assessment Yearbook: The EA agenda for Johannesburg and beyond. Lincoln: Institute of Environmental Management \& Assessment and Manchester: EIA Centre.

Pool, D. 1982. Eritrea: Africa's Longest War. London: Anti-Slavery Society.

Rees, C. 2000. Environmental Assessment in Development Banks and Aid Agencies. In: Lee, N. and George, C. (eds). Environmental Assessment in Developing and Transition Countries: Principles, Methods and Practice. Chichester: John Wiley and Sons, Ltd.

Republic of South Africa. 1997. Environmental Impact Assessment Regulations (Environmental Conservation Act 1989), No R 1182- 1184, Government Gazette, 387, No18621, 5 September 1997. Pretoria: Government Printers.

Roe, D., B. Dalal-Clayton and R. Hughes. 1995. A Directive of Impact Assessment Guidelines. Environmental Planning Group. London: International Institution for Environment and Development.

Rout, D.K. 1994. An analysis of the ELA process and EIA reports produced for selected industrial developments in the state of Orissa in India. Unpublished Msc dissertation. Manchester: University of Manchester.

Sadler, B. 1999. A Framework for Environmental Sustainability Assessment and Assurance. In: Petts, J. (ed). Handbook of Environmental Assessment: Environmental Impact Assessment in Practice, Impact and Limitations. Vol. 2. Oxford: Blackwell Science.

Sadler, B. 2002a. From Environmental Assessment to Sustainable Appraisal. In: Environmental Assessment Yearbook: The EA agenda for Johannesburg and beyond. Lincoln: Institute of Environmental Management \& Assessment and Manchester: EIA Centre. 
Sadler, B. 2002b. Global Environmental Agenda- From Rio to Johannesburg. In: Environmental Assessment Yearbook: The EA agenda for Johannesburg and beyond. Lincoln: Institute of Environmental Management \& Assessment and Manchester: EIA Centre.

Sadler, B. 1996. Environmental Assessment in a Changing World: Evaluating Practice to Improve Performance. (Final Report of the International Study of the Effectiveness of Environmental Assessment). [Online]. Canadian Environmental Assessment Agency and International Association for Impact Assessment, Ottawa.

Available at: httm://www.ea.gov.au/assessments/eianet/eastudy/aprilworkshop/paper1.html [Accessed 16 July 2002].

Smith, D.B. and M. van der Wansem. 1995. Strengthening EIA Capacity in Asia: Environmetal Impact Assessment in Philippines, Indonesia and Sri Lanka. Washington D.C: World Resource Institute.

Smith, L. G. 1984. Institutional Arrangements for Electric Power Planning in Ontario. Wilfrid Laurier Research Paper Series No. 8472. Waterloo, Ont: Wilfrid Laurier University.

Smith, L. G. 1993. Impact Assessment and Sustainable Resource Management. Harlow: Longman Group UK Limited.

Taylor, C. N., C. H., Bryan, and C.G., Goodrich. 1995. Social Assessment: Theory, process and Techniques. $2^{\text {nd }}$ ed. Christchurch: Taylor Brain and Associates.

T. Consult. 2001. Environmental Assessment: Eritrea- Emergency Reconstruction Program. Vol. 1. Asmara: Ministry of Finance.

Treweek, J. 1999. Ecological Impact Assessment [online]. Blackwell Publishing. Available at: http://www.cplpress.com/contents/C713.htm [Accessed 4 April 2003].

United Nations Environment Program. 1988. Environmental Impact Assessment: Basic Procedures for Developing Countries. Bangkok: UNEP. 
United Nations Environment Program. 1997. Global Environmental Outlook. Oxford: UNEP/Oxford University Press.

Wathern, P. (ed). 1988. Environmental Impact Assessment: Theory and Practice. London: Unwin Hyman.

Welford, R. 1998. Corporate environmental management: Systems and strategies. $2^{\text {nd }}$ ed. London: Earthscan Publications, Ltd.

West Australian Environmental Authority. 1993. Environmental Impact Assessment: administrative procedures. Perth: EPA.

Wood, C. 1995. Environmental Impact Assessment: A Comparative Review. Harlow: Longman Scientific \& Technology.

Wood, C. 1999a. Pastiche or Postiche? Environmental Impact Assessment in South Africa. South African Geographical Journal 81 (1): 52-59.

Wood, C. 1999b. Comparative evaluation of environmental impact assessment systems. In: Petts, J. (ed). 1999. Handbook of Environmental Assessment: Environmental Impact Assessment in Practice, Impact and Limitations. Vol. 2. Oxford: Blackwell Science.

Wood, C. 2000. Screening and Scoping. In: Lee, N. and George. C. (eds). Environmental Assessment in Developing and Transition Countries: Principles, Methods and Practice. Chichester: John Wiley and Sons, Ltd.

World Bank. 1995. Social Assessment. Environment Department Dissemination Notes, Number 36. Washington D.C: World Bank.

World Bank. 1996a. The Impact of Environmental Assessment, The World Bank's Experience: Second Environmental Assessment Review. Washington D.C: World Bank.

World Bank. 1996b. West Central Africa: Building Ownership for Environmentally Sustainable Development [online]. Findings: Africa Region 76. 5 December. World Bank. 
Available at: http://www.worldbank.org/afr/findings/english/find76.htm [accessed 29 March 2003]

World Bank. 1999a. Environmental Assessment Sourcebook [Online]. World Bank. Available at:

http://lnweb18.worldbank.org/ESSD/essdext.nsf/47DocByUnid/4E2F820D6C2DA787852 56B9900727DBC/\$FILE/Chapter1 TheEnvironmentalReviewProcess.pdf [Accessed 16 July 2002]

World Bank. 1999b. Public Consultation in the EA process: A Strategic Approach. Environmental Assessment Sourcebook Update no 26. May. Washington D.C: World Bank.

World Commission on Environment and Development. 1987. Our Common Future. Oxford: Oxford University Press.

\section{Personal Communications}

Filmon, T. 2002 pers. comm. Department of Environment, Ministry of Land Water and Environment, Eritrea. 


\section{APPENDICES}

\section{Appendix 1: EIS review criteria (IAU, Oxford Brookes University)}

EIS number:

Project name:

Reviewer name:

Marking criteria

(A-F) to summarise how well EIA fulfils criterion for all criteria

A-good

B-generally satisfactory (minor omissions etc.)

$\mathrm{C}$-just satisfactory (despite omissions)

D-just unsatisfactory (because of omissions etc.)

E-not satisfactory (significant omission etc.)

F-poor

\section{DESCRIPTION OF THE DEVELOPMENT}

Principal features of project

1.1 Explains the purpose(s) and objectives of the development.

\begin{tabular}{l|l|l|l} 
Criterion & Performance & Comments
\end{tabular}

1.2 Indicates the nature and status of the decision(s) for which the environmental information has been prepared.

1.3 Gives the estimated duration of the construction, operational and, where appropriate, decommissioning phase

and the program within these phases.

1.4 Describes the proposed development, including its design and size or scale. Diagram, plans, or maps will

usually be necessary for this purpose.

1.5 Indicates the physical presence or appearance of the completed development within the receiving environment.

1.6 Describes the methods of construction.

1.7 Describes the nature and methods of production or other types of activity involved in the operation of the

project. 
Criterion

1.8 Describes any additional service (water, electricity, emergency service etc.) and developments require as a consequence of the project.

1.9 Describes the project's potential for accidents, hazards and emergencies.

Land requirements

1.10 Defines the land area taken up by the development site and associated arrangements, auxiliary facilities and landscaping areas and by the construction site(s), and shows their location clearly on a map. For a linear project, describes the land corridor, vertical and horizontal alignment and need for tunnelling and earthworks.

1.11 Describes the uses to which this land will be put, and demarcates the different land use area.

1.12 Describes the reinstatement and after-use of landtake during construction.

Project Inputs

1.13 Describe the nature and quantities of materials needed during the construction and operational phases.

1.14 Estimates the number of workers and visitors entering the project site during both construction and operation

1.15 Describe their access to the site and likely means of transport.

1.16 Indicates the means of transporting materials and products to and from the site during construction, operation, and number of movements involved.

Residues and emissions

1.17 Estimates the types and quantities of waste matter, energy (noise, vibration, light, heat, radiation, etc.) and residual materials generated during construction and operation of the project, and rate at which these will be produced.

1.18 Indicates how these wastes and residual materials are expected to be handled/treated prior to release/disposal, and the routs by which they will be eventually be disposed of to the environment.

1.19 Identifies any special or hazardous wastes (defined as ...) which will be produced, and describes the methods for their disposal as regards their likely main environmental impacts.

1.20 Indicates the methods by which the quantities of residuals and wastes were estimated. Acknowledges any

uncertainty, and gives ranges of confidence limits where appropriate.

Overall mark:

\begin{tabular}{|l|l|}
\hline Performance & Comments \\
\hline & \\
\hline
\end{tabular}

2. DESCRIPTION OF THE ENVIRONMENT

\section{DESCRIPTION OF THE ENVIRONMENT

Description of the area occupied by and surrounding the project

2.1 Indicates the area expected to be significantly affected by the various aspects of the project with the aid of suitable maps. Explains the time over which these impacts are likely to occur.

2.2 Describes the land uses on the site(s) and in surrounding areas.

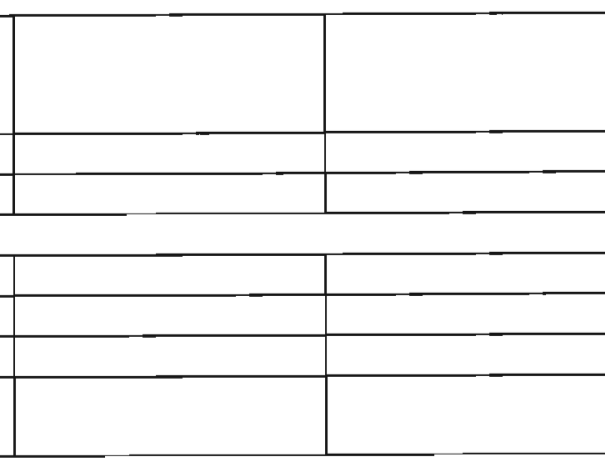

\begin{tabular}{|l|l|}
\hline & \\
\hline & \\
\hline & \\
\hline & \\
\hline & \\
\hline
\end{tabular}




\begin{tabular}{|l|l|l|}
\hline \multicolumn{1}{|c|}{ Criterion } & Performance & Comments \\
\hline $\begin{array}{l}\text { 2.3 Defines the affected environment broadly enough to include any potentially significant effects occurring away } \\
\text { from the immediate areas of construction and operation. These may be caused by, for example, the dispersion of } \\
\text { pollutants, infrastructural requirements of the project, traffic etc. }\end{array}$ & \\
\hline Baseline conditions & & \\
\hline 2.4 Indicates and describes the components of the affected environment potentially affected by the project. & \\
\hline $\begin{array}{l}2.5 \text { The methods used to investigate the affected environment are appropriate to the size and complexity of the } \\
\text { assessment task. Uncertainty is indicated. }\end{array}$ & $\begin{array}{l}\text { 2.6 Predicts the likely future environmental conditions in the absence of the project. Identifies variability in natural } \\
\text { systems and human use. }\end{array}$ & \\
\hline $\begin{array}{l}\text { 2.7 Uses existing technical data sources, including records and studies carried out for environmental agencies and } \\
\text { for special interest groups. }\end{array}$ & $\begin{array}{l}\text { 2.8 Review local, regional and national plan and policies, and other data collected as necessary to predict future } \\
\text { environmental conditions. Where the proposal does not conform to these plans and policies, the departure is } \\
\text { justified. }\end{array}$ & \\
\hline $\begin{array}{l}\text { 2.9 Local, regional and national agencies holding information on baseline environmental conditions have been } \\
\text { approached. }\end{array}$ & \\
\hline Overall mark: & \\
\hline
\end{tabular}

\section{SCOPING, CONSULTATION AND IMPACT IDENTIFICATION}

\section{Scoping and consultation}

3.1 There has been a genuine attempt to contact the general public agencies, relevant experts and special interest groups to appraise them of the project and its implication. List the groups approached.

3.2 Statutory consultees have been contacted. List the consultees approached.

3.3 Identifies valued environmental attributes on the bases of this consultation.

3.4 Identifies all project activities with significant impacts on valued environmental attributes. Identifies and selects

key impacts for more intense investigation. Describes and justifies the scoping methods used.

3.5 Includes a copy or summary of the main comments from consultees and the public, and measures taken to

respond to these comments.

\section{Impact Identification}

3.6 Considers direct and indirect/secondary effects of constructing, operating and, where relevant, after-use or

decommissioning of the project (including positive and negative effects). Considers whether effects will arise as a

result of "consequential" development.

\begin{tabular}{|l|l|l|}
\hline 2 & Performance & Comments \\
\hline & & \\
\hline & & \\
\hline & & \\
\hline & & \\
\hline
\end{tabular}




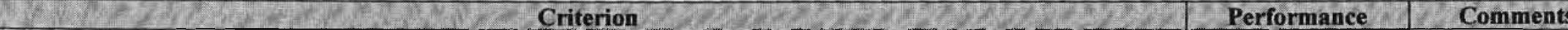

3.7 Investigates the above types of impacts in so far as they affect: human being, flora, fauna, soil, water, air, climate, landscape, interactions between the above, material assets, cultural heritage.

3.8 Also noise, land use, historic heritage, communities.

3.9 If any of the above are not concern in relation to the specific project and its location, this is clearly stated.

3.10 Identifies impacts using a systematic methodology such as project specific checklists, matrices, panels of

experts, extensive consultations, etc. Describes the methods/approaches used and the rationale for using them.

3.11 The investigation of each type of impact is appropriate to its importance for decision, avoiding unnecessary information and concentrating on the key issues.

3.12 Consider impacts which may not themselves be significant but which may contribute incrementally to a significant effect.

3.13 Consider impacts which might arise from non-standard operating conditions, accidents and emergencies.

3.14 If the nature of the project is such that accidents are possible which might cause sever damage within the surrounding environment, an assessment of the probability and likely consequence of such events is carried out and the main findings reported.

Overall mark:

\begin{tabular}{|l|l|l|}
\hline & Performance & Comments \\
\hline & & \\
\hline & & \\
\hline & & \\
\hline & & \\
\hline
\end{tabular}

\section{PREDICTION AND EVALUATION OF IMPACTS}

Prediction of magnitude impacts

4.1 Describes impacts in terms of the nature and magnitude of the change occurring and the nature, location, number value, sensitivity of the affected receptors.

4.2 Predicts the timescale over which the effects will occur, so that it is clear whether impacts are short, medium or

long term, temporary or permanent, reversible or irreversible.

4.3 Where possible, expresses the impact predictions in quantitative terms. Qualitative descriptions, where necessary are fully defined as possible.

4.4 Describe the likelihood of impacts occurring and the level of uncertainty attached to the results.

Methods and data

4.5 The methods used to predict the nature, size and scale of impacts are described, and are appropriate to the size

and importance of the projected disturbance.

4.6 The data used to estimate the size and scale of the main impacts are sufficient for the task, clearly described, and

their sources clearly identified. And gaps in the data are indicated and accounted for.

Evaluation of impact significance

4.7 Discusses the significance of effects in terms of the on the impact local community (including distribution of

impacts) and on the protection of environmental resources.

4.8 Discusses the available standards, assumptions and value systems which can be used to assess significance. 
4.9 Where there are no generally accepted standards or criteria for the evaluation of significance, alternative approaches are discussed and, if so, a clear distribution is made between fact, assumption and professional judgment.

4.10 Discusses the significance of effects taking into account the appropriate national and international standards or norms, where these are available. Otherwise the magnitude, location and duration of the effects are discussed in conjunction with the value, sensitivity and rarity of the resource.

4.11 Differentiate project-generated impacts from other changes resulting from non-project activities and variables.

4.12 Includes a clear identification of which impacts may be significant and which may not

Overall mark:

\section{ALTERNATIVES}

Criterion $\quad$ Comments

5.1 Consider the "no action" alternative, alternative processes, scales, layouts, designs and operating conditions where available at an early stage of project planning, and investigates their main environmental advantages and disadvantages.

5.2 If an expectedly sever adverse impacts are identified during the course of the investigation, which are difficult to mitigate, alternatives rejected in the earlier planning phases are re-appraised.

5.3 Gives the reasons for selecting the proposed project, and the part environmental factors played in the selection. 5.4 The alternatives are realistic and genuine.

5.5 Compares the alternatives' main environmental impacts clearly and objectively with those of the proposed project and with the likely future environmental conditions without the project.

Overall mark:

\section{MITIGATION AND MONITORING}

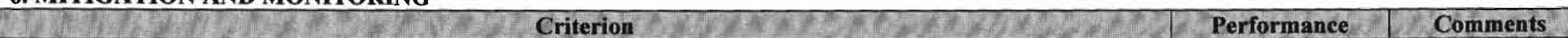

Description of mitigation measure

6.1 Considers the mitigation of all significant negative impacts and, where feasible, proposes specific mitigation measures to address each impact.

6.2 Mitigation measures considered include modification of project design, construction and operation, the

replacement of facilities/ resources, and the creation of new resources, as well as 'end-of-pipe' technologies for

pollution control.

6.3 Describes the reasons for choosing the particular type of mitigation, and the other options available. 


\section{W 7 Criterion}

6.4 Explains the extent to which the mitigation methods will be effective. Where the effectiveness is uncertain, or

where the mitigation may not work, this is made clear and data are introduced to justify the acceptance of these

assumptions.

6.5 Indicates the significance of any residual or unmitigated impact remaining after mitigation, and justifies why

these impacts should be mitigated.

Commitment to mitigation and monitoring

6.6 Gives details of how the mitigation measures will be implemented and function over the time span for which

they are necessary.

6.7 Proposes monitoring arrangements for all significant impacts, specially where uncertainty exists, to check the

environmental resulting from the implementation of the project and their conformity with the prediction made.

6.8 The scale of any proposed monitoring arrangements corresponds to the potential scale and significance of

deviations from expected impacts.

Environmental effects of mitigation

6.9 Investigates and describes any adverse Environmental effects of mitigation measures.

6.10 Considers the potential for conflict between the benefits of mitigation measures and their adverse impacts.

Overall mark:

\section{NON-TECHNICAL SUMMURY}

$\begin{array}{lll}\text { Criterion } & \text { Performance } & \text { Comments }\end{array}$

7.2 The summary avoids technical terms, list of data and detailed explanation of scientific reasoning.

7.3 The summary presents the main findings of the assessment and covers all the main issues raised in the

information.

7.4 The summary includes a brief explanation of the overall approach to the assessment.

7.5 The summary indicates the confidence which can be placed in the results.

Overall mark:

8. ORGANISATION AND PRESENTATION OF INFORMATION

\begin{tabular}{|c|c|c|c|c|c|c|c|c|} 
Criterion & Performance & Comments
\end{tabular}

Organisation of the information

8.1 Logically arranges the information in sections.

8.2 Identifies the location of information in a table or list of contents.

8.3 There are chapter or section summaries outlining the main findings of each phase of the investigation.

\begin{tabular}{|l|l|l|}
\hline Performance & Comments \\
\hline & & \\
\hline & \\
\hline
\end{tabular}

\begin{tabular}{|l|l|l|}
\hline & & \\
\hline & & \\
\hline & & \\
\hline & & \\
\hline
\end{tabular}




\section{Appendix 2: Documents requested and interview questions}

\section{Department of Environment}

The following document, data and information are requested by Tedros Kubrom, a masters student in Environment and Development at University of Natal-South Africa, for the purpose of completing the dissertation component of the degree. Please note that, whatever input you provide me will be very helpful and all the information will be used only for academic purposes.

\section{Documents and Data required}

1. National Environmental Proclamation (Draft document).

2. National EIA guidelines and procedures.

3. Two EIA reports from two different sectors (e.g. one from water sector and one from transport sector)

4. Number and list of projects (1995-2002): that are exempted from EIA, that require no EIA (Category C), that require only Environmental Evaluation (Category B), that have undergone full EIA (Category A), that are Category $\mathrm{C}$ but later screened to Category $\mathrm{B}$, that are Category $\mathrm{B}$ but later screened to category $\mathrm{A}$, that are having ongoing monitoring, with annual auditing reports, that are rejected, and that applied for appeal.

The Table 1 will be used to indicate the number of the projects with the above stated information.

Table 1: Annual trend of ELA application for project planning (1995-2002).

\begin{tabular}{|c|c|c|c|c|c|c|c|c|c|c|c|}
\hline Year & $\begin{array}{l}\text { Total } \\
\text { application } \\
\text { received } \\
\text { from pro. } \\
\text { proponent }\end{array}$ & $\begin{array}{c}\text { Pro. } \\
\text { Exemp } \\
\text { ted from } \\
\text { EIA }\end{array}$ & $\begin{array}{l}\text { Cat. } \\
\text { C } \\
\text { Pro. }\end{array}$ & $\begin{array}{c}\text { Cat. C } \\
\text { Scree } \\
\text { ned } \\
\text { to Cat. } \\
\text { B } \\
\end{array}$ & $\begin{array}{l}\text { Cat. } \\
\text { B } \\
\text { Pro. }\end{array}$ & $\begin{array}{c}\text { Cat. B } \\
\text { Screened } \\
\text { to Cat. } \\
\text { A }\end{array}$ & $\begin{array}{c}\text { Cat. } \\
\text { A } \\
\text { Pro. }\end{array}$ & $\begin{array}{c}\text { Pro. } \\
\text { with on } \\
\text { going } \\
\text { monitoring }\end{array}$ & $\begin{array}{l}\text { Pro. with } \\
\text { annual } \\
\text { auditing } \\
\text { report }\end{array}$ & $\begin{array}{l}\text { Pro. that } \\
\text { are } \\
\text { rejected }\end{array}$ & $\begin{array}{l}\text { Pro. that } \\
\text { applied } \\
\text { for } \\
\text { appeal }\end{array}$ \\
\hline \multicolumn{12}{|l|}{1995} \\
\hline \multicolumn{12}{|l|}{1996} \\
\hline \multicolumn{12}{|l|}{1997} \\
\hline \multicolumn{12}{|l|}{1998} \\
\hline \multicolumn{12}{|l|}{1999} \\
\hline \multicolumn{12}{|l|}{2000} \\
\hline \multicolumn{12}{|l|}{2001} \\
\hline 2002 & & & & & & & & & & & \\
\hline
\end{tabular}

Pro. $=$ Project $\quad$ Cat. $=$ Category $\quad$ EIA $=$ Environmental Impact Assessment

5. Organisational structure of the Department of Environment; an organogram containing title, line managers, function and job discretion with special reference to number of people involved in EIA.

\section{Interview questions}

\section{Historical background of EIA in Eritrea}

1. When did EIA start in Eritrea?

2. How was it started and how did it evolve?

3. Who are the major development partners of Eritrea and how did they contribute to the development of EIA system in Eritrea? 
4. What other organizations (National and International) are involved in designing and implementation of EIA in Eritrea?

5. What is the similarity and difference between the Eritrean and the World Bank's ELA system?

\section{Institutional issues for EIA administration and application}

1. Who is the national body responsible for application and administration of EIA in Eritrea?

2. Is this body recognized by the different sectors as the responsible body in all matters of development that affect the environment?

3. Does this body have a legal mandate for functioning, if so what is it?

4. How does this body work with the other sectors?

5. Are there sector specific guidelines (e.g. water projects)?

6. If yes, where do they come from and who looks after them?

7. Which EIA guideline standards are used for projects funded by donor agencies?

8. Does this create a problem of dual standards?

9. Are there consultants in Eritrea that deal with EIA?

10. If yes, how many are they? And are they foreigners or local?

11. Are there enough qualified multidisciplinary local personnel and specialists or experts within the Department of Environment to make meaningful judgment on EIA, to manage and carryout EIA?

12. What is their number and their distribution in the country (central, provincial, local)?

13. If there is a shortage of personnel and experts, what has been done to limit these shortages?

14. Are adequate environmental data and information available for carrying out EIA?

15. If there is limitation of environmental data and information, what have been done to limit this problem?

16. Is there any national environmental, specifically EIA, information centre?

17. Do you have a contact with other international or regional EIA information centers?

18. What opportunities and challenges are there for environmental management and for EIA specifically in the country?

\section{Legislation Issues}

1. What is the legislative basis of EIA in Eritrea? (Constitution, Environmental Act, EIA regulations, others)

2. What are the key reasons for environmental concern (to have laws and regulations) in Eritrea?

3. Who is (will be) the regulatory body responsible for enforcing this legislation?

5. What is the reason for not having promulgated EIA regulations?

6. Are there any other regulations that give provision for EIA from other ministries?

8. If yes, what is done to avoid fragmentation of regulations and ensure uniformity of EIA practice?

9. Are there any sanctions for non-compliance?

\section{Coverage of EIA the system}

1. Does the EIA system apply to all public and private environmentally significant projects?

2. Is there omission or exemption for certain activities? 
3. Why are certain activities such as Mining and Military activities not included in the EIA guidelines? How are they assessed?

\section{Screening}

1. Is information about actions, criteria, threshold, and screening procedures readily accessible?

\section{EIA report preparation}

1. Who does the EIA reports? (Consultant, proponent, government)

2. Do checks on the content, form, objectivity, and accuracy exist before publication?

3. If yes, how are they done?

\section{Decision Making}

1. Does published guidance on the factors to be considered in decision making exist?

2. Is the finding of EIA report and the review (in case of no action or refusal decision) be a central determinant of the decision on the action?

3. If no, why?

\section{Monitoring of action}

1. Does published guidance on monitoring and auditing action implementation and impact exist?

2. What challenges exist for effective monitoring?

\section{Public Consultation and Participation}

1. Can copies of EIA documents be obtained/purchased at a reasonable price?

2. Are consultations limited because of confidentiality or secrecy?

3. Who are the stakeholders who involved in public participation?

4. Are NGO's involved in public participation?

5. If yes how and please give an example?

6. Do people participate? If yes, are they empowered?

7. Is funding provided for public participants?

8. Does published guidance on public consultation exist?

9. Who is responsible for public consultation (the proponent or authorities)?

\section{EIA system Monitoring}

1. Do the authorities keep a register of all applications?

2. Is a record of ELA reports for various types of actions kept and made public? Who is responsible for this?

3. Is there an annual report on ELA?

4. Are records of other EIA reports kept and made public?

5. If yes, where are they located?

6. Are records of financial costs of EIA and the time required kept and made public?

7. Was there any review of the EIA system and any changes made to the system?

8. If yes, did consultation and participation take place?

9. If no, what are the reasons for inadequate EIA system monitoring?

\section{Cost and benefits of EIA}


1. What is the average or range of EIA financial cost in relation to the cost of the project?

2. Is the cost acceptable or overestimated?

3. What is the duration of EIA process?

4. Do you believe that EIA process in Eritrea has altered the behavior of stakeholders (proponent, consultants, consultees, the public and the decision making authorities)?

5. Do you believe that the environmental quality and acceptability of decisions are improved by EIA process?

6. What empirical evidence exists that the EIA process has significantly altered the outcome of decisions?

\section{Strategic environmental assessment}

1. Does ELA in Eritrea apply to programs, plans, and policies? If not why?

2. Are there skills for SEA in the country?

\section{Sector ministries}

\section{Documents}

1. Law or regulation or proclamation that deal with EIA (If any).

2. Sector EIA guideline document (If any)

3. EIA report for Category A project (if any)

\section{Interview Questions}

1. When did ELA start in your Ministry (sector)?

2. If you have sector specific guidelines, where do they come from and who looks after them?

3. Do you have a unit or a section that deals with EIA?

4. Who carry out EIA for your sector?

5. How did you involved in the process?

6. Do you have enough qualified multidisciplinary local personnels and specialists or experts within the Ministry (Sector) to make meaningful judgment on ELA, to manage and carryout EIA?

7. What is their distribution in the country (central, regional/zone)?

8. How do you work with Department of Environment with regard to EIA?

9. How is public participation process in the EIA process?

10. If people participate, are they empowered?

11. Are NGOs involved in public participation? Please give example.

12. Are copies of EIA documents available and accessible to the public?

13. Does the EIA system apply to all public and private environmentally significant projects?

14. Is there omission or exemption for certain activities?

15. What is the average or range of EIA costs in relation to the cost of the project?

16. Is the cost acceptable or overestimated?

17. What is the duration of the EIA process? 
18. Do you believe that the EIA process in Eritrea has altered the behavior of stakeholders (proponent, consultants, consultees, the public and the decision making authorities)?

19. Do you believe that the environmental quality and acceptability of decisions are improved by EIA process?

20. What empirical evidence exists that the EIA process has significantly altered the outcome of decisions?

21. Do you apply EIA for projects only or does it also include programs, plans and policies? Give examples?

22. Does your sector have skills for SEA?

23. What opportunities and challenges do you see in carrying out effective EIA in your sector specifically and in the country in general?

\section{World Bank-Eritrea}

1. How many projects have you funded in Eritrea during the last 5 years? And how many of them had an EIA clearance?

2. Is EIA carried out by foreign experts or local? If foreigners why?

3. How are you involved in the EIA process in Eritrea?

4. What are the challenges of the ELA process in Eritrea? What have you done (contributed) and plan to solve these problems?

5. Do you believe that the EIA process in Eritrea has altered the behavior of proponent, consultants, consultees, the public, and the decision-making authorities?

6. What is the average or range of EIA costs in relation to the cost of the project?

7. What is the duration of the ELA process?

8. Do you believe that the environmental quality and acceptability of decisions are improved by the EIA process?

9. If yes, what empirical evidence exists that the EIA process has significantly altered the outcome of decisions?

10. How is the experience in Eritrea compared with the countries you have worked in?

\section{Consultants who involve in EIA}

1. Which EIA guideline standards do you use for projects funded by donor agencies?

2. Does this create a problem of dual standards?

3. How many EIA consultants do you know?

4. How is the effectiveness of institutions, their commitment and intersectorally coordination?

5. Are adequate environmental data and information about actions, criteria, threshold and procedures available for carrying out EIA? And are they readily available?

6. Are there enough guidelines on different steps of the EIA process (e.g. mitigation, monitoring, consideration of alternatives)? 
7. Who is responsible for public participation (proponent or government)?

8. If people participate, are they empowered?

9. Are NGOs involved in public participation? If yes, please give examples.

10. Does the EIA system apply to all public and private environmentally significant projects?

11. What is the average or range of EIA financial cost in relation to the cost of the project?

12. Is the cost acceptable or overestimated?

13. What is the duration of the EIA process?

14. Do you believe that EIA process in Eritrea has altered the behavior of stakeholders (proponent, consultants, consultees, the public and the decision-making authorities)?

15. Do you believe that the environmental quality and acceptability of decisions are improved by EIA process?

16. What empirical evidence exists that the EIA process has significantly altered the outcome of decisions?

17. Does EIA in Eritrea apply to programs, plans, and policies? If not why?

18. Are there skills for SEA in the country?

19. If you have worked in other countries before, how does the Eritrea system compare with others?

20. What are the strength and weakness of NEAPG?

21. What opportunities and challenges are there for environmental management and EIA specifically in the country? 
COMPONENT

$\mathrm{B}$ 


\section{AN EVALUATION OF ENVIRONMENTAL IMPACT ASSESSMENT IN ERITREA}

\section{INTRODUCTION}

After thirty years of war for independence and self-determination Eritreans joined the global community in 1991, with a commitment to sustainable development and to the principles of Agenda 21. In 1995 a National Environmental Management Plan for Eritrea (NEMP-E) was developed by an interministerial committee to address environmental problems and promote sustainable development (Government of Eritrea, 1995a). In 1997, the Constitution of Eritrea was ratified with a provision that the State shall be responsible for land, water, air and natural resource management to ensure sustainable development (Article 8). In response to these policy initiatives, the National Environmental Assessment Guidelines and Procedures (NEAGP) manual was developed and instituted in 1999. NEAGP is recognised as a landmark in the introduction of environmental assessment in Eritrea, although there had been some environmental assessment of individual projects in the past (Department of Environment, 1999). The NEAGP was prepared on the basis of the World Bank environmental assessment principles and more or less corresponds with procedures and guidelines of the World Bank (T.Consult, 2001). The legal and technical instruments which are very important in translating this policy document into specific procedures, however, are still under development.

Currently Eritrea is party to several different international conventions. Some of these conventions (e.g. Convention on Climate Change (CCC), Convention to Combat Desertification (CCD), and Convention on Biological Diversity (CBD)) recognise domestic EIA as a basic requirement for their implementation. Thus, if Eritrea is to remain committed to these international conventions and development projects are going to be sustainable as stated in the policy directives, an effective national EIA system is mandatory. This paper, therefore, aims to review current EIA policy and practice in Eritrea with respect to international principles and procedures, with an intention to make recommendations for better application. 


\section{METHODOLOGY}

A review of national EIAs against international principles and procedures has been adopted as a way of improving EIA application in many countries. As Fuller (1999) indicates, the two notably comprehensive and independent EIA system evaluation criteria are those developed by Wood (1995) and Sadler (1996). This study utilizes a slightly modified version of Wood's (1995) criteria (Box 4.1 of Component A). These have been adapted to incorporate the experience of developing countries on what constitutes effective EIA, mainly on the institutional aspects of EIA system.

Based on these criteria, the NEAPG document and the Draft Environmental Proclamation (DEP) were reviewed. To obtain background information, certain relevant documents such as annual reports on environmental assessment, the NEMPE, the country assessment report on sustainable development (Anon, 2002) and the impact assessment report for the Eritrea emergency reconstruction program ( $T$. Consult, 2001) were sourced. The purpose of the review was to collect and analyze information on institutional aspects of EIA system (policy, institutional strength and responsibilities for EIA administration, EIA legislation, and availability of resources); EIA process (screening, scoping, EIA study, documentation, review, decision-making, and monitoring and auditing); and other features of the EIA system (coverage, consideration of alternatives, public consultation and participation, system monitoring, cost and benefit of EIA system and SEA).

However, due to the limited literature on the national EIA system and scarcity of documents, a number of interviews with key stakeholders (Appendix 1) were also conducted. The focus of these interviews was to evaluate the institutional arrangements with respect to EIA administration and implementation. Interviews were principally semi-structured (Appendix 2 of Component A). In addition to the interviews, informal discussions with people from different institutions were also held.

To examine the quality of EIAs conducted in Eritrea, two case studies of sectoral EIAs were reviewed. The case studies are Massawa International Airport Project and Keren Water Supply Project. Massawa International Airport Project is situated $10 \mathrm{~km}$ northeast of the port of Massawa, one of the major economic centers of the country 
which serves as a gateway to the Eritrean hinterland, the northern part of Ethiopia, and the eastern part of Sudan. The project is aimed to enhance the tourist industry, fishing and other cargo and commercial activities and accelerate development of the area's socio-economic sector. The airport includes a $3500 \mathrm{~m}$ by $45 \mathrm{~m}$ runway, an apron and a partial parallel taxiway linking the extremities of the apron to the runway and it occupies a fenced area of about $19.3 \mathrm{~km}^{2}$. The developer was the Government of Eritrea and EIA report was prepared in May 2002 by BCEOM (in collaboration with Government Officials), one of the companies entrusted with the design of the project. Though it is indicated that the EIA study was part of the detailed design phase, the study was carried out once many parts of the construction works of the airport had already been completed. The DoE was consulted during the stakeholders consultation, but the Department does not acknowledge its full involvement according to the requirements of the NEAPG.

The Keren Water Supply Project was proposed to identify a reliable potable water supply to Keren, the second largest city in the country with a population of approximately 83,248 . The components of the project included: construction of a permanent diversion dam (which covers about 85 ha of land) on the Anseba River; construction of a $3 \mathrm{~km}$ long supply canal; construction of a $54 \mathrm{~m}$ high storage dam; laying of a $3 \mathrm{~km}$ long raw water pipeline $(750 \mathrm{~mm}$ diameter) from the storage dam to the water treatment plant; phased construction of a $48,000 \mathrm{~m}^{3}$ per day water treatment plant; and laying of $22 \mathrm{~km}$ of treated water pipeline to Keren, delivering water to the existing storage reservoirs within the city. The developer was the Ministry of Public Works of the Government of Eritrea. The EIA study of the project was part of the feasibility and preliminary design work conducted by the National Resource Consulting Engineers, in June 2002. The EIA report is presented as an appendix part of the final preliminary design report. The EIA report attempts to conform to the format stated in NEAPG and is the only Category A project acknowledged by the DoE to pass through the requirements of the NEAPG under close supervision of the department.

Both case studies were selected on the basis that they are two of the few projects categorised as Category A projects (undertake full EIA); they are from two different sectors (water and transport sectors respectively); and they reflect the current EIA 
practice in the country (they are recently published). The case studies were reviewed using the EIA report review criteria developed by IAU, Oxford Brookes University. The criteria are an amalgamation and extension of Lee and Colley's (1990) and the European Commission's EIA report review criteria. The criteria are comprehensive and set in-depth requirements (Glasson et al., 1999). A full evaluation of each case study is provided in Appendix 2.

\section{PERFORMANCE OF EIA SYSTEM IN ERITREA}

\subsection{INSTITUTIONAL ASPECTS OF EIA}

\subsubsection{Policy development}

Evaluation: The first important institutional aspect to facilitate the use of EIA as a decision making tool is the presence of national policy which reflects the goals of development and environment (Ahmad \& Sammy, 1985). Eritrea has developed five documents (Table 1) that reflect the country's national strategies for sustainable development. In addition, the Constitution of Eritrea (1997) provides the basis for sustainable development in the country (Article 8 and Article 21). Article 8 (3) in particular, stipulates that,

"In the interest of present and future generations, the State shall be responsible for managing all land, water, air and natural resources and for ensuring their management in a balanced and sustainable manner; and for creating the right conditions to secure the participation of the people in safeguarding the environment" (Government of Eritrea, 1997; page 8).

Table 1: National policy documents for sustainable development

\begin{tabular}{|l|c|}
\hline \multicolumn{1}{|c|}{ Policy document } & Year \\
\hline The Macro Policy & 1994 \\
\hline National Environment Management Plan for Eritrea (NEMP-E) & 1995 \\
\hline National Biodiversity Strategy and Action Plan (NBSP) & 2000 \\
\hline Economic Growth and Poverty Reduction Strategy (PRS) & 2001 \\
\hline $\begin{array}{l}\text { National Action Program to Combat Desertification and Mitigate the } \\
\text { Effect of Drought (NAP) }\end{array}$ & 2001 \\
\hline
\end{tabular}

The NEMP-E, in particular, was developed as a blueprint for the protection of environmental resources and for the promotion of sustainable development (Government of Eritrea, 1995a). The NEMP-E has the following key objectives: the repairing of harmful practice; the steps needed for a sustainable and rational use of 
resources; and the protection and permanent conservation of certain habitats for Eritrea's indigenous flora and fauna and historical heritage. Such a national policy, therefore, provides a framework within which the EIA process can be conducted. The NEMP-E also addresses the financial, institutional and human resources needed for implementation and sets out 53 projects and programs to be implemented over the next 10 to 15 years (Government of Eritrea, 1995a). The NEMP-E recognizes the importance of environmental assessment (EA) and stipulates a program to determine legal requirements and procedures for carrying out EAs for new developments within the country. The NEMP-E also requires that legislation for EA should be enacted under an environmental act (Government of Eritrea, 1995a). This, however, has not yet occurred.

Lessons from the case studies: Both of the reviewed case studies recognize the NEMP-E as a national environmental management policy and make use of it in identifying the base-line condition of the affected environment. The Keren Water Supply Project in particular, uses the NEMP-E to predict if the proposed project may have an impact on the endangered flora and fauna listed in the NEMP-E. This indicates the NEMP-E's potential to serve as a guidance policy within which the EIA process can be carried out.

\section{Recommendations:}

- Periodic revision of the implementation of the policy documents, particularly the NEMP-E, is crucial to provide for amendment on the basis of experience.

- For more precise and focused environmental management, the NEMP-E needs to be supplemented by regional and local EMPs.

\subsubsection{Legal basis of EIA}

Evaluation: One of the mechanisms whereby environmental policy is implemented is through legislation. However, in Eritrea there is as yet no national legislation that requires compulsory EIA. The current EIA system in Eritrea, thus works on a voluntary basis. For this reason most of the projects for which an EIA has been undertaken are those funded by international development agencies, such as the World Bank. A few sectors such as the petroleum and mining sector, however, are subject to legislation that requires EIA. Article 11(5) of the Revised Regulations on 
Petroleum Operation Legal Notice No. 45/2000 (Government of Eritrea, 2000) and Article 43 (2) (f) of the Mining Proclamation No. 68/1995 as well as Article 5 (1) (j) of Mining Operations Regulation-Legal Notice No. 19/1995 requires that the applicant for a mining license prepare an EIA report before granting of the license (Government of Eritrea, 1995b). However, besides stating the purpose of the report and listing the activities that need to be included, the legislation is not prescriptive regarding content and process. Furthermore, at the time of writing no single full EIA had been undertaken for a mining project. Apparently this is due to the fact that there have been not sufficiently large projects requiring an EIA (Mebrahtu, 2002 pers. comm.).

A Draft Environmental Proclamation (DEP) has been under development and is expected to be enacted in the near future. Articles 32 and 33 of this proclamation give a framework for EIA preparation and post-EIA auditing, respectively. These articles stipulate the legal requirements of EIA for all projects, the powers of the Minister, the responsibility of the proponent and institutional responsibility of Department of Environment and other government agencies. In addition the proclamation contains articles with general application.

Article 23 provides a mechanism for conflict resolution including the right for appeal against a decision of the Minister or Council to the High Court. The proclamation also includes a provision to ensure compliance, specifically, Article 60 which provides a framework for sanctions regarding offences related to EIA. In addition, Article 66 empowers the Minister to issue regulations.

However, although the proclamation could be a reasonable start for a legally based EIA system in the country, its provisions are inadequate. Key areas have not been addressed in the proclamation including; the specific lists of activities that are subject to EIA, the different steps in the EIA process, and time limitations.

Lessons from the case studies: Due to the absence of relevant national environmental legislation, conformance of the reviewed case studies against legislation cannot be tested. However, both case studies referred to the lack of legal clarity for the EIA and 
hence utilised the NEAPG and NEMP-E policy document, which draws the general environmental principles that need to be respected.

\section{Recommendation:}

- To translate the words of the policy documents into action, the legal basis for EIA needs to come into effect immediately. Although this could commence through the ratification of the DEP, it would be better to amend the DEP to address deficiencies before doing so.

\subsubsection{Environmental institution and responsibility for EIA administration}

Evaluation: Lee and George (2000) state that in developing countries, if the implementation of EIA is to be effective, there is a need for the establishment of a strong institutional body mandated with environmental issues. In Eritrea, the Department of Environment (DoE) under the Ministry of Land, Water, and Environment (MLWE) was formed in 1997 for such a purpose. The DoE oversees the implementation and monitoring of EIA through its Monitoring and Evaluation Unit, under the Environmental Management/Inspection Division. The organizational structure of the DoE is given in Figure 1.

NEAPG indicates that during the EIA process responsibilities for certain activities, such as screening, preparation of Terms of Reference (TOR), completion of Environmental Evaluation Questionnaire (EEQ), and completion of public consultation are shared between the proponent and relevant government agencies. The DoE's role is to:

- Co-ordinate the process;

- give advice when required;

- ensure the coverage and the completeness of the EIA report;

- make the final decision for environmental clearance; and

- monitor the effectiveness of environmental assessment process.

The proposed DEP, however, seems to decentralise EIA administration by empowering the Minister of MLWE to authorize any government institution to develop sector-specific EIA procedures and guidelines, as well as to undertake EIAs, and issue an environmental clearance permit for any project within its jurisdiction 
(Article 32 (2)). Article 33(3) also provides for authorization of any public institution by the Minister to undertake post-EIA auditing for projects under its jurisdiction.

Nevertheless, the proclamation empowers the DoE to supervise all EIA undertakings, review all EIAs as well as carryout a periodic audit of each project to ensure that mitigation measures are implemented (Article 33 (4)).

In cases where the line ministry is the proponent as well as the monitoring agency, it might be difficult to obtain full compliance. The proclamation seems to address this by empowering the DoE to carryout all necessary sectoral monitoring, inspection and enforcement, when the line ministry does not adequately monitor compliance with environmental quality standards in its sector (Article 49 (3)). However, the current institutional strength of the DoE, particularly in the area of EIAs, is perceived by interviewees to be weak. This is mainly due to the lack of a legal mandate that empowers the DoE to monitor activities and prosecute those who fail to comply, as well as a lack of adequate skilled personnel.

Lessons from the case studies: The EIA report of the Massawa International Airport, indicates that the report was approved by the French Development Fund and the Government (without stating which ministry). However, according to the DoE only the Keren Water Supply Project has passed through the requirements of the NEAPG with close supervision of the Department (Teclemariam, 2000 pers. comm.). This suggests that the responsibilities set out in the NEAPG, which require the DoE to firstly ensure the coverage and the completeness of the EIA report and secondly make the final decision for environmental clearance, are weakly practiced at present. This is mainly due to the lack of the legal mandate for implementing those provisions.

\section{Recommendations:}

- Training of DoE staff in managing and reviewing EIAs and in making meaningful judgments on EIA reports, is required.

- Provisions to empower other sectoral ministries to develop EIA procedures and guidelines may lead to duplication and multiple standards. To minimise this risk it is recommended that all guidelines, procedures and standards be developed within the framework of the NEAPG. 


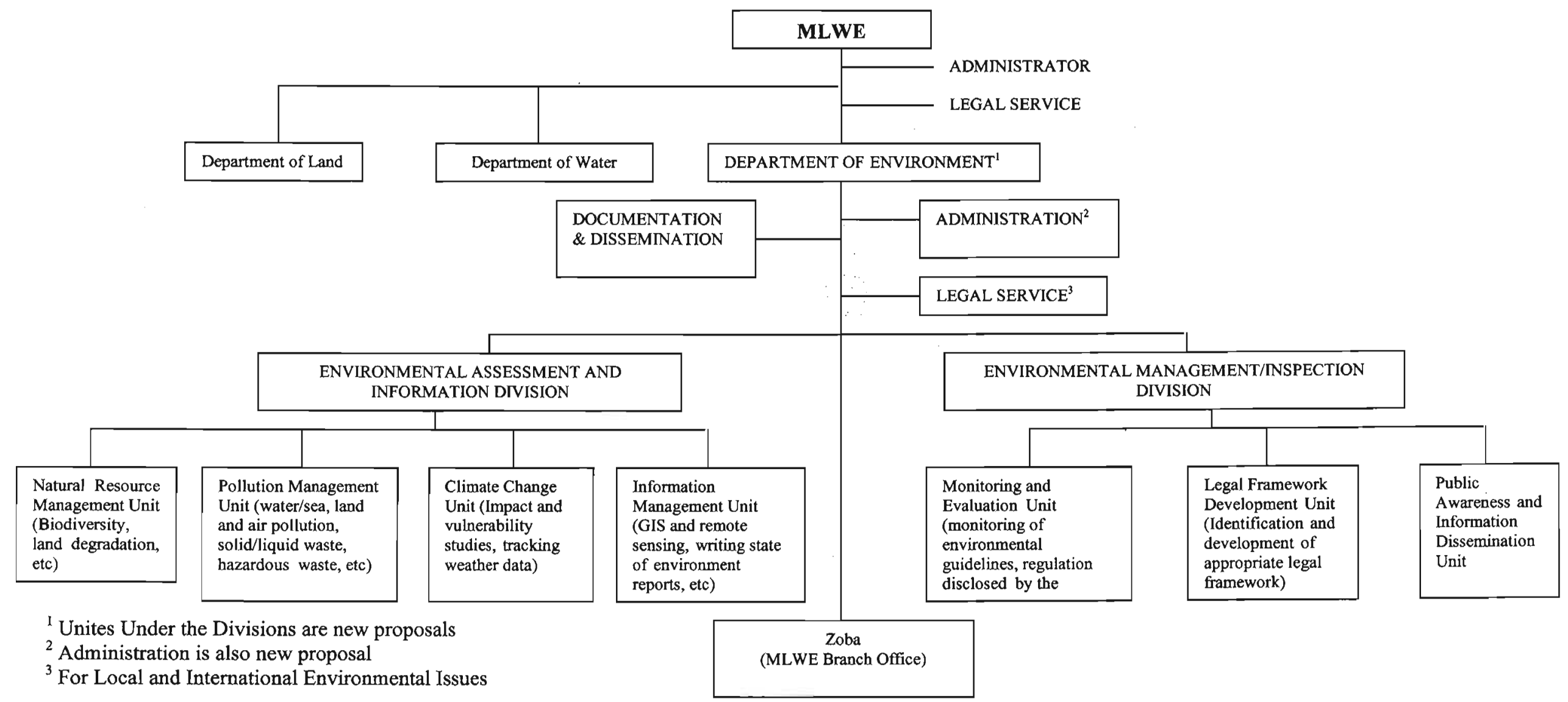

Figure 1: Organisational structure of Department of Environment, Ministry of Land Water and Environment (Department of Environment, undated) 


\subsubsection{Resource adequacy}

Evaluation: Almost all interviewees pointed out that the most challenging issue in the implementation of an effective EIA system in Eritrea is the lack of multidisciplinary local experts. The DoE is working with a limited staff complement and at the time of the study, some regions of the country did not have a departmental representative. Most of the ELAs that have been carried out in the country (for projects funded by development agencies) have been undertaken by foreign experts. There are very few local EIA experts and, those who are available, are professionals with specific expertise (e.g. engineering, geology, hydrology, etc.) with limited knowledge of environmental management.

Another important resource for EIAs are environmental data and information. Although the DoE is custodian of some data, and information regarding issues such as the biodiversity of the country exists, in many cases, data are not available. If data do exist, they are within different sectors or ministries and are not readily accessible. Recently, the DoE has initiated the collection of environmental data from the different ministries. Moreover, the DEP tries to address this issue by empowering the Director General of DoE to establish and maintain a coordination system and information exchange-network with designed environmental focal points. The focal points need to be located in each line ministry, the concerned private sector and such regions or international environmental institutions so as to facilitate and harmonize EIA procedures and environmental clearance requirements of projects (Article $16(2)(d))$.

Lessons from the case studies: The lack of adequate local skilled EIA experts is reflected in both of the case studies. The EIA for the Massawa International Airport Project was conducted by foreign environmental scientists during their visit to Eritrea as part of the design work entrusted to French consultants (BCEOM-engineering consultants and SOFREAVIA-civil aviation and meteorology consultants). For the Keren Water Supply Project, the EIA was done by locally-based engineering consultants (NRCE) (involvement of local or foreign EIA consultants or environmentalists is not indicated) as part of the overall feasibility and preliminary design study of the project. The scarcity of environmental data was also obvious, in that both studies had to collect primary data in order to formulate the base line studies. 


\section{Recommendations:}

- For successful implementation of an effective EIA system throughout the country, continuous training in EIA for government officials, consultants, and research and educational institutions is required.

- To limit the shortage of environmental data and information in the country, information sharing between different sector ministries within the country and data synthesis from similar projects within the country, or from other countries with similar climate and other conditions is required. This could be achieved through expanding the current Public Awareness and Information Dissemination Unit to include a centre which serves the stated objectives.

\subsection{EIA PROCESS}

\subsubsection{Screening}

Evaluation: As in many developing countries, the EIA system in Eritrea uses an approach to screening that involves the use of both lists and thresholds to identify whether an EIA is required, and if so whether, an Environmental Evaluation (EE) ${ }^{2}$ or a full EIA, is appropriate. Based on the type, size, location, and mode of operation the NEAPG assigns projects into one of three categories. These are: Category A (projects that require full EIA); Category $\mathrm{B}$ (projects that require only $\mathrm{EE}$ ); and Category $\mathrm{C}$ (projects which do not require environmental assessment). Projects which do not appear in the list, are considered to be Category B projects. There is also a provision for discretionary evaluation during the screening process. For example, the relevant authority could, if justified, increase original screening category from a Category $\mathrm{C}$ to a B. The rationale for this screening of projects is that it allows simple environmental clearance mechanisms without compromising the effectiveness of EIA for larger and more complex ones, and without creating unnecessary delays for small and simple projects. Screening is undertaken by the relevant government authority (at central or regional level) responsible for regulation, development, implementation, management, and/or supervision of a particular development project. This is so that the screening

\footnotetext{
${ }^{2}$ EE means the process by which the potential impact of a proposed project on the environment is determined using primarily Eritrean resource and existing information (by filling an Environmental Evaluation Questionnaire). The results of the evaluation are contained in Environmental Evaluation Report.
} 
decision is taken quickly and efficiently, as near to the point of project origin and as early in the project cycle as possible.

NEAPG provides clear and simple screening procedures and guidelines. However, tools such as maps of environmentally sensitive areas (ESA) that facilitate and strengthen the screening process are not available and the list of projects needs to be completed and reviewed. The screening process allows consultation with the line ministry responsible for ESA or relevant government institutions, but provision for right of appeal against the screening decision has not been considered.

Table 2 shows the annual trend of screening of projects in Eritrea since the initial implementation of EIA in 1999 until mid-2002. The full list of projects is also given in Appendix 3. Of the 156 projects subjected to screening, 87 were evaluated as Category B, 67 were evaluated as Category C and only two were evaluated as Category A projects. The two projects evaluated as Category A are from the industrial sector. However, according to the Department of Industry, no project within the jurisdiction of the Department has been subject to a full EIA. Currently one project is screened as a Category A project and it is under discussion with the DoE to re-screen it as Category B (Sengal, 2002 pers. comm.). Informal review of certain reports by the researcher and discussion with interviewees also found that there are cases where Category A projects, according the NEAPG classification, are screened as Category B projects. This indicates that the current screening practice is not fully based on the provisions of the NEAPG.

Table 2: Annual trend of project screening (1999-mid 2002) ${ }^{3}$

\begin{tabular}{|l|c|c|c|c|l|}
\hline \multirow{2}{*}{ Screening of Project } & \multicolumn{4}{|c|}{ YEAR } & Total \\
\cline { 2 - 6 } & 1999 & 2000 & 2001 & mid-2002 & \\
\hline Category C & - & 17 & 15 & 35 & 67 \\
\hline Category B & 7 & 16 & 48 & 16 & 87 \\
\hline Category A & $\begin{array}{l}\text { 1(screening } \\
\text { under } \\
\text { process) }\end{array}$ & 0 & 0 & $\begin{array}{l}1 \text { (screening } \\
\text { under } \\
\text { process) }\end{array}$ & 2 \\
\hline $\begin{array}{l}\text { Total application for } \\
\text { environmental clearance }\end{array}$ & 8 & 33 & 63 & 52 & 156 \\
\hline
\end{tabular}

\footnotetext{
${ }^{3}$ The figures in the table are extracted from the annual report on EIA of projects for environmental clearance (Appendix 3) and do not include the case studies.
} 
Lessons from the case studies: Both of the reviewed case studies were evaluated as Category A projects, to undergo full EIA, based on the NEAPG screening approach.

\section{Recommendation:}

- If the current screening process is to be implemented effectively, the provisions in the NEAPG need to be incorporated into legislation and the guidelines applied consistently.

\subsubsection{Scoping}

Evaluation: Scoping is the first stage of the EIA for Category A projects. The NEAPG stipulates that scoping should take place as early as possible in the project cycle. The proponent is responsible for the scoping process but needs to agree with relevant government agency in preparing the TOR. The advantage of such an approach is that it allows the developers (and their consultants) to identify all the potential significant impacts of their proposals (with which they are more familiar than any one else) and it minimizes the burden on the relevant government authorities to define the scope of the assessment. The success of such an approach, however, depends on the integrity of the proponent and their consultants.

The NEAPG provides a scoping checklist and sets a clear procedure for project scoping. In addition, consultation with stakeholders and the incorporation of their opinions and concerns into the list of potentially significant impacts/issues, as well as any additional realistic project alternatives is required. This is important in that it might eliminate those issues generally agreed as being of little or no significance and increases transparency. The scoping process also requires a completed project scoping report which must contain a record of the scoping process undertaken, including the details of stakeholders, record of site visits etc., for public record. Furthermore, a copy of it is to be used as a reference during the review process.

Lessons from the case studies: The Keren Water Supply Project report indicates that the EIA was done as part of the preliminary design report and provides a summary of the concerns of the stakeholders. However, it failed to undertake a meaningful analysis of alternatives; one of the principal requirements of scoping. In the case of the Massawa International Airport, the EIA was only undertaken once construction of 
a large part of the project was completed, which is contrary to the requirement of NEAPG that scoping (the first stage of EIA) has to take place as early as possible in the project cycle and certainly prior to construction. In addition, the report failed to include a copy of a summary of comments from consultees and the public; a key requirement of the scoping stage of the NEAPG.

\section{Recommendations:}

- To establish a well practiced scoping process legal promulgation of the provisions in the NEAPG as regulations is necessary.

- To minimise the potential danger of the current scoping approach (preparation of TOR by the proponent) provisions for the following should be considered: a thorough discussion between the proponent and the relevant government authority; release of the TOR (to the public) for comment; and submission of more information about the project by the proponent if there is a request from the relevant authority or the public. Furthermore, these requirements need to be included in the relevant legislation.

\subsubsection{The EIA study}

Evaluation: To assist the EIA study team, the NEAPG provides a checklist of project activities and environmental attributes and features which may be impacted. This helps the team identify and highlight the specific project activities and predict their potential impact on the environment. During the assessment of impact significance, the methods to be employed are left open to the study teams, but need to be discussed fully during the scoping process. This avoids unnecessary expense by limiting the sophistication of the methods to the scope of the EIA (Modac \& Biswas, 1999). The NEAPG, however, is silent on how the evaluation of significance of impact will take place besides mentioning the need for the evaluation of alternatives summarized in a form of table or matrix.

To mitigate impacts arising from a project, the NEAPG requires an EMP which must include:

- List of impacts for which mitigation is proposed;

- responsibility for implementation of each mitigation activity; 
- timeframe over which the mitigation will be implemented;

- spatial extent for which the mitigation will be implemented and over which its impacts will be effective; and

- an estimate cost of the mitigation measures.

Besides these, the NEAPG mentions that mitigation should be considered during the different stages of EIA, including scoping, the ELA review, and monitoring and postauditing. Mitigation is thus emphasised in the Eritrean EIA system.

Lessons from the case studies: Apart from a mention that consultation with different government agencies occurred, the EIA report of the Massawa International Airport does not mention any systematic methodology used in identifying impacts. The Keren Water Supply Project, used consultation with government authorities, and field assessment by a multidisciplinary team for impact identification, and attempted to use matrices (although it is incomplete) to present the summary of the impacts of the proposed project and the no-action alternative. The description of impacts in both reports, however, lacks detail and in most cases was not quantified.

Both of the case studies consider the mitigation of the significant negative impacts but do not provide reasons for choosing a particular type of mitigation and fail to indicate the significance of any unmitigated impact remaining after mitigation. Both case studies however, prepared an EMP to monitor the implementation and efficiency of mitigation measures over the entire life cycle of the project. The Massawa International Airport EIA report does not provide the estimated cost of the mitigation measures, and only mentions that they are integral part of the project budget.

\section{Recommendations:}

- To help EIA practitioners make an objective assessment and provide transparency as well as reduce the subjectivity of decision-making, quantitative methods of assessing the significance of impacts should be adapted or established. Where this is not possible guidelines for impact significance evaluation should be prepared. 
- The mitigation provisions in the NEAPG should be encoded in legislation for their effective implementation.

\subsubsection{Documentation}

Evaluation: For Category B projects the NEAPG requires the production of an environmental evaluation report (EER). The EER comprises the questionnaire response, completed by the relevant government agency and project owner and other relevant information. For Category A projects, however, a comprehensive EIA report document which describes consideration of alternatives for proposed actions, the affected environment and the assessment of impact significance is required. There is a provision for a clear, non-technical and short executive summary of the report. To make the report locally accessible, the NEAPG requires the executive summary to be translated into the local languages.

NEAPG provides a guideline on formulating the structure and content of EIA reports, though it is not mandatory that all EIA completed in Eritrea must conform exactly to the format. In addition, there is also a provision that the EIA report should contain a draft EMP which must include all type of activities that might be proposed in mitigation for different impacts of the project. To help with the preparation of the EMP, the NEAPG provides guidance concerning the minimum content of an EMP.

An EIA report has to be completed by a multidisciplinary team coordinated by the proponent. For reasons of clarification and request of additional information, the proponent is required to include the list of names of those who are involved in the different components of the study including, qualifications/field of expertise, professional affiliations, current position, contribution to the overall study and report, and contact details.

Lessons from the case studies: Neither the Massawa International Airport nor the Keren Water Supply project conformed fully with the minimum content of an EIA report as required by the NEAPG. The EIA report for Massawa International Airport does not provide the details of those who were involved in different components of the study, although it mentions the name of the organization that prepared the report and the names of the stakeholders. However, it does contain an executive summary 
and the information is fairly organized and well-presented, although definitions of technical terms and acronyms are missing. Similarly, the EIA report for the Keren Water Supply Project organizes and presents its information in a logical format. It provides the name of the organisation that prepared the report and the details of those who participated in different components of the study. However, the details of a contact person, definitions of technical terms and acronyms, and executive summary are absent.

\section{Recommendation:}

- The format, structure and content requirements of EIA reports or EIA reports should be defined in legislation and supported by the production of appropriate national guidelines for report preparation.

\subsubsection{Review}

Evaluation: The NEAPG states that the two final outputs of the EIA study, the EIA report and draft EMP, have to undergo a review process before the final decision for environmental clearance is given. The review process has two components: an adequacy review and an impact review. During the adequacy review the DoE checks the adequacy of the coverage and completeness of the report/plan against a set of criteria. During the impact review an Impact Review Committee (IRC) coordinated by the DoE, reviews the technical information about impacts and mitigation contained in the report in order to arrive at a recommendation regarding environmental clearance and project approval, taking into consideration the alternatives and/or the need for improved design, mitigation, compensation, etc. The composition of the IRC includes representatives of zonal (regional) administration, representatives of government agencies identified as stakeholders in the scoping process, a qualified social/development expert, qualified professional to assess the soundness of the project proposal and its environmental mitigation activities, and representatives of the project owner and the relevant implementing government agency.

As in the scoping stage, the review stage also provides a chance for all stakeholders, and any other interested public parties to comment on the EIA report and the draft EMP, though some parts of the reports may be considered confidential and could be withheld at the discretion of DoE. To assist with the review process the NEAPG 
provides procedural steps for both adequacy and impact reviews. It also provides time limits for the review process. The NEAPG provides a sample form for guidance during the adequacy review and stipulates that the TOR prepared during the scoping process must be the basis for the impact review.

Lessons from the case studies: The practical experience of review in Eritrea is very limited. So far, the Keren Water Supply Project is the only project that has undergone such a review. When evaluated against the DoE's guidelines for review of adequacy of content and structure of EIA report, even this is incomplete. This is mainly due to the inadequate consideration of impacts of alternatives; lack of an executive summary, definition of acronyms, and absence of an appendix that contains the TOR.

\section{Recommendation:}

- In order to increase the practical implementation of review, immediate ratification of the current DEP which empowers the DoE to review all EIA reports (Article $15(2)(c))$ is required.

\subsubsection{Decision-making}

Evaluation: Based on the review of the EIA report and the EMP by the IRC, the DoE makes the decision for environmental clearance of the proposal. Decisions for environmental clearance can be:

- Unconditional: environmental clearance is automatically granted as no potential impacts requiring changes to the project were identified.

- Conditional: environmental clearance granted subject to incorporation of agreed, additional mitigation measures into the final EMP.

- Postponed (Environmental Objections): for Category B projects where significant potential negative impacts are identified or there is not enough knowledge about potential impacts, and consequently the project is referred for a full EIA. For Category A projects approval is delayed until the project is extensively redesigned to eliminate existing environmental concerns.

- No environmental clearance: project should not be approved because of a lack of evidence that the significance adverse impacts can be mitigated adequately. 
Figures extracted from the DoE report (from 1999 to mid-2000) on the decisions for environmental clearance (Table 3) show that, out of 79 decisions granted for Category B projects 62 were unconditional, and the rest (17) were conditional. For Category $\mathrm{C}$ projects (64 decisions), 28 were unconditional and 36 were conditional. No projects were rejected (no environmental clearance) or referred for a full EIA (environmental objection). In the full report (Appendix 3) there are three non-environmental clearance decisions, but again no indication is given on the category of the projects and no report of decision is provided for Category A projects.

Table 3: Annual trend of decisions for environmental clearance (1999-mid 2002)

\begin{tabular}{|c|c|c|c|c|c|c|c|c|c|c|c|c|c|}
\hline \multirow{2}{*}{$\begin{array}{c}\text { Decision } \\
\text { Type }\end{array}$} & \multicolumn{4}{|c|}{ Category A } & \multicolumn{4}{|c|}{ Category B } & \multicolumn{4}{|c|}{ Category $\mathrm{C}$} & \multirow[t]{2}{*}{ Total } \\
\hline & 1999 & 2000 & 2001 & 2002 & 1999 & 2000 & 2001 & 2002 & 1999 & 2000 & 2001 & 2002 & \\
\hline Uncon & 0 & 0 & 0 & 0 & $(-)$ & 4 & 45 & 13 & - & $\overline{13}$ & 13 & 2 & 88 \\
\hline Con & 0 & 0 & 0 & 0 & $(-)$ & 11 & $\overline{3}$ & 3 & - & 2 & $\overline{1}$ & 33 & 53 \\
\hline EO & $\overline{0}$ & 0 & 0 & 0 & $(-)$ & 0 & 0 & 0 & - & 0 & 0 & 0 & 0 \\
\hline NEC & 0 & 0 & 0 & 0 & $(-)$ & 0 & 0 & 0 & - & $\overline{0}$ & 0 & 0 & 0 \\
\hline Total & & & $\overline{0}$ & & & & & & & & & & 141 \\
\hline
\end{tabular}

Con: Conditional; Uncon: Unconditional; EO: Environmental Objection; NEC: No environmental clearance; $(-)$ : No report on decision

The final decision whether to approve or reject the project is undertaken by the approving authority (not the DoE). On this matter, section 5.19 of the NEAPG stipulates that:

"Environmental clearance, or a failure to receive environmental clearance from the IRC, does not automatically mean that a project will, or will not, be approved and implemented. Environmental considerations are only one of a number of different factors influencing project approval" (Department of Environment, 1999; page 43).

This clearly indicates that, in Eritrea, as in many developing countries (Wood, 1995; Lee, 2000), the findings of the EIA report and the review are not the central determinant of the decision on the action. Due to the overwhelming need for development, it is unusual for a project to be refused as a result of the EIA process. 
Nevertheless, in cases where the recommendations of the IRC are overridden by the approving authority, the NEAPG requires a public disclosure to that effect, together with a justification of its decision.

\section{Recommendation:}

- If the role of EIA as a decision-making tool is to be achieved and sustainable development in Eritrea is to be accomplished, the findings of the EIA report and the review need to be the central determinant of the decision and supported in legislation.

\subsubsection{Monitoring and post-auditing}

Evaluation: For Category A projects monitoring is an important part of the EMP. For Category B projects, if the EER results in conditional environmental clearance, the recommendations make up an informal EMP and can be used as a basis for monitoring of potential negative environmental impacts. Monitoring of the EMP implementation is part of the normal project cycle. For this reason the project owner and managers are responsible for the day-to-day monitoring of environmental performance and prepare a report to be submitted to the DoE at agreed intervals. The EMP is required to contain necessary details of:

- The government agency responsible for monitoring and taking action in the event of non-compliance;

- the methodologies to be used for monitoring of potential negative impacts;

- the effectiveness of mitigation; and

- procedures to be activated in the event that monitoring reveals a failure of mitigation and/or unacceptable negative impacts arising even with full mitigation.

The coordination of all efforts of monitoring of mitigation activities is the responsibility of DoE and all the monitoring reports need to be forwarded to DoE or its zonal branch office. The DoE is also responsible for undertaking post-investment monitoring of a sub-set of all projects screened as Category $\mathrm{C}$, in order to ensure that no significant impacts arise from these projects. Guidelines for the monitoring process and specific date/intervals of the monitoring reports, are not provided in the NEAPG. The DEP, however, empowers the DoE to formulate and implement operating 
procedures which include provisions for monitoring environmental quality and postEIA auditing (Article 48 (1) (b)).

Interviewees perceive the current monitoring practice in the country to be weak. This is mainly because of the lack of appropriate experts and the lack of the legal back-up to prosecute for non-compliance. The proposed DEP, however, tries to address the latter by empowering the line ministries to undertake inspection, enforcement and monitoring of compliance with environmental quality standards, and to conduct environmental audits in their respective sectors (Article 49 (1)). It also empowers the DoE to coordinate overall monitoring of environmental quality (Article 49 (2)) as well as to carry out all necessary sectoral monitoring, inspections and enforcement where a line ministry does not adequately monitor compliance with environmental quality standards in its sector (Article 49 (3)). However, it is the proponent who is expected to monitor and record environmental impacts and consequences during the project commencement and implementation process and thereafter. Such an approach is highly dependent on the integrity of the proponent, and therefore, additionally requires independent evaluation.

Lessons from the case studies: Both of the reviewed case studies developed an environmental monitoring program to monitor the implementation of the mitigation measures and take appropriate measures if unforeseen environmental damage occurs, or the measures implemented prove inadequate. The reports also indicate the government agency responsible for monitoring. The Keren Water Supply Project, in particular, establishes an environmental monitoring unit composed of appropriately skilled persons drawn from the main stakeholders. Both of the case studies, however, do not provide the methodologies to be used for monitoring of potential negative impacts, or the procedures to be activated in the event that monitoring reveals a failure of mitigation and/or unacceptable negative impacts arising even with full mitigation.

\section{Recommendations:}

- To improve the current monitoring practice, appropriate training for staff members of DoE and all sector ministries responsible for monitoring of actions in their jurisdiction is necessary. 
- To make the monitoring and post-auditing process effective and standardized, national guidelines that apply to internal and external monitoring and postauditing processes are required.

- To develop a consistent monitoring and auditing system, based on the project's category, the date/interval for submission of monitoring and auditing reports needs to be specified.

\subsection{OTHER FEATURES OF EIA}

\subsubsection{Coverage}

Evaluation: In principle, the EIA system in Eritrea applies to all projects (both public and private) with potential significant negative environmental impacts. However, with EIA being a new issue in the country and due to the lack of legal backup to the DoE to enforce EIA, not all projects are passing through an EIA process. Nevertheless, there are indications that the use of the NEAPG by government bodies is increasing, mainly due to pressure from international development funding agencies and local investment banks which require EIA as part of the project appraisal (Teclemarian, 2002 pers. comm.). Certain project types, such as full scale mining or oil and gas production, which fall under other (sectoral) environmental impact guidelines or regulations, and which are covered by other legislation need not pass through this NEAPG procedure. Such omissions, however, reflect fragmentation of legislation and administration of the EIA system in the country and may result in increasing confusion and administrative difficulty.

The NEAPG provides a broad definition of the environment, covering significant impacts on the biophysical environment, direct and indirect hazardous effects of human health, ecosystem integrity and the socio-cultural environment. The NEAPG requires EIA for all activities which involve a change in land or water use, which result in the modification or expansion of an existing land or water use, or establishment of a new land use on previously unused land or water. However, it is confined to projects only, though it states that the definition of a project can be extended to cover plans, policies and programmes where appropriate. The DEP requires EIA for both private and public projects (by indicating that the proponent can be a private or a public body). In addition, it provides the broad definition of environment and indicates that a project can include a plan or a program. Unlike the 
NEAPG, the DEP, however, lacks clarity on whether the EIA requirement is for new projects only or whether it includes projects under modification or expansion.

Lessons from the case studies: So far no private projects in the whole of Eritrea have undergone a full EIA. Both of the case studies were projects initiated by the Government. The case studies consider the environment broadly to include effects of the project on biophysical, social and cultural environment. Although the emphasis was on the positive impacts, the case studies consider the direct and indirect negative impacts to a limited extent.

Recommendations: In addition to the immediate enforcement of the DEP, the following recommendations are made:

- Omission of activities from the NEAPG should be avoided in order to prevent fragmentation of guidelines and regulations. That is, all activities with substantial detrimental effects on the environment (including mining and oil and gas exploration) should be included in the NEAPG as well as in the environmental proclamation.

- The DEP should clearly stipulate that the EIA requirement is for both new projects, as well as projects under modification or expansion.

\subsubsection{Consideration of alternatives}

Evaluation: The NEAPG requires the analysis of alternatives as part of the study in preparing the TOR for scoping. It stipulates a need for:

- A list of project alternatives;

- a list of project activities for each alternative, with any potential negative impacts;

- assessment of the area, scale, duration, frequency and probability of occurrence, of each alternatives potential negative impacts and the actions which might be taken to mitigate negative impacts;

- justification of the preferred alternative on the basis of environmental impacts, but paying attention to economic and engineering constraints and opportunities; and

- development of the draft EMP to mitigate negative impacts and to monitor effectiveness of mitigation for the preferred alternative. 
The NEAPG requires the assessment of significant environmental impacts for each of the different alternatives identified by the scoping exercise to be the main part of EIA report. It also gives advice on assessing the significant impacts by providing a checklist of project activities and environmental attributes.

Lessons from the case studies: The reviews indicate that these provisions are hardly implemented. Consideration of alternatives is absent from the EIA report for Massawa International Airport. The Keren Water Supply Project, also fails to give a full analysis of possible project alternatives. The latter attempts to make a comparison between the proposed project and the no-action alternative, but the analysis is incomplete. Consideration of alternatives is the heart of EIA report (Council of Environmental Quality, 1992). Thus, omitting of such requirements in the EIA reports indicates that there is a principal weakness in EIA practice in the country.

\section{Recommendation:}

- To make a meaningful assessment of impacts, a legal test for evidence of consideration of the environmental impact of reasonable alternative actions is required. This can be done by enacting EIA regulations under the provision of Article 66 of the DEP.

\subsubsection{Public participation and consultation}

Evaluation: One of the requirements during the preparation of a TOR is to ensure appropriate consultation of stakeholders takes place during the study period. The NEAPG indicates that at the scoping stage the project proponent and the relevant government agency should agree on a list of stakeholders and the mechanisms by which they will be consulted, and at completion of project a scoping report for public record is required. In addition, the NEAPG requires that where the local communities are important stakeholders, the TOR should clearly set out the extent of, and methodology for, public consultation throughout the assessment study and review. To access the local knowledge in the project location and potential impact zone, the NEAPG mentions certain techniques such as interviews, questionnaires, and PRA.

However, the emphasis is on consultation (with key stakeholders) rather than wide public participation. The NEAPG defines a stakeholder as any person or group likely 
to be affected by a proposed project. This suggests that the consultation and participation process in Eritrea is limited to the affected parties, rather than including a formal provision for interested parties such as NGOs and the general public. Nevertheless, the NEAPG also provides a chance for all stakeholders plus any other interested public parties to comment on the EIA report and the draft EMP during the review stage.

The proposed DEP tries to incorporate public consultation and participation into legislation by providing a right to every person, to a clean and healthy environment (Article 7). More specifically, it stipulates that communities and the public shall be involved in environmental rehabilitation, restoration, protection, planning and decision-making and shall have access to appropriate information, to ensure conscious and effective participation (Article 8). Moreover, Article 30 stipulates that every person has the freedom of access to any information related to the implementation of the provisions of the proclamation and other laws relating to the management of the environment from the MLWE, the DoE, or any line ministry.

Lessons from the case studies: For the Keren Water Supply Project, consultation with relevant government officials, village elders and the community around the project area were held and their comments are reflected in the EIA report. The Massawa International Airport, however, does not provide any indication of public participation and consultation besides a mention that there were contacts with relevant government officials.

\section{Recommendation:}

- To increase the transparency during the ELA process, the current provision for public consultation and participation needs to be expanded to include affected and interested parties (including NGOs) and the general public. Such a provision needs to be a legal requirement.

\subsubsection{EIA system monitoring}

Evaluation: In Eritrea, as in many other developing countries (Wood, 1995), there is no formal requirement for EIA system monitoring. However, the NEAPG acknowledges that the current knowledge of projects' impact on the environment is 
limited, and as a result it requires the revision of the project screening list and the list of the ESA at regular intervals. In addition, if the post-investment monitoring of Category $\mathrm{C}$ projects indicates that a project is producing significant environmental impact, then it is required to be added to the project screening list as Category B (or even A) when the list is next revised. The NEAPG also states that one of the reasons for monitoring of approved projects is to gain knowledge from project implementation which can be fed back into the environmental assessment process (via improved questionnaires for environmental evaluation and improved scoping for full EIA).

Though it is not a legal requirement, copies of different documents, such as the scoping report, EIA report, EMP and monitoring reports are required to be delivered to the DoE. In addition, annual reports of environmental assessment of projects are required to be submitted (from zonal representative) to the DoE. These would be very helpful in monitoring the EIA system. In reality, however, there is very little (if any) practical experience of system monitoring in the country. The main reason is the lack of adequate staff with appropriate expertise at the DoE and other government agencies. Furthermore, the border conflict with Ethiopia is also cited as a principal factor (Tekleab, 2002 pers. comm.).

\section{Recommendation:}

- To strengthen the EIA system, the formation of a section responsible for keeping copies of all records of EIA reports for various types of actions and other EIA documents, the financial costs and time required, as well as, to carry out a review of the EIA system, is required.

\subsubsection{Costs and benefits of EIA}

Evaluation: The NEAPG stipulates that the financial cost of EIA, including the cost of additional work completed by Eritrean Government officials which contribute to the assessment (e.g. completion of local public consultation), should be borne by the proponent. At this stage EIA costs of projects are met principally through external or donor funding with very few examples of costs being met by Eritrean proponents. As a consequence there is a general perception that the EIA process is cost-effective, although this is likely to be due to the fact that the costs are borne externally. All the 
interviewees, however, believe that it is too early to say that EIA process in Eritrea has altered the behaviour of stakeholders.

Lessons from the case studies: The EIA costs for the case studies are integral costs of the project and interviewees considered it to be reasonable.

\section{Recommendation:}

- To maximize the benefits of EIA, mechanisms that make it cost-effective and affordable by the local investors need to be adopted.

\subsubsection{Strategic environmental assessment (SEA)}

Evaluation: With the exception of very few plans and programs (funded by World Bank), the experience of SEA in Eritrea is limited. Besides stating that the definition of a project can be extended to cover plans, policies and programs, there is no mention of SEA in the NEAPG document. However, the strategies in the NEMP-E, to achieve sustainable development, indicate the need for application of EIA to policies, plans, and programs (SEA), i.e. project EIAs need to be sustained by SEA. Government plans, such as the mass returning of refugees from neighbouring countries, and government policies such as national military service (especially with respect to training camps) are more appropriate examples that require the application of SEA in the country.

\section{Recommendation:}

- To achieve environmental sustainability at local, regional and global scale, the current EIA system in Eritrea needs to be expanded to address the environmental impact of plans and policies. Thus, formal provision for SEA is required.

\section{CONCLUSION}

This study has reviewed the application of EIA in Eritrea in reference to international principles and procedures of EIA at both policy and practice levels. The current EIA system meets ten of the 17 evaluation criteria at policy level (Table 4), partially meets three and fails to meet four. The major weakness relate to the legal provisions for EIA, to adequacy of resources (human and environmental data/information), to 
Table 4: Performance of the Eritrea EIA system

\begin{tabular}{|c|c|c|}
\hline Criteria & $\begin{array}{c}\text { Criterion } \\
\text { met }\end{array}$ & Comments \\
\hline \multicolumn{3}{|l|}{ Institutional aspect of EIA system } \\
\hline $\begin{array}{l}\text { 1. Does a clearly documented } \\
\text { environmental policy at national, } \\
\text { regional and local levels exist? }\end{array}$ & Partially & $\begin{array}{l}\text { Policies are set at national level and are present. The regional and local } \\
\text { environmental policies are absent. Policies not always implemented } \\
\text { within the planed time. }\end{array}$ \\
\hline $\begin{array}{l}\text { 2. Is there institution body mandated with } \\
\text { environmental matters and do } \\
\text { responsibilities for EIA administration } \\
\text { clearly specified? }\end{array}$ & Yes & $\begin{array}{l}\text { DoE within MLWE does exist. Shared responsibilities between DoE and } \\
\text { relevant authorities are also clearly specified. However, currently the } \\
\text { institutional power and capacity of the department is weak. }\end{array}$ \\
\hline $\begin{array}{l}\text { 3. Is the EIA system based on clear and } \\
\text { specific legal provisions? }\end{array}$ & No & $\begin{array}{l}\text { Currently the EIA system in Eritrea is on a voluntary basis. But a DEP } \\
\text { with enabling legislation is under process. }\end{array}$ \\
\hline $\begin{array}{l}\text { 4. Are there adequate resource to carry out } \\
\text { meaningful EIA? }\end{array}$ & No & $\begin{array}{l}\text { Lack of multidisciplinary local experts and scarcity of environmental } \\
\text { data/information are among the most challenging issues for the } \\
\text { implementation of EIA in the country. }\end{array}$ \\
\hline \multicolumn{3}{|c|}{ EIA Process } \\
\hline $\begin{array}{l}\text { 5. Must screening of actions for } \\
\text { environmental significance take place? }\end{array}$ & Yes & $\begin{array}{l}\text { A simple screening approach that involves the use of both lists and } \\
\text { thresholds is utilised. }\end{array}$ \\
\hline $\begin{array}{l}\text { 6. Must scoping of the environmental } \\
\text { impacts of actions take place and specific } \\
\text { guidelines be produced? }\end{array}$ & Yes & $\begin{array}{l}\text { TOR is prepared by the proponent in agreement with relevant authority. } \\
\text { A completed scoping report is also required for public record and as a } \\
\text { reference during the review process. }\end{array}$ \\
\hline $\begin{array}{l}\text { 7. Are there enough guidelines prepared to } \\
\text { assist during the EIA study (prediction and } \\
\text { evaluation) and is mitigation of action } \\
\text { impacts be considered at the various stages } \\
\text { of the EIA process? }\end{array}$ & Partially & $\begin{array}{l}\text { In principle there is an emphasis on mitigation. The guidelines that help } \\
\text { during impact prediction and evaluation are not available. }\end{array}$ \\
\hline $\begin{array}{l}\text { 8. Must EIA reports meet prescribed } \\
\text { content requirements and do checks to } \\
\text { prevent the release of inadequate ELA } \\
\text { reports exist? }\end{array}$ & Yes & $\begin{array}{l}\text { Minimum requirement for ElA reports and EMPs is provided but } \\
\text { conformance with the structure is not mandatory. Nevertheless, the DoE } \\
\text { does review the adequacy of the reports. However, there is only little } \\
\text { institutional experience. }\end{array}$ \\
\hline $\begin{array}{l}\text { 9. Must ELA reports be publicly reviewed } \\
\text { and the proponent respond to the points } \\
\text { raised? }\end{array}$ & Yes & $\begin{array}{l}\text { All stockholders plus any other interested parties are given a chance to } \\
\text { comment on the EIA report and the draft EMP, but some part of the } \\
\text { report may be confidential and could be withheld at the discretion of } \\
\text { DoE. Again, there is only little experience. }\end{array}$ \\
\hline $\begin{array}{l}\text { 10. Must the findings of EIA reports and } \\
\text { the review be a central determinant of the } \\
\text { decision on the action? }\end{array}$ & No & $\begin{array}{l}\text { Findings of EIA reports and the review serve for environmental } \\
\text { clearance, but they are not the central determinant of the decision for the } \\
\text { project. So far not a single project has been rejected. }\end{array}$ \\
\hline $\begin{array}{l}\text { 11. Must monitoring of action and post- } \\
\text { auditing take place? }\end{array}$ & Yes & $\begin{array}{l}\text { Monitoring is set as an important part of EMP and provisions for } \\
\text { inspection and post auditing are given, but they are weakly practiced. }\end{array}$ \\
\hline \multicolumn{3}{|l|}{ Other features of EIA system } \\
\hline $\begin{array}{l}\text { 12. Must the relevant environmental } \\
\text { impacts of all significant actions be } \\
\text { assessed? }\end{array}$ & Yes & $\begin{array}{l}\text { The environment is broadly defined to include biophysical, social and } \\
\text { cultural impacts. All projects (public and private) with significant } \\
\text { environmental impact require ElA. }\end{array}$ \\
\hline $\begin{array}{l}\text { 13. Must evidence of the consideration, by } \\
\text { the proponent, of the environmental } \\
\text { impacts of reasonable alternative actions } \\
\text { be demonstrated in the ELA process? }\end{array}$ & Yes & $\begin{array}{l}\text { Analysis of alternatives is considered during the preparation of TOR } \\
\text { (scoping report) and environmental impact report. In practice, however, it } \\
\text { is weakly established. }\end{array}$ \\
\hline $\begin{array}{l}\text { 14. Must consultation and participation } \\
\text { take place prior to, and following, EIA } \\
\text { report publication? }\end{array}$ & Yes & $\begin{array}{l}\text { Consultation with different stakeholders is required during scoping and } \\
\text { ELA preparation. All stakeholders and any other interested public parties } \\
\text { are also given a chance to comment on the scoping report, and on the EIA } \\
\text { reports and the draft EMP during the review stage. However, only limited } \\
\text { experience exists. }\end{array}$ \\
\hline $\begin{array}{l}\text { 15. Must the EIA system be monitored } \\
\text { and, if necessary, be amended to } \\
\text { incorporate feedback from experience? }\end{array}$ & Partially & $\begin{array}{l}\text { No formal ELA system monitoring exists. However, provisions such as } \\
\text { review for list of project screening, list of ESA, incorporation of feedback } \\
\text { from monitoring experience, submission of scoping reports, EIA, EMP, } \\
\text { and monitoring reports are required. Again, they are weakly practiced. }\end{array}$ \\
\hline $\begin{array}{l}\text { 16. Are the financial costs and time } \\
\text { requirements of ELA system acceptable to } \\
\text { those involved and are they believed to be } \\
\text { outweighed by discernible environmental } \\
\text { benefits? }\end{array}$ & Yes & $\begin{array}{l}\text { At this stage costs are met by external donor funding agencies and appear } \\
\text { to be acceptable. }\end{array}$ \\
\hline $\begin{array}{l}\text { 17. Does the EIA system apply to } \\
\text { significant programmes, plans and } \\
\text { policies, as well as to projects? }\end{array}$ & No & $\begin{array}{l}\text { Experience of SEA is limited to very few plans and programs funded by } \\
\text { World Bank. }\end{array}$ \\
\hline
\end{tabular}


centrality of EIA as a decision making of the action, and to the formal provision for SEAs of programmes, plans and policies. In practice, however, the overall EIA system in the country is weakly established.

A review of the EIA reports for each of the two sectoral case studies (Table 5) shows that while each of the reports scored relatively highly on one or more components, several criteria also scored poorly. Overall the review could not be assessed at a performance level greater than C. This indicates that, in Eritrea, the principles and procedures that comprise effective EIA are not exercised in a full manner, and this might undermine the use of ELA as a decision-making tool in the country. With the increase of experience in undertaking and documenting of EIAs, however, the quality of EIA reports are expected to improve. Nevertheless, improvement of the existing performance of the EIA system in the country will be mandatory if EIA practice is to be effective and qualitative EIA reports are to be achieved. This is because good EIA report can only result from good EIA system (Fuller 1999).

Table 5: Summary of the EIA report review for the two sectoral case studies

\begin{tabular}{|l|c|c|}
\hline \multicolumn{1}{|c|}{ Evaluation Criteria } & \multicolumn{2}{|c|}{ Performance (on the scale A-F) } \\
\cline { 2 - 3 } & $\begin{array}{l}\text { Massawa International } \\
\text { Airport Project }\end{array}$ & Keren Water Supply Project \\
\hline 1. Description of the development & $\mathrm{B}$ & $\mathrm{C}$ \\
\hline 2. Description of the environment & $\mathrm{C}$ & $\mathrm{B}$ \\
\hline $\begin{array}{l}\text { 3. Scoping, consultation, and } \\
\text { impact identification }\end{array}$ & $\mathrm{D}$ & $\mathrm{C}$ \\
\hline $\begin{array}{l}\text { 4. Prediction and evaluation of } \\
\text { impacts }\end{array}$ & $\mathrm{C}$ & $\mathrm{D}$ \\
\hline $\begin{array}{l}\text { 5. Consideration of alternatives } \\
\text { 6. Mitigation and monitoring }\end{array}$ & $\mathrm{F}$ & $\mathrm{D}$ \\
\hline 7. Non-technical summary & $\mathrm{B}$ & $\mathrm{F}$ \\
\hline $\begin{array}{l}\text { 8. organisation and presentation } \\
\text { of information }\end{array}$ & $\mathrm{A}$ & $\mathrm{C}$ \\
\hline $\begin{array}{l}\text { Overall Performance } \\
\text { Byys }\end{array}$ & C & $\mathrm{C}$ \\
\hline $\begin{array}{l}\text { * Where: A-good; B-generally satisfactory (minor omissions etc.); C-just satisfactory (despite } \\
\text { omissions); D-just unsatisfactory (because of omissions etc.); E-not satisfactory (significant omission } \\
\text { etc.) and F-poor. }\end{array}$ & \\
\hline
\end{tabular}

The reasons for the limited application of EIA in the country include: lack of environmental awareness of some government officials and the general public; pressure for quick development (emergency development projects); financial problems to cover the cost of full EIA for locally owned projects; lack of expertise 
with environmental assessment skills in both sector ministries and the DoE; and the lack of legal requirements for environmental assessment in the country.

Furthermore, the border conflict with Ethiopia has also greatly hindered the implementation of a EIA system in the country. This is mainly due to the fact that many of the existing local experts were required to undertake National military service.

There are, however, also several reasons for optimism with respect to improving EIA practice in Eritrea. These include:

- The general increase in awareness of environmental issues (environmental assessment in particularly) mainly due to the pressure that comes from international development funding agencies and local investment banks which require EIA as part of the project appraisal;

- the return of local people from foreign countries who have been taking higher degrees and training in environmental matters;

- the increasing number of local experts with the opening of a new B.Sc. degree in Land Resource and Environment at University of Asmara (Eritrea), and the incorporation of EIA as one of the main courses;

- the formulation of environmental units in different sector ministries and the publication of certain sector specific EIA guidelines in the near future;

- the imminent ratification of the currently DEP which will make environmental assessment a legal requirement in the country;

- and finally, peace with Ethiopia will facilitate the implementation of the EIA system in the country and will create opportunities for the country to share experiences with its neighbours.

Nevertheless, to strengthen the current EIA system in Eritrea, the following are considered urgent priorities: increasing environmental awareness, continuous training in EIA for government officials, consultants, research institutions, and educational institutions, and establishment of the legal basis for EIA. 


\section{REFERENCES}

Ahmad, J Y and G K Sammy (1985), Guidelines to Environmental Impact Assessment in Developing Countries (Hodder and Stoughton, London).

Anon (2002), Earth Summit II Rio + Ten, Country Assessment Report on Sustainable Development (Government Printers, Asmara).

Council of Environmental Quality (1992), Environmental Quality 1991: Twenty second Annual Report (USGPO, Washington DC).

Department of Environment (1999), National Environmental Assessment Procedures and Guidelines (Government Printers, Asmara).

Department of Environment (undated), Organizational structure of Department of Environment, Ministry of Land Water and Environment (Department of Environment, Unpublished leaflet).

Fuller, K (1999), "Quality and Quality Control in EIA", in J Petts (editor), Handbook of Environmental Assessment, Environmental Impact Assessment in Practice: Impact and Limitations. Vol.2. (Blackwell Science, Great Britain) pages 55-82.

Government of Eritrea (No date), Draft Environmental Proclamation, (Unpublished).

Glasson, J, R Therivel and A Chadwick (1999), Introduction to Environmental Impact Assessment, 2nd ed. (UCL Press, London).

Government of Eritrea (1995a), National Environmental Management Plan for Eritrea (Eritrean Agency for Environment, Asmara).

Government of Eritrea (1995b), "Mining Proclamation No. 68/1995, Legal Notice No. 19/1995", Gazette of Eritrean Laws, 20 March 1995.

Government of Eritrea (2000), "Revised Regulations on Petroleum Operation, Legal Notice No. 45/2000", Gazette of Eritrean Laws, 15 July 2000.

Government of Eritrea (1997), The Constitution of Eritrea (Government Printer, Asmara).

Lee, N (2000), "Reviewing the Quality of Environmental Assessments", Lee, N and C George (editors) Environmental Assessment in Developing and Transition Countries: Principles, Methods and Practice (John Wiley and Sons Ltd, Chichester) pages 137147

Lee, N and C George (editors) (2000), Environmental Assessment in Developing and Transition Countries: Principles, Methods and Practice (John Wiley and Sons Ltd, Chichester).

Modac, P and A K Biswas (1999), Conduction Environmental Impact Assessment for Developing Countries (United Nations University Press, Tokyo). 
Massawa International Airport Project Consulting Services (2002), Environmental Impact Assessment-Final Report, (Ministry of Transport and Communication, Asmara).

Natural Resources Consulting Engineers (2002), Final Preliminary design Report: Keren Water Supply Project; Appendix 1. Environmental Impact Assessment and Environmental Management Plan, (Ministry of Public Works, Asmara).

Sadler, B (1996), International Study of the Effectiveness of Environmental Assessment, Environmental Assessment in a Changing World, Evaluating Practice to Improve Performance (Ministry of Supply and Service, Ottawa, International Association for Impact Assessment and Canadian Environmental Assessment Agency).

T. Consult. (2001), Eritrea- Emergency Reconstruction Program: Environmental Assessment, Vol. 1, (Ministry of Finance, Asmara).

Wood, C (1995), Environmental Impact Assessment: A Comparative Review (Longman Scientific \& Technology, Harlow).

\section{Personal Communication}

Mebrahtu, Ogbazgi (2002 pers. comm.), Mine Inspection Head, Department of Mines, Ministry of Energy and Mines. Asmara, 17 October 2002.

Sengal, Weldetensae (2002 pers. comm.), Industrial Strategy and Control Division, Department of Industry, Ministry of Trade and Industry. 3 November 2002.

Tekleab Mesghena (2002 pers. comm.), Director General, Department of Environment, Ministry of Land, Water and Environment. 10 October 2002.

Teclemarian Zego (2002 pers. comm.), T. Consult. (PVT). 10 December 2002. 


\section{APPENDICES}

Appendix 1: List of Interviewees

\begin{tabular}{|c|c|c|c|c|}
\hline Name & Position/expertise & Organisation & Telephone No. & Date \\
\hline Gezae Kibreab & $\begin{array}{l}\text { Environmental } \\
\text { manager }\end{array}$ & $\begin{array}{l}\text { CCD unit, } \\
\text { Ministry of } \\
\text { Agriculture }\end{array}$ & 2911181077 & 17 October 2002 \\
\hline $\begin{array}{l}\text { Leake } \\
\text { Woldegiorgis }\end{array}$ & Geologist & $\begin{array}{l}\text { Department of } \\
\text { Energy, Ministry } \\
\text { of Energy and } \\
\text { Mines }\end{array}$ & 2911127944 & 6 November 2002 \\
\hline Marilou Bradley & Operations Officer & $\begin{array}{l}\text { World Bank } \\
\text { Eritrea }\end{array}$ & 2911124302 & 14 October 2002 \\
\hline $\begin{array}{l}\text { Mebrahtu } \\
\text { Ogbazgi }\end{array}$ & $\begin{array}{l}\text { Mine Inspection } \\
\text { Head }\end{array}$ & $\begin{array}{l}\text { Department of } \\
\text { Mines, Ministry } \\
\text { of Energy, Mine } \\
\text { and Water } \\
\text { Resources }\end{array}$ & 2911117766 & 4 November 2002 \\
\hline $\begin{array}{l}\text { Mogos Welde- } \\
\text { Yowhannis }\end{array}$ & Director & $\begin{array}{l}\text { Study and Design } \\
\text { Division, Ministry } \\
\text { of Agriculture }\end{array}$ & 2911186614 & 17 October 2002 \\
\hline Petros Tsegay & $\begin{array}{l}\text { Environmental } \\
\text { Engineer (Water } \\
\text { Resource } \\
\text { Engineer) }\end{array}$ & $\begin{array}{l}\text { Department of } \\
\text { Infrastructure, } \\
\text { Ministry of Public } \\
\text { Works }\end{array}$ & 2911122477 & 22 October 2002 \\
\hline $\begin{array}{l}\text { Semereab } \\
\text { Habtetsion (PhD.) }\end{array}$ & Director & $\begin{array}{l}\text { Department of } \\
\text { Energy, Ministry } \\
\text { of Energy, Mines } \\
\text { and Water } \\
\text { Resources }\end{array}$ & 2911127944 & 6 November 2002 \\
\hline $\begin{array}{l}\text { Sengal } \\
\text { Weldetensae }\end{array}$ & Director & $\begin{array}{l}\text { Industrial Strategy } \\
\text { and Control } \\
\text { Division, } \\
\text { Department of } \\
\text { Industry, Ministry } \\
\text { of Trade and } \\
\text { Industry }\end{array}$ & 2911118170 & 3 November 2002 \\
\hline $\begin{array}{l}\text { Teclemariam } \\
\text { Berhane }\end{array}$ & $\begin{array}{l}\text { Senior Expert in } \\
\text { Resource } \\
\text { Management }\end{array}$ & $\begin{array}{l}\text { Department of } \\
\text { Environment, } \\
\text { Ministry of Land, } \\
\text { Water and } \\
\text { Environment }\end{array}$ & 2911120311 & 8 October 2002 \\
\hline $\begin{array}{l}\text { Teclemariam } \\
\text { Zego (Dr) }\end{array}$ & Private Consultant & T.consult. (PVT) & P.O. Box 282 & 10 December 2002 \\
\hline $\begin{array}{l}\text { Yohannes } \\
\text { Debresion }\end{array}$ & $\begin{array}{l}\text { Water Resource } \\
\text { Engineer }\end{array}$ & $\begin{array}{l}\text { Natural Resource } \\
\text { Consulting } \\
\text { Engineers. }\end{array}$ & 2911200860 & 13 December 2002 \\
\hline
\end{tabular}




\section{Appendix 2: EIA report review for sectoral case studies}

ELA report review is one of the most important quality control features of the EIA system (Fuller, 1999). This section, will review the quality of the EIA reports of two case studies (Massawa International Airport Project and Keren Water Supply Project) to assess the practice of ELA in the Eritrea. The case studies were reviewed using the EIA report review criteria developed by IAU, Oxford Brookes University. Each report is reviewed against the established criteria on the following issues: the description of the development; the description of the environment; scoping, consultation, and impact identification; prediction and evaluation of impacts; consideration of alternatives; mitigation and monitoring; presence and content of non-technical summary; and the organisation and presentation of information. The performance against the criteria is described using the following marking criteria ${ }^{1}$.

(A-F) to summarize how well ElA fulfils criterion for all criteria

A-good

B-generally satisfactory (minor omissions etc.)

C-just satisfactory (despite omissions)

D-just unsatisfactory (because of omissions etc.)

E-not satisfactory (significant omission etc.)

F-poor

\section{CASE STUDY 1: MASSAWA INTERNATIONAL AIRPORT PROJECT ${ }^{2}$}

Massawa International Airport Project is situated $10 \mathrm{~km}$ north-east of the port of Massawa, one of the major economic centers of the country which serves as a gateway to the Eritrean hinterland, the northern part of Ethiopia, and the eastern part of Sudan. The project is aimed to enhance the tourist industry, fishing and other cargo and commercial activities and accelerate development of the area's socio-economic sector and indeed of the nation. The airport includes a $3500 \mathrm{~m}$ by $45 \mathrm{~m}$ runway, an apron and a partial parallel taxiway linking the extremities of the apron to the runway and it occupies a fenced area of about $19.3 \mathrm{~km}^{2}$. The developer was the Government of Eritrea and EIA report was prepared in May 2002 by BCEOM, one of the companies entrusted with the design of the project.

${ }^{1}$ For the purpose of this study all the criterion are valued equally. In order to mark the overall performance: $\mathrm{A}$ is ranked 5 ; $\mathrm{B}$ is ranked 4; $\mathrm{C}$ is ranked 3 ; D is ranked 2; $\mathrm{E}$ is ranked 1 ; and $\mathrm{F}$ is ranked 0 .

${ }^{2}$ Unless otherwise indicated all the information is taken from Massawa International Airport Project Consulting Services (2002). 
Though it is indicated that the EIA study was part of the detailed design study, the study was carried out once many parts of the construction works of the airport had already been completed. The DoE was consulted during the stakeholders consultation, but the Department does not acknowledge its full involvement according to the requirements of the NEAPG. The full analysis of the content of the report against the stated criteria is given below ${ }^{2}$.

1. DESCRIPTION OF THE DEVELOPMENT

\begin{tabular}{|c|c|c|}
\hline 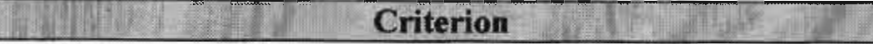 & Performance & 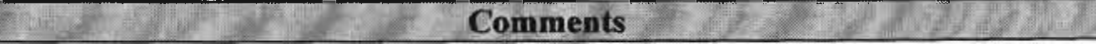 \\
\hline \multicolumn{3}{|l|}{ Principal features of project } \\
\hline 1.1 Explains the purpose(s) and objectives of the development. & $\bar{B}$ & $\begin{array}{l}\text { Clear explanation of purpose and objectives does exist but a statement that explains } \\
\text { the existing problem is missing. }\end{array}$ \\
\hline $\begin{array}{l}1.2 \text { Indicates the nature and status of the decision(s) for which the } \\
\text { environmental information has been prepared. }\end{array}$ & A & Clearly indicated. \\
\hline $\begin{array}{l}1.3 \text { Gives the estimated duration of the construction, operational and, } \\
\text { where appropriate, decommissioning phase, and the program within } \\
\text { these phases. }\end{array}$ & $\mathrm{D}$ & $\begin{array}{l}\text { The programs (for short and long term periods) within the different phases (excluding } \\
\text { decommissioning) do exist, but they lack starting and ending dates/times. Only a } \\
\text { mention of the duration of the whole project (lifespan of the project) exists. }\end{array}$ \\
\hline $\begin{array}{l}\text { 1.4 Describes the proposed development, including its design and } \\
\text { size or scale. Diagram, plans, or maps will usually be necessary for } \\
\text { this purpose. }\end{array}$ & B & $\begin{array}{l}\text { The proposed development is fairly well described including its design and size. There } \\
\text { is also a diagram that shows the different components of the project. }\end{array}$ \\
\hline $\begin{array}{l}1.5 \text { Indicates the physical presence or appearance of the completed } \\
\text { development within the receiving environment. }\end{array}$ & A & $\begin{array}{l}\text { Verbal description is supported by diagram that shows the completed development } \\
\text { within the receiving environment does exist. }\end{array}$ \\
\hline 1.6 Describes the methods of construction. & D & $\begin{array}{l}\text { Only a general mention of the methods used for the construction of already existing } \\
\text { works exists. The methods for constructing the remaining works are not described. }\end{array}$ \\
\hline $\begin{array}{l}\text { 1.7 Describes the nature and methods of production or other types of } \\
\text { activity involved in the operation of the project. }\end{array}$ & A & $\begin{array}{l}\text { A clear description of the activities involved during the operation of the project is } \\
\text { provided. }\end{array}$ \\
\hline $\begin{array}{l}\text { 1.8 Describes any additional service (water, electricity, emergency } \\
\text { service etc.) and developments require as a consequence of the } \\
\text { project. }\end{array}$ & A & $\begin{array}{l}\text { The required additional services and developments (water, electricity supply and } \\
\text { construction of the access road) are clearly described. }\end{array}$ \\
\hline $\begin{array}{l}\text { 1.9 Describes the project's potential for accidents, hazards and } \\
\text { emergencies. }\end{array}$ & A & $\begin{array}{l}\text { A description of the project's potential for accident, refueling spills, and the } \\
\text { emergency procedures needed during such an accident is specified. }\end{array}$ \\
\hline \multicolumn{3}{|l|}{ Land requirements } \\
\hline $\begin{array}{l}1.10 \text { Defines the land area taken up by the development site and } \\
\text { associated arrangements, auxiliary facilities and landscaping areas } \\
\text { and by the construction site(s), and shows their location clearly on a } \\
\text { map. For a linear project, describes the land corridor, vertical and } \\
\text { horizontal alignment and need for tunneling and earthworks. }\end{array}$ & $\mathrm{B}$ & $\begin{array}{l}\text { The overall land area taken by the project is clearly defined, with a specified size, and } \\
\text { a map that shows the location is provided. However, the size of the associated } \\
\text { arrangements, auxiliary facilities and landscaping areas and the construction site(s) is } \\
\text { not available. }\end{array}$ \\
\hline
\end{tabular}

horizontal alignment and need for tunneling and earthworks.

${ }^{2}$ For the purpose of this study all the criterion are valued equal and in order to mark the overall performance: $\mathrm{A}$ is ranked 5 ; $\mathrm{B}$ is ranked 4 ; C is ranked 3; D is ranked $2 ; \mathrm{E}$ is ranked 1 ; and $\mathrm{F}$ is ranked 0 . 
Criterion

1.11 Describes the uses to which this land will be put, an demarcates the different land use area.

1.12 Describes the reinstatement and after-use of landtake during construction.

\section{Project Inputs}

1.13 Describe the nature and quantities of materials needed during the construction and operational phases.

1.14 Estimates the number of workers and visitors entering the project site during both construction and operation.

1.15 Describe their access to the site and likely means of transport

1.16 Indicates the means of transporting materials and products to and from the site during construction, operation, and number of

movements involved.

\section{Residues and emissions}

1.17 Estimates the types and quantities of waste matter, energy

(noise, vibration, light, heat, radiation, etc.) and residual materials

generated during construction and operation of the project, and rate at which these will be produced.

1.18 Indicates how these wastes and residual materials are expected

to be handled/treated prior to release/disposal, and the routs by which they will be eventually be disposed of to the environment.

1.19 Identifies any special or hazardous wastes (defined as) which will be produced, and describes the methods for their disposal as

regards their likely main environmental impacts.

1.20 Indicates the methods by which the quantities of residuals and

wastes were estimated. Acknowledges any uncertainty, and gives

ranges of confidence limits where appropriate.

Overall mark:
Performance

A description of the proposed different land use areas is given but areas are not clearly demarcated

A description of the reinstatement and after-use of landtake during construction exists, but the exact location of the polluted materials is not indicated

C $\quad$ A description of the nature of the materials needed during the construction and

operational phases exists. However, there is no description of quantities except for some of the materials used during the construction of the existed works (before the EIA took place).

An estimate number of workers and passengers entering the site during the different phases of the project is provided. But the number of visitors is not estimated.

A Clear description of the access to the site (two unpaved roads) and the likely means of transport (bas, taxi, or private cars) exists.

The means of transport and the number of movements during the operation phase for both materials and people are clearly indicated. For the construction phase, a mention of the means of transport for some of the materials exists but the number of movements involved is not provided.

A description of, almost all the potential types of waste matter, energy (noise) and residual materials exists. However, only the quantities of certain waste matter (those related to water pollution) are provided. That is, the estimated quantities for noise,

light, solid waste and other residues are missing.

light, solid waste and other residues are missing. and fuel spills) do exist, but no such provision for solid (domestic) and air pollutant wastes exists.

Certain chemicals/wastes were identified as wastes that cause chronic pollution (mainly to the ground water) and the method for their depolution and disposal is

identified.

E $\quad$ Besides the few references from which the data is taken, no indication of methods used for estimation of the quantities of residuals and wastes exists. 


\begin{tabular}{|c|c|c|}
\hline Criterion & Performance & Comments \\
\hline \multicolumn{3}{|c|}{ Description of the area occupied by and surrounding the project } \\
\hline $\begin{array}{l}2.1 \text { Indicates the area expected to be significantly affected by the } \\
\text { various aspects of the project with the aid of suitable maps. Explains } \\
\text { the time over which these impacts are likely to occur. }\end{array}$ & $\mathrm{D}$ & $\begin{array}{l}\text { Suitable maps that indicate the area expected to be significantly affected by the } \\
\text { various aspects of the project do not exist, but a mention of these areas does exist. } \\
\text { Again, there is no indication of the time over which these impacts are likely to occur. }\end{array}$ \\
\hline 2.2 Describes the land uses on the site(s) and in surrounding areas. & A & A clear description of the land uses on the site and in surrounding areas exists. \\
\hline $\begin{array}{l}\text { 2.3 Defines the affected environment broadly enough to include any } \\
\text { potentially significant effects occurring away from the immediate } \\
\text { areas of construction and operation. These may be caused by, for } \\
\text { example, the dispersion of pollutants, infrastructural requirements of } \\
\text { the project, traffic etc. }\end{array}$ & A & $\begin{array}{l}\text { The affected environment is defined broadly enough to include the potentially } \\
\text { significant effects that might result from the project. }\end{array}$ \\
\hline \multicolumn{3}{|l|}{ Baseline conditions } \\
\hline $\begin{array}{l}2.4 \text { Indicates and describes the components of the affected } \\
\text { environment potentially affected by the project. }\end{array}$ & A & $\begin{array}{l}\text { An indication and description of the different components of the affected environment } \\
\text { potentially affected by the project exists. }\end{array}$ \\
\hline $\begin{array}{l}2.5 \text { The methods used to investigate the affected environment are } \\
\text { appropriate to the size and complexity of the assessment task. } \\
\text { Uncertainty is indicated. }\end{array}$ & $\mathrm{C}$ & $\begin{array}{l}\text { Investigation methods such as site visits, consultation with government } \\
\text { officials/experts and review of reports were used. In many cases these were } \\
\text { appropriate to the size and complexity of the assessment task. }\end{array}$ \\
\hline $\begin{array}{l}2.6 \text { Predicts the likely future environmental conditions in the absence } \\
\text { of the project. Identifies variability in natural systems and human } \\
\text { use. }\end{array}$ & F & $\begin{array}{l}\text { No prediction on the likely future environmental conditions in the absence of the } \\
\text { project exists. }\end{array}$ \\
\hline $\begin{array}{l}2.7 \text { Uses existing technical data sources, including records and } \\
\text { studies carried out for environmental agencies and for special interest } \\
\text { groups. }\end{array}$ & $\mathrm{C}$ & $\begin{array}{l}\text { An indication of the use of some kind of data source, mainly reports of certain studies } \\
\text { exists, and a list of documents used is provided. }\end{array}$ \\
\hline $\begin{array}{l}2.8 \text { Review local, regional and national plan and policies, and other } \\
\text { data collected as necessary to predict future environmental } \\
\text { conditions. Where the proposal does not conform to these plans and } \\
\text { policies, the departure is justified. }\end{array}$ & $\mathrm{C}$ & $\begin{array}{l}\text { Existing national plan, NEPM-E, and other data sources such as FAO reports on } \\
\text { biodiversity conservation were reviewed (to a certain extent) to predict future } \\
\text { environmental conditions. }\end{array}$ \\
\hline $\begin{array}{l}2.9 \text { Local, regional and national agencies holding information on } \\
\text { baseline environmental conditions have been approached. }\end{array}$ & $\mathrm{C}$ & $\begin{array}{l}\text { An indication that national and regional government agencies and relevant private } \\
\text { organizations that hold information on baseline environmental conditions were } \\
\text { approached, exists. }\end{array}$ \\
\hline Overall mark: & $\mathbf{C}$ & \\
\hline
\end{tabular}




\begin{tabular}{|c|c|c|}
\hline 10 Criterion & Performance & Comments \\
\hline \multicolumn{3}{|l|}{ Scoping and consultation } \\
\hline $\begin{array}{l}\text { 3.1 There has been a genuine attempt to contact the general public } \\
\text { agencies, relevant experts and special interest groups to appraise } \\
\text { them of the project and its implication. List the groups approached. }\end{array}$ & $\mathrm{E}$ & $\begin{array}{l}\text { Besides the mention that the consultants in charge of the ELA study met with different } \\
\text { government officials and certain private organizations during their visit to Eritrea, no } \\
\text { indication that the general public, and special interest groups were contacted to } \\
\text { appraise the project and its implication exists. }\end{array}$ \\
\hline $\begin{array}{l}3.2 \text { Statutory consultees have been contacted. List the consultees } \\
\text { approached. }\end{array}$ & A & $\begin{array}{l}\text { All the relevant statutory consultees have been contacted and a list of their names } \\
\text { exists. }\end{array}$ \\
\hline $\begin{array}{l}3.3 \text { Identifies valued environmental attributes on the bases of this } \\
\text { consultation. }\end{array}$ & $\mathrm{F}$ & $\begin{array}{l}\text { The statement fails to indicate if any valued environmental attributes were identified } \\
\text { on the basis of the consultation. }\end{array}$ \\
\hline $\begin{array}{l}\text { 3.4 Identifies all project activities with significant impacts on valued } \\
\text { environmental attributes. Identifies and selects key impacts for more } \\
\text { intense investigation. Describes and justifies the scoping methods } \\
\text { used. }\end{array}$ & $\mathrm{C}$ & $\begin{array}{l}\text { Almost all project activities with significant impacts on valued environmental } \\
\text { attributes were identified and an intense investigation into some of these impacts } \\
\text { occurred, but no description on the scoping method used exists. }\end{array}$ \\
\hline $\begin{array}{l}3.5 \text { Includes a copy or summary of the main comments from } \\
\text { consultees and the public, and measures taken to respond to these } \\
\text { comments. }\end{array}$ & $\mathrm{F}$ & Neither a copy nor a summary of the comments from consultees and the public exists. \\
\hline \multicolumn{3}{|l|}{ Impact identification } \\
\hline $\begin{array}{l}\text { 3.6 Considers direct and indirect/secondary effects of constructing, } \\
\text { operating and, where relevant, after-use or decommissioning of the } \\
\text { project (including positive and negative effects). Considers whether } \\
\text { effects will arise as a result of "consequential" development. }\end{array}$ & $\mathrm{C}$ & $\begin{array}{l}\text { Consideration of direct and indirect (to certain extent) impact of the development } \\
\text { exists. Also certain considerations of the effects that will arise as a result of } \\
\text { consequential development do exist, but the after use effects are not considered. }\end{array}$ \\
\hline $\begin{array}{l}3.7 \text { Investigates the above types of impacts in so far as they affect: } \\
\text { human being, flora, fauna, soil, water, air, climate, landscape, } \\
\text { interactions between the above, material assets, cultural heritage. }\end{array}$ & $\mathrm{C}$ & $\begin{array}{l}\text { Investigation of the impacts on human beings, flora, fauna, soil, water, air, climate, } \\
\text { landscape, material assets, and cultural heritages exists, but they are not detailed. }\end{array}$ \\
\hline 3.8 Also noise, land use, historic heritage, communities. & $\mathrm{C}$ & These also exist, but again not detailed. \\
\hline $\begin{array}{l}3.9 \text { If any of the above are not concern in relation to the specific } \\
\text { project and its location, this is clearly stated. }\end{array}$ & - & All the stated impacts are a concern for the project. \\
\hline $\begin{array}{l}3.10 \text { Identifies impacts using a systematic methodology such as } \\
\text { project specific checklists, matrices, panels of experts, extensive } \\
\text { consultations, etc. Describes the methods/approaches used and the } \\
\text { rationale for using them. }\end{array}$ & $\mathrm{E}$ & $\begin{array}{l}\text { Beside the stated consultation with different government agencies, there is no mention } \\
\text { of the methodology used to identify the impacts. }\end{array}$ \\
\hline $\begin{array}{l}\text { 3.11 The investigation of each type of impact is appropriate to its } \\
\text { importance for decision, avoiding unnecessary information and } \\
\text { concentrating on the key issues. }\end{array}$ & $\mathrm{C}$ & $\begin{array}{l}\text { In many cases the investigations are concentrated on the key issues, but sometimes full } \\
\text { information on the investigated issue is lacking (e.g. noise level, number of } \\
\text { households to relocate). }\end{array}$ \\
\hline $\begin{array}{l}3.12 \text { Consider impacts which may not themselves be significant but } \\
\text { which may contribute incrementally to a significant effect. }\end{array}$ & $\mathbf{F}$ & No consideration of such impacts does exist. \\
\hline
\end{tabular}


Criterion

3.13 Consider impacts which might arise from non-standard operating conditions, accidents and emergencies.

3.14 If the nature of the project is such that accidents are possible

which might cause sever damage within the surrounding

environment, an assessment of the probability and likely

consequence of such events is carried out and the main findings

reported.

Overall mark:
Performance

C

Consideration of impacts which might arise from non-standard operating conditions and accidents (oil drain and fuel spills) exists.

Spillage during refueling was identified to be the major possible accident, but there is no assessment of its probability or likely consequences.

\section{PREDICTION AND EVALUATION OF IMPACTS}

\section{\begin{tabular}{|c|l|l|l|l|l|} 
Criterion & Performance
\end{tabular} \\ Prediction of magnitude impacts}

4.1 Describes impacts in terms of the nature and magnitude of the

change occurring and the nature, location, number value, sensitivity

of the affected receptors.

4.2 Predicts the timescale over which the effects will occur, so that it is clear whether impacts are short, medium or long term, temporary or permanent, reversible or irreversible.

4.3 Where possible, expresses the impact predictions in quantitative terms. Qualitative descriptions, where necessary are fully defined as possible.

4.4 Describe the likelihood of impacts occurring and the level of uncertainty attached to the results.

$\mathrm{C}$

Description of the nature of impacts and magnitude of the change occurring and the nature, the location, of the affected receptors exists. Many of the impacts (e.g. air and noise pollution) however, are not quantified, so the predicted magnitude of the change occurring in the affected receptor may not be satisfactory.

E $\quad$ Besides a description of impacts that occur during the construction time and the different phases of operation time, there exists no prediction of the timescale over which the effects will occur

C $\quad$ Most of the predicted impacts are described qualitatively and in many cases they are fairly defined. Few quantitative (e.g. impact on socio-economic and impact on water requirement) descriptions, however, exist.

Few cases where the likelihood of impacts occurring and the level of uncertainty attached to the results exist. For example, pollution of underground soil and aquifer by oil from the mechanical maintenance.

\section{Methods and data} are described, and are appropriate to the size and importance of the projected disturbance.

4.6 The data used to estimate the size and scale of the main impacts are sufficient for the task, clearly described, and their sources clearly identified. And gaps in the data are indicated and accounted for.

Evaluation of impact significance

4.7 Discusses the significance of effects in terms of the on the impact

local community (including distribution of impacts) and on the

protection of environmental resources.

\begin{tabular}{|c|c|}
\hline & \\
\hline$C$ & M \\
\hline
\end{tabular}

No description of methods used to predict the nature, size and scale of impacts exists.

Much of the data used to estimate the impacts is sufficient for the task, clearly described, and their sources are clearly identified. But some are not sufficient (e.g.

A

Discussions of the significance of effects include both impact on the local community and on the protection of environmental resources. noise pollution, birds safety). 


\section{Criterion}

4.8 Discusses the available standards, assumptions and value systems which can be used to assess significance.

4.9 Where there are no generally accepted standards or criteria for the evaluation of significance, alternative approaches are discussed and, if so, a clear distribution is made between fact, assumption and professional judgment.

4.10 Discusses the significance of effects taking into account the appropriate national and international standards or norms, where these are available. Otherwise the magnitude, location and duration of the effects are discussed in conjunction with the value, sensitivity and rarity of the resource.

4.11 Differentiate project-generated impacts from other changes

resulting from non-project activities and variables.

4.12 Includes a clear identification of which impacts may be significant and which may not.

\section{ALTERNATIVES}

\section{Criterion}

5.1 Consider the "no action" alternative, alternative processes, scales, layouts, designs and operating conditions where available at an early stage of project planning, and investigates their main environmental advantages and disadvantages.

5.2 If an expectedly sever adverse impacts are identified during the course of the investigation, which are difficult to mitigate,

alternatives rejected in the earlier planning phases are re-appraised. 5.3 Gives the reasons for selecting the proposed project, and the part environmental factors played in the selection.

5.4 The alternatives are realistic and genuine.

5.5 Compares the alternatives' main environmental impacts clearly and objectively with those of the proposed project and with the likely future environmental conditions without the project.

\section{Performance}

D

Besides a few assumptions (poliution of underground soil and aquifer by oil), no standards which can be used to assess significance, were indicated.

The approach used in evaluation of significance is a bit cloudy. There is no clear indication (in some of the impacts), whether the evaluation is based on a clear factual finding from an investigation or professional judgment. For example, effect of the project on fauna/mammals and birds safety.

C Certain consideration of value, sensitivity and rarity of the resource in discussing the magnitude and location of significance of effects exist. But no indication on the use of international or national standards exists.

B

A

A

C
There is a clear indication that all the stated impacts are project generated. However changes resulting from non-project activities and variables are not included. A clear identification of which impacts may be significant and which may not exists.
Performance

$\mathrm{F}$
Comments

No consideration of alternatives, including the no action alternative exists.

No impact was identified as an impact which is difficult to mitigate.

E

There is no comparison of alternatives which result in selection of a proposed project. However, the economic reasons why the project is important are provided. No alternative exists.

No alternative exists. 


\begin{tabular}{|c|c|c|}
\hline Criterion & Performance & 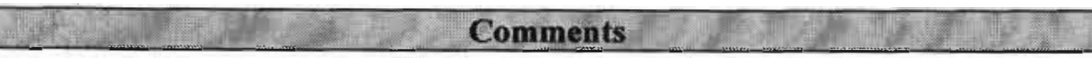 \\
\hline \multicolumn{3}{|l|}{ Description of mitigation measure } \\
\hline $\begin{array}{l}6.1 \text { Considers the mitigation of all significant negative impacts and, } \\
\text { where feasible, proposes specific mitigation measures to address } \\
\text { each impact. }\end{array}$ & B & $\begin{array}{l}\text { Consideration of mitigation of significant negative impacts exists, specific mitigation } \\
\text { measures are also proposed to address each impact. For few of the identified impacts, } \\
\text { however, mitigation measures are not provided. For example, air pollution was } \\
\text { identified to have a local effect, but no mitigation measure was mentioned either to } \\
\text { avoid or reduce this effect. }\end{array}$ \\
\hline $\begin{array}{l}6.2 \text { Mitigation measures considered include modification of project } \\
\text { design, construction and operation, the replacement of facilities/ } \\
\text { resources, and the creation of new resources, as well as 'end-of-pipe' } \\
\text { technologies for pollution control. }\end{array}$ & B & The considered mitigation measures include all the stated types of mitigation. \\
\hline $\begin{array}{l}6.3 \text { Describes the reasons for choosing the particular type of } \\
\text { mitigation, and the other options available. }\end{array}$ & $\mathrm{D}$ & $\begin{array}{l}\text { With the exception of the mitigation stated to protect soil erosion and land scaping } \\
\text { (i.e. planting trees) no alternative method of mitigation where a choice can be made } \\
\text { exists. }\end{array}$ \\
\hline $\begin{array}{l}\text { 6.4 Explains the extent to which the mitigation methods will be } \\
\text { effective. Where the effectiveness is uncertain, or where the } \\
\text { mitigation may not work, this is made clear and data are introduced } \\
\text { to justify the acceptance of these assumptions. }\end{array}$ & B & $\begin{array}{l}\text { Some kind of explanation that indicates the effectiveness of the mitigation method } \\
\text { used exists. E.g. section } 2.2 \text {. of part three of the report clearly explains the } \\
\text { effectiveness of the recommended system (mitigation measure) for treating waste } \\
\text { water. }\end{array}$ \\
\hline $\begin{array}{l}6.5 \text { Indicates the significance of any residual or unmitigated impact } \\
\text { remaining after mitigation, and justifies why these impacts should be } \\
\text { mitigated. }\end{array}$ & F & $\begin{array}{l}\text { No indication of the significance of any residual or unmitigated impact remaining after } \\
\text { mitigation exists. }\end{array}$ \\
\hline \multicolumn{3}{|l|}{ Commitment to mitigation and monitoring } \\
\hline $\begin{array}{l}6.6 \text { Gives details of how the mitigation measures will be } \\
\text { implemented and function over the time span for which they are } \\
\text { necessary. }\end{array}$ & $\bar{A}$ & $\begin{array}{l}\text { The environmental monitoring program is prepared to monitor the implementation and } \\
\text { function of mitigation measures over the entire life cycle of the project. }\end{array}$ \\
\hline $\begin{array}{l}\text { 6.7 Proposes monitoring arrangements for all significant impacts, } \\
\text { specially where uncertainty exists, to check the environmental } \\
\text { resulting from the implementation of the project and their conformity } \\
\text { with the prediction made. }\end{array}$ & A & $\begin{array}{l}\text { Monitoring arrangements for all significant impacts to take appropriate measures if } \\
\text { unforeseen environmental damage is highlighted or the measures implemented prove } \\
\text { inadequate exist. }\end{array}$ \\
\hline $\begin{array}{l}\text { 6.8 The scale of any proposed monitoring arrangements corresponds } \\
\text { to the potential scale and significance of deviations from expected } \\
\text { impacts. }\end{array}$ & B & $\begin{array}{l}\text { The scale of the proposed monitoring arrangements fairly corresponds to the potential } \\
\text { scale and significance of deviations from expected impacts. }\end{array}$ \\
\hline \multicolumn{3}{|l|}{ Environmental effects of mitigation } \\
\hline $\begin{array}{l}6.9 \text { Investigates and describes any adverse Environmental effects of } \\
\text { mitigation measures. }\end{array}$ & $\mathrm{C}$ & The effect of planting on water requirements was investigated and identified. \\
\hline $\begin{array}{l}\text { 6.10 Considers the potential for conflict between the benefits of } \\
\text { mitigation measures and their adverse impacts. }\end{array}$ & B & $\begin{array}{l}\text { Consideration of the potential for conflict between the benefits of mitigation measures } \\
\text { and their adverse impacts exists. A particular example is, the plantation of mangroves } \\
\text { and their effect on water requirement. }\end{array}$ \\
\hline Overall mark: & B & \\
\hline
\end{tabular}




\begin{tabular}{|c|c|c|}
\hline Criterion & Performance & 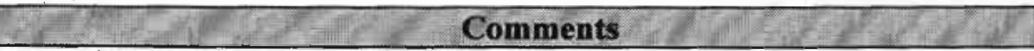 \\
\hline $\begin{array}{l}\text { 7.1 There is a non-technical summary of the main finding of the } \\
\text { study, which contains at least a brief description of the project and } \\
\text { environment, an account of the main mitigation measures to be } \\
\text { undertaken by the developer, and a description of any remaining or } \\
\text { residual impacts. }\end{array}$ & $\mathrm{A}$ & A non-technical summary with all the stated requirement exists. \\
\hline $\begin{array}{l}7.2 \text { The summary avoids technical terms, list of data and detailed } \\
\text { explanation of scientific reasoning. }\end{array}$ & A & $\begin{array}{l}\text { The summary avoids technical terms, lists of data and detailed explanations of } \\
\text { scientific reasoning. }\end{array}$ \\
\hline $\begin{array}{l}\text { 7.3 The summary presents the main findings of the assessment and } \\
\text { covers all the main issues raised in the information }\end{array}$ & A & All requirements exist. \\
\hline $\begin{array}{l}\text { 7.4 The summary includes a brief explanation of the overall } \\
\text { approach to the assessment. }\end{array}$ & A & The overall approach followed in the assessment is also included in the summary. \\
\hline $\begin{array}{l}7.5 \text { The summary indicates the confidence which can be placed in } \\
\text { the results. }\end{array}$ & $\mathrm{C}$ & Some kind of confidence can be placed in the results by reading the summary. \\
\hline Overall mark: & $\overline{\mathbf{A}}$ & \\
\hline
\end{tabular}

\section{ORGANISATION AND PRESENTATION OF INFORMATION}

\begin{tabular}{|l|c|}
\hline \multicolumn{1}{|c|}{ Criterion } & Performance \\
\hline Organisation of the information & $\mathrm{A}$ \\
\hline 8.1 Logically arranges the information in sections. & $\mathrm{A}$ \\
\hline 8.2 Identifies the location of information in a table or list of contents. & $\mathrm{D}$ \\
\hline $\begin{array}{l}\text { 8.3 There are chapter or section summaries outlining the main } \\
\text { findings of each phase of the investigation. }\end{array}$ & $\mathrm{D}$ \\
\hline $\begin{array}{l}\text { 8.4 When information from external sources has been introduce, a } \\
\text { full reference to the source is included. }\end{array}$ & \\
\hline
\end{tabular}

full reference to the source is included.

$\mathrm{C}$

8.5 Mentions the relevant ELA legislation, name of the developer, name of competent authority(ies), name of organisation preparing the EIS, and name, address and contact number of a contact person.

8.6 Include an introduction briefly describing the project, the aims of the assessment, and the methods used.

8.7 The statement is presented as an integrated whole. Data presented in appendices are fully discussed in the main body of the text.

\section{All the information is arranged in sections.} To indicate the location of the information a full table of contents exists.
Besides the summary of the lasting impacts, no section summaries exist.

There are many cases (especially in part one of the statement) with no reference to the source of data. Even the existing few are not properly referenced.

Mention of the existing environmental policies and EIA guideline (for there is no national EIA regulations) exists. The name of the organisation preparing the EIS is also given but the name, address and contact number of a contact person is missing. Though it is not clearly indicated, by reading the report, one can understand that the Government of Eritrea is the developer and Ministry of Transport and Communications is the competent authority.

A brief introduction that describes the project, and the aims of the assessment exists. However, besides the consultation with relevant government agencies and private companies no description of the method used is provided. A $\quad$ The statement is presented as an integrated whole. No data is presented in appendices. 
Criterion

8.8 Offers information and analysis to support all conciusions drown.

8.9 Presents information so as to be comprehensible to the non specialist. Uses maps, tables, graphical material and other devices as appropriate. Avoids unnecessarily technical or obscure language. 8.10 Discuses all the important data and results in an integrated fashion.

8.11 Avoids superfluous information (i.e. information not needed for the decision). terminology and logical link between different sections.

8.13 Gives prominence and emphasis to sever adverse impacts, substantial environmental benefits, and controversial issues.

8.14 Defines technical terms, acronyms and initials.

8.15 The information is objective, and does not lobby for any

particular point of view. Adverse impacts are not distinguished by

euphemisms or platitudes.

Difficulties compiling the information

8.16 Indicates any gaps in the required data and explains the means

used to deal with them in the assessment.

8.17 Acknowledges and explains any difficulties in assembling or analyzing the data needed to predict impacts, and any basis for questioning assumptions, data or information.

Overall mark

\section{COLLATION}

1 Description of the development

2 Description of the environment
Performance

\section{in many cases it offers information and analysis to support conclusions drown, but} there are few cases where the conclusions drown are not supported fully or eise the

information to draw the conclusion is missing. For example, not enough illustration is provided to conclude that the effects of the fenced area on the natural environment and human activity are limited due to the low intrinsic interest of the area in its initial stage.

The presented information avoids unnecessary technical language and is

comprehensible to the non-specialist. In many cases the information is presented using comprehensible to the non-specialist. In many
different devices, such as maps and tables.

All the important data and results are discussed in an integrated fashion.

In most cases superfluous information is avoided. However, there is certain information (particularly in part one of the statement) not needed or used in decisionmaking. That part presents information and data, which are only relevant at national or regional level rather than providing information relevant to the particular site (local level).

The information is presented in a concise form with consistent terminology and logical links between different sections exists.

Some kind of prominence and emphasis on certain severe impacts do exist. However, the report does not give emphasis on noise pollution, one of the most controversial issues in EIA of airports projects.

No definition of technical terms, acronyms, and initials exists.

In many cases the information is objective, though some subjectivity exists. But this

does not necessarily mean lobbying for a particular point of view. In addition adverse impacts are not distinguished by euphemisms or platitudes.

the required data (pollution by oil spill and its contamination on soil and ground aquifer) and ways of dealing with it (depollution and test of ground water at certain interval) exists.

Besides mentioning that the pollution of the ground water is not known and cannot be ignored, no acknowledgement and explanation of any difficulties in assembling or analyzing the data needed to predict its impact exists. 
6 Mitigation and monitoring

7 Non-technical summary

8 Organisation and presentation of information

Overall mark (A-F):

\section{CASE STUDY 2: KEREN WATER SUPPLY PROJECT ${ }^{3}$}

Keren Water Supply Project was proposed to identify a reliable potable water supply to Keren, the second largest city in the country with a population of approximately 83,248. The components of the project included: construction of a permanent diversion dam (which covers about 85 ha of land) on the Anseba River; construction of a $3 \mathrm{~km}$ long supply canal; construction of a $54 \mathrm{~m}$ high storage dam; laying of a $3 \mathrm{~km}$ long raw water pipeline (750 mm diameter) from the storage dam to the water treatment plant; phased construction of a $48,000 \mathrm{~m}^{3}$ per day water treatment plant; and laying of $22 \mathrm{~km}$ of treated water pipeline to Keren, delivering water to the existing storage reservoirs within the city. The developer was Ministry of Public Works of the Government of Eritrea. The EIA study of the project was part of the feasibility and preliminary design work conducted by the National Resource Consulting Engineers, in June 2002. The EIA report is presented as an appendix part of the final preliminary design report. The EIA report attempts to conform to the format stated in NEAPG and is the only Category A project acknowledged by the DoE to pass through the requirements of the NEAPG under close supervision of the department. The full analysis of the content of the report against the stated criteria is given below.

\section{DESCRIPTION OF THE DEVELOPMENT}

\begin{tabular}{|l|l|l|}
\hline \multicolumn{1}{|c|}{ Criterion } & Performance & \\
\hline \multicolumn{2}{|l|}{} \\
\hline Principal features of project
\end{tabular}

\footnotetext{
${ }^{3}$ Unless otherwise indicated all the information is taken from Natural Resource Consulting Engineers (2002).
} 


\section{Criterion}

1.3 Gives the estimated duration of the construction, operational and, where appropriate, decommissioning phase, and the program within these phases.

1.4 Describes the proposed development, including its design and size or scale. Diagram, plans or maps will usually be necessary for this purpose.

1.5 Indicates the physical presence or appearance of the completed development within the receiving environment.

1.6 Describes the methods of construction

1.7 Describes the nature and methods of production or other types of activity involved in the operation of the project.

1.8 Describes any additional service (water, electricity, emergency service etc.) and developments require as a consequence of the project.

1.9 Describes the projects potential for accidents, hazards and emergencies.

\section{Land requirements}

1.10 Defines the land area taken up by the development site and associated arrangements, auxiliary facilities and landscaping areas and by the construction site (s), and shows their location clearly on a map. For a linear project, describes the land corridor, vertical and horizontal alignment and need for tunneling and earthworks.

1.11 Describes the uses to which this land will be put, and demarcates the different land use area.

1.12 Describes the reinstatement and after-use of landtake during

construction.
Performance total period for sediment deposition, i.e the life span of the project (45 years) ars) exists. Estimated duration for mitigation of certain activities also exists but there is no clear estimation of the duration of construction and the programs within the different phases.

C $\quad$ Clear verbal description of the different components of the project exists. However, diagrams, plans and maps are missing.

Verbal indication of the physical presence or appearance of the completed development within the receiving environment exists, but the diagram, plans or maps that could help to give a clear and simple illustration are missing.

Besides the mention that the construction will involve some machinery, no detailed and clear description of the methods of construction exists.

A general description of the activities involved during the operation (purification and distribution of water) of the project exists. However, the detailed method of production, especially the treatment of water, is not well described.

Besides mention of an access road and building of temporary living facilities, offices, and temporary residential complexes for construction workers, there exists no

description of additional services (water, electricity, emergency service etc.).

Though not in detail, the statement provides a description of the projects potential for accidents and hazards. These are mainly, probability of dam failure/damage due to earthquake, falling of children into the dam, and hazards of disease such as malaria and bilharzia.

The land area taken up by the development site and landscaping areas are defined but the associated arrangements, auxiliary facilities such as the building of temporary

living facilities, offices, and temporary residential complexes for construction workers are only mentioned and they still need to be defined. Moreover, a map that shows their clear location is missing.

The uses to which this land will be put are clearly described but no demarcation of the different land use area exists.

Reinstatement and after-use of landtake during construction are describes as part of the contractor's operational task. But the description lacks detail. 


\begin{tabular}{|c|c|c|}
\hline 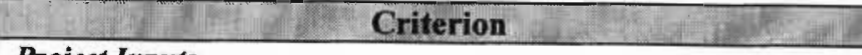 & Performance & Comments \\
\hline \multicolumn{3}{|l|}{ Project Inputs } \\
\hline $\begin{array}{l}\text { 1.13 Describe the nature and quantities of materials needed during } \\
\text { the construction and operational phases. }\end{array}$ & $\mathrm{D}$ & $\begin{array}{l}\text { Beside the mention that some materials such as aggregates, cement, and pozzolana } \\
\text { will be used in the construction and the contractor's operations might involve realizing } \\
\text { pollutants such as untreated sewage and sanitary waste, tailing, petroleum products, } \\
\text { chemicals, biocides, mineral salts, and thermal pollution, no proper description of the } \\
\text { nature and quantities of materials needed during the construction and operational } \\
\text { phases exists. }\end{array}$ \\
\hline $\begin{array}{l}\text { 1.14 Estimates the number of workers and visitors entering the } \\
\text { project site during both construction and operation. }\end{array}$ & F & No such estimation exists. \\
\hline 1.15 Describe their access to the site and likely means of transport. & - & $\begin{array}{l}\text { In order to proceed with this question, the performance of section } 1.14 \text { need be } \\
\text { different form } F \text {. }\end{array}$ \\
\hline $\begin{array}{l}\text { 1.16 Indicates the means of transporting materials and products to } \\
\text { and from the site during construction, operation, and number of } \\
\text { movements involved. }\end{array}$ & $\mathrm{E}$ & $\begin{array}{l}\text { Besides the mention of the involvement of machinery during the construction time, } \\
\text { neither the means of transporting materials to and from the site during construction nor } \\
\text { the number of movements involved are indicated. }\end{array}$ \\
\hline \multicolumn{3}{|l|}{ Residues and emissions } \\
\hline $\begin{array}{l}\text { 1.17 Estimates the types and quantities of waste matter, energy } \\
\text { (noise, vibration, light, heat, radiation, etc.) and residual materials } \\
\text { generated during construction and operation of the project, and rate } \\
\text { at which these will be produced. }\end{array}$ & $\mathrm{D}$ & $\begin{array}{l}\text { Besides the mention of some of the types of waste matter and energy (noise) generated } \\
\text { during construction and operation of the project, no estimated quantities exist. }\end{array}$ \\
\hline $\begin{array}{l}1.18 \text { Indicates how these wastes and residual materials are expected } \\
\text { to be handled/treated prior to release/disposal, and the routs by } \\
\text { which they will be eventually be disposed of to the environment. }\end{array}$ & $\mathrm{C}$ & $\begin{array}{l}\text { Some mechanisms are indicated to handle the release of the stated wastes. E.g. water } \\
\text { sprinkling, to minimize dust; noise avoidance, by limiting construction at night time. } \\
\text { However, some of the handling mechanisms are very general rather than being } \\
\text { specific and to the point. E.g. to prevent contamination of ground water, the statement } \\
\text { requires the contractor to ensure proper disposal of waste material and trash by } \\
\text { whatever methods, rather that specifying the relevant method. }\end{array}$ \\
\hline $\begin{array}{l}1.19 \text { Identifies any special or hazardous wastes (defined as) which } \\
\text { will be produced, and describes the methods for their disposal as } \\
\text { regards their likely main environmental impacts. }\end{array}$ & - & This might not be relevant to such kind of projects. \\
\hline $\begin{array}{l}1.20 \text { Indicates the methods by which the quantities of residuals and } \\
\text { wastes were estimated. Acknowledges any uncertainty, and gives } \\
\text { ranges of confidence limits where appropriate. }\end{array}$ & $\mathrm{F}$ & No such provision exists. \\
\hline Overall mark: & C & \\
\hline
\end{tabular}




\begin{tabular}{|c|c|c|}
\hline Criterion $\quad$ All & Performance & Comments \\
\hline \multicolumn{3}{|c|}{ Description of the area occupied by and surrounding the project } \\
\hline $\begin{array}{l}2.1 \text { Indicates the area expected to be significantly affected by the } \\
\text { various aspects of the project with the aid of suitable maps. } \\
\text { Explains the time over which these impacts are likely to occur. }\end{array}$ & $\mathrm{C}$ & $\begin{array}{l}\text { Verbal explanation exists, but maps and the specific time over which the impacts are } \\
\text { likely to occur are missing. }\end{array}$ \\
\hline 2.2 Describes the land uses on the site(s) and in surrounding areas. & B & $\begin{array}{l}\text { The land uses on the site and in surrounding areas are well described. However, it } \\
\text { might be better illustrated if it was supported by diagrams or plans. }\end{array}$ \\
\hline $\begin{array}{l}2.3 \text { Defines the affected environment broadly enough to include any } \\
\text { potentially significant effects occurring away from the immediate } \\
\text { areas of construction and operation. These may be caused by, for } \\
\text { example, the dispersion of pollutants, infrastructural requirements } \\
\text { of the project, traffic etc. }\end{array}$ & $\bar{B}$ & $\begin{array}{l}\text { Besides lack of detail in a few areas (e.g. the effect of the project on water } \\
\text { requirement of villages down stream), the affected environment is defined broadly } \\
\text { enough to include any potentially significant effects occurring away from the } \\
\text { immediate areas of construction and operation }\end{array}$ \\
\hline \multicolumn{3}{|l|}{ Baseline conditions } \\
\hline $\begin{array}{l}2.4 \text { Indicates and describes the components of the affected } \\
\text { environment potentially affected by the project. }\end{array}$ & A & Clear indication and description exists. \\
\hline $\begin{array}{l}2.5 \text { The method used to investigate the affected environment are } \\
\text { appropriate to the size and complexity of the assessment task. } \\
\text { Uncertainty is indicated. }\end{array}$ & A & $\begin{array}{l}\text { Based on the description given for the significance of the affected environment the } \\
\text { methods used for investigation are appropriate to the size and complexity of the } \\
\text { assessment task. In cases of uncertainty (e.g. the caution for archeological interest of } \\
\text { the area) decisions were taken by experts by having a field assessment. }\end{array}$ \\
\hline $\begin{array}{l}2.6 \text { Predicts the likely future environmental conditions in the } \\
\text { absence of the project. Identifies variability in natural systems and } \\
\text { human use. }\end{array}$ & $\mathrm{C}$ & $\begin{array}{l}\text { Prediction of the likely future environmental conditions in the absence of the project } \\
\text { exists. However, it lacks detail on identifying the variability, particularly, in natural } \\
\text { systems with and without which the project is not identified. }\end{array}$ \\
\hline $\begin{array}{l}2.7 \text { Uses existing technical data sources, including records and } \\
\text { studies carried out for environmental agencies and for special } \\
\text { interest groups. }\end{array}$ & A & $\begin{array}{l}\text { The use of existing technical data sources, including records and studies carried out } \\
\text { for both national and international environmental agencies and for special interest } \\
\text { groups is clearly indicated. }\end{array}$ \\
\hline $\begin{array}{l}2.8 \text { Review local, regional and national plan and policies, and other } \\
\text { data collected as necessary to predict future environmental } \\
\text { conditions. Where the proposal does not conform to these plans and } \\
\text { policies, the departure is justified. }\end{array}$ & B & $\begin{array}{l}\text { Existing national plans and policies are fairly reviewed in order to conform with their } \\
\text { requirements. }\end{array}$ \\
\hline $\begin{array}{l}2.9 \text { Local, regional and national agencies holding information on } \\
\text { baseline environmental conditions have been approached. }\end{array}$ & $\bar{A}$ & $\begin{array}{l}\text { All the relevant ministries were approached for baseline information of the } \\
\text { environmental conditions. }\end{array}$ \\
\hline Overall mark: & $\mathbf{B}$ & \\
\hline
\end{tabular}




\section{SCOPING, CONSULTATION AND IMPACT IDENTIFICATION}

\begin{tabular}{|c|c|c|}
\hline Criterion & Performance & Comments \\
\hline \multicolumn{3}{|l|}{ Scoping and consultation } \\
\hline $\begin{array}{l}\text { 3.1 There has been a genuine attempt to contact the general public } \\
\text { agencies, relevant experts and special interest groups to appraise } \\
\text { them of the project and its implication. List the groups approached. }\end{array}$ & $\overline{\mathrm{A}}$ & $\begin{array}{l}\text { The EMP of the statement indicates that there have been different meetings and } \\
\text { conferences with village administration, community council members, residents of } \\
\text { the village and main government stakeholders. The names of the groups approached } \\
\text { are also provided. }\end{array}$ \\
\hline $\begin{array}{l}\text { 3.2 Statutory consultees have been contacted. List the consultees } \\
\text { approached. }\end{array}$ & A & A list of the statutory consultees that were contacted during the study exists. \\
\hline $\begin{array}{l}3.3 \text { Identifies valued environmental attributes on the bases of this } \\
\text { consultation. }\end{array}$ & A & $\begin{array}{l}\text { The statement indicates that valued environmental attributes were identified on the } \\
\text { basis of the consultation. }\end{array}$ \\
\hline $\begin{array}{l}\text { 3.4 Identifies all project activities with significant impacts on } \\
\text { valued environmental attributes. Identifies and selects key impacts } \\
\text { for more intense investigation. Describes and justifies the scoping } \\
\text { methods used. }\end{array}$ & $\mathrm{C}$ & $\begin{array}{l}\text { Activities with significant environmental impacts are identified. But they are not } \\
\text { detailed, and no description of the scoping methods used exists. }\end{array}$ \\
\hline $\begin{array}{l}3.5 \text { Includes a copy or summary of the main comments from } \\
\text { consultees and the public, and measures taken to respond to these } \\
\text { comments. }\end{array}$ & $\mathrm{B}$ & $\begin{array}{l}\text { A summary of the main meetings and the activities within these meetings is } \\
\text { described, and a summary of the requirement of the local community and the } \\
\text { measures taken to respond to these requirements is given in the EMP of the } \\
\text { statement. Comments from the consultees are indicated in the statement but the } \\
\text { summaries are missing. }\end{array}$ \\
\hline \multicolumn{3}{|l|}{ Impact identification } \\
\hline $\begin{array}{l}\text { 3.6 Considers direct and indirect/secondary effects of constructing, } \\
\text { operating and, where relevant, after-use or decommissioning of the } \\
\text { project (including positive and negative effects). Considers whether } \\
\text { effects will arise as a result of "consequential" development. }\end{array}$ & $\mathrm{C}$ & $\begin{array}{l}\text { There is no clear differentiation between direct and indirect impact in the statement, } \\
\text { but reading the statement it can be understood that both direct and indirect are } \\
\text { considered to certain extent. The emphasis, however, was more on the positive } \\
\text { effects. Similarly, the report considers only the positive effects of the consequential } \\
\text { development. }\end{array}$ \\
\hline $\begin{array}{l}3.7 \text { Investigates the above types of impacts in so far as they affect: } \\
\text { human being, flora, fauna, soil, water, air, climate, landscape, } \\
\text { interactions between the above, material assets, cultural heritage. }\end{array}$ & $\mathrm{C}$ & $\begin{array}{l}\text { The investigation covers the impact on human beings, flora, fauna, soil, water, air, } \\
\text { climate, landscape, material assets and cultural heritage. However, the emphasis, } \\
\text { especially on the indirect impacts, is on the positive effects. }\end{array}$ \\
\hline 3.8 Also noise, land use, historic heritage, communities. & $\mathrm{C}$ & They are looked into, but not in detail. \\
\hline $\begin{array}{l}3.9 \text { If any of the above are not concern in relation to the specific } \\
\text { project and its location, this is clearly stated. }\end{array}$ & - & All of them are a concern for the project. \\
\hline $\begin{array}{l}3.10 \text { Identifies impacts using a systematic methodology such as } \\
\text { project specific checklists, matrices, panels of experts, extensive } \\
\text { consultations, etc. Describes the methods/approaches used and the } \\
\text { rationale for using them. }\end{array}$ & $\mathrm{C}$ & $\begin{array}{l}\text { There is a mention that impacts were identified through consultation with } \\
\text { government authorities, experts and field assessment done by a multidisciplinary } \\
\text { team. There also exist matrices that present the comparison effect of the proposed } \\
\text { project and the no action alternative, but it lacks details and presents only the } \\
\text { positives of the proposed project and the negatives of the no action alternative. }\end{array}$ \\
\hline
\end{tabular}




\begin{tabular}{|c|c|c|}
\hline Criterion & Performance & Comments \\
\hline $\begin{array}{l}\text { 3.11 The investigation of each type of impact is appropriate to its } \\
\text { importance for decision, avoiding unnecessary information and } \\
\text { concentrating on the key issues. }\end{array}$ & $\mathrm{C}$ & $\begin{array}{l}\text { The investigation avoids unnecessary information by concentrating on the key issues. } \\
\text { In addition many of the impacts are investigated by relevant experts and the final } \\
\text { decision for their significance was made by the experts themselves. However in } \\
\text { many cases they are not detailed or quantified. }\end{array}$ \\
\hline $\begin{array}{l}3.12 \text { Consider impacts which may not themselves be significant but } \\
\text { which may contribute incrementally to a significant effect. }\end{array}$ & $\mathrm{F}$ & No consideration of such impacts exists. \\
\hline $\begin{array}{l}3.13 \text { Consider impacts which might arise from non-standard } \\
\text { operating conditions, accidents and emergencies. }\end{array}$ & $\mathrm{B}$ & $\begin{array}{l}\text { Consideration of certain impacts which might arise from non-standard contractor's } \\
\text { operations such as accidental spillage of contaminants, debris, or other pollutants and } \\
\text { emergency from earthquake on dam damage exists. }\end{array}$ \\
\hline $\begin{array}{l}3.14 \text { If the nature of the project is such that accidents are possible } \\
\text { which might cause sever damage within the surrounding } \\
\text { environment, an assessment of the probability and likely } \\
\text { consequence of such events is carried out and the main findings } \\
\text { reported. }\end{array}$ & B & $\begin{array}{l}\text { The major accident mentioned for the project is earthquake and measures that need to } \\
\text { minimize its effect are described. But the extent of the damage, if the accident } \\
\text { happened, is not fully described. }\end{array}$ \\
\hline Overall mark: & $\mathbf{C}$ & \\
\hline
\end{tabular}

\section{PREDICTION AND EVALUATION OF IMPACTS}

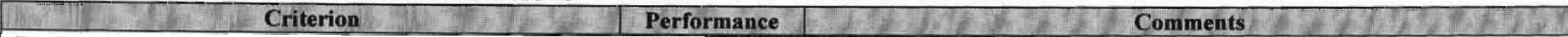
Prediction of magnitude impacts

\begin{tabular}{|l|l|l|l} 
4.1 Describes impacts in terms of the nature and magnitude of the & C & Description is provided but lacks detail and quantification with regard to the extent of
\end{tabular} change occurring and the nature, location, number value, sensitity of the affected receptors.

it is clear whether impacte over which the effects will occur, so that

temporary or per impacts are short, medium or long term,

porary or permanent, reversible or irreversible.

4.3 Where possible, expresses the impact predictions in quantitative terms. Qualitative descriptions, where necessary are fully defined as possible.

4.4 Describe the likelihood of impacts occurring and the level of

uncertainty attached to the results.

\section{Methods and data}

4.5 The methods used to predict the nature, size and scale of

impacts are described, and are appropriate to the size and the impact.

importance of the projected disturbance.

$\mathrm{D}$

Besides the mention that some of the impacts (e.g. air pollution from dust) are temporary and a description of impacts that occur during the different phases of the project, no full and clear prediction of the timescale over which the effects will occur exists.

$\mathrm{D}$ not fully defined. Few quantitative (e.g. number of homes to be relocated and size of land taken by the project) descriptions, however, exist.

Description of some likelihood of impacts, for example, the impact on archeological remains and effect of water shortage that could occur on one of the down stream commercial farms, exists.

Methods, such as consultation with relevant government authorities and field assessment by experts were held to identify the nature of impacts and the use of matrices to make a comparison effect of the proposed project and the no action alternative are mentioned. But the use of appropriate methods to predict the size and scale of the impact are not properly described. 


\section{Criterion}

4.6 The data used to estimate the size and scale of the main impacts are sufficient for the task, clearly described, and their sources

clearly identified. And gaps in the data are indicated and accounted for.

\section{Evaluation of impact significance}

4.7 Discusses the significance of effects in terms of the impact local community (including distribution of impacts) and on the protection of environmental resources.

4.8 Discusses the available standards, assumptions and value systems which can be used to assess significance

4.9 Where there are no generally accepted standards or criteria for the evaluation of significance, alternative approaches are discussed and, if so, a clear distribution is made between fact, assumption and professional judgment.

4.10 Discusses the significance of effects taking into account the appropriate national and international standards or norms, where these are available. Otherwise the magnitude, location and duration of the effects are discussed in conjunction with the value, sensitivity and rarity of the resource

4.11 Differentiate project-generated impacts from other changes resulting from non-project activities and variables.

4.12 Includes a clear identification of which impacts may be significant and which may not Overall mark:

5. ALTERNATIVES

\section{Performance}

5.1 Consider the "no action" alternative, alternative processes, scales, layouts, designs and operating conditions where available at an early stage of project planning, and investigates their main environmental advantages and disadvantages.

5.2 If an expectedly sever adverse impacts are identified during the course of the investigation, which are difficult to mitigate, alternatives rejected in the earlier planning phases are re-appraised. 5.3 Gives the reasons for selecting the proposed project, and the part environmental factors played in the selection.

\begin{tabular}{|c|c|}
\hline & $\mathrm{C}$ \\
\hline & $\mathrm{D}$ \\
\hline
\end{tabular}

B

C

\section{Performance}

It is hard to say that the data used to estimate the size and scale of the main impacts is sufficient for the task. Because they are not quantified or detailed either.

The discussion on significance of effects includes both impact on local community and protection of environmental resources at certain levels.

Besides a mention of some assumption (e.g. the attraction of the water reservoir for birds) and standards of the water quality, no detailed discussion on standards, assumptions and value systems which can be used to assess significance exists. The approach used in evaluation of significance is a bit cloudy. There is no a clear indication (in some of the impacts) if the evaluation is based on a clear factual finding from an investigation or professional judgment. E.g. effect of the project on fauna.

C $\quad$ There exist certain considerations of value, sensitivity and rarity of the resource in discussing the magnitude and location of significance of effects. But no indication on the use of international or national standards exists.

There is a clear indication that all the stated impacts are project generated. However changes resulting from non-project activities (e.g. soil erosion problems) are also included.

Although there exists identification of which impacts are significant and which are not, no impact was identified having a major significantly negative impact.

$\mathrm{D}$

Besides the no action alternative (oments

Besides the no action alternative (only its disadvantages) no consideration of alternative processes, scales, layouts, designs or operating conditions exists.

e

No alternatives exist, to have/ not to have such provisions.

The reasons for selecting the proposed project, and the part environmental factors played in the selection are provided. However, the selection is only in comparison with the negative impacts of the no action alternative option. 
Performance

5.4 The alternatives are realistic and genuine.

5.5 Compares the alternatives' main environmental impacts clearly

and objectively with those of the proposed project and with the

likely future environmental conditions without the project.

Overall mark:

\section{Comments}

The proposed alternative and the no alternative could be realistic but for them to be more realistic and genuine they need to be compared with other alternatives and

should be described in detail including both their advantages and disadvantages.

Only the negative impacts (on health and socio economics) of the no option

alternative were compared with the proposed project.

\section{MITIGATION AND MONITORING}

\begin{tabular}{|c|c|c|}
\hline Criterion & Performance & Comments \\
\hline \multicolumn{3}{|l|}{ Description of mitigation measure } \\
\hline $\begin{array}{l}\text { 6.1 Considers the mitigation of all significant negative impacts and, } \\
\text { where feasible, proposes specific mitigation measures to address } \\
\text { each impact. }\end{array}$ & $\overline{\mathrm{C}}$ & Some kind of mitigation measures for the significant negative impacts exists. \\
\hline $\begin{array}{l}\text { 6.2 Mitigation measures considered include modification of project } \\
\text { design, construction and operation, the replacement of facilities/ } \\
\text { resources, and the creation of new resources, as well as 'end-of- } \\
\text { pipe' technologies for pollution control. }\end{array}$ & $\mathrm{C}$ & The mitigation measures include all the stated types of mitigation. \\
\hline $\begin{array}{l}\text { 6.3 Describes the reasons for choosing the particular type of } \\
\text { mitigation, and the other options available. }\end{array}$ & $\overline{\mathrm{D}}$ & $\begin{array}{l}\text { Besides the general reason for all mitigation measures, i.e. to be consistent with the } \\
\text { economy and efficiency in the execution of the project, no description of reasons for } \\
\text { choosing the particular type of mitigation exists. }\end{array}$ \\
\hline $\begin{array}{l}\text { 6.4 Explains the extent to which the mitigation methods will be } \\
\text { effective. Where the effectiveness is uncertain, or where the } \\
\text { mitigation may not work, this is made clear and data are introduced } \\
\text { to justify the acceptance of these assumptions. }\end{array}$ & $\mathrm{D}$ & $\begin{array}{l}\text { Besides the mitigation taken to minimize the effect of earthquake damage on the } \\
\text { dam, no explanation on the extent to which the mitigation methods will be effective } \\
\text { exists. }\end{array}$ \\
\hline $\begin{array}{l}6.5 \text { Indicates the significance of any residual or unmitigated impact } \\
\text { remaining after mitigation, and justifies why these impacts should } \\
\text { not be mitigated. }\end{array}$ & F & $\begin{array}{l}\text { No indication of significance of any residual or unmitigated impact remaining after } \\
\text { mitigation exists. }\end{array}$ \\
\hline \multicolumn{3}{|l|}{ Commitment to mitigation and monitoring } \\
\hline $\begin{array}{l}\text { 6.6 Gives details of how the mitigation measures will be } \\
\text { implemented and function over the time span for which they are } \\
\text { necessary. }\end{array}$ & $\mathrm{B}$ & $\begin{array}{l}\text { EMP is prepared to monitor the implementation and function of mitigation measures } \\
\text { over the entire life cycle of the project. However, some of the mitigation measures } \\
\text { mentioned lack detail. }\end{array}$ \\
\hline $\begin{array}{l}6.7 \text { Proposes monitoring arrangements for all significant impacts, } \\
\text { specially where uncertainty exists, to check the environmental } \\
\text { resulting from the implementation of the project and their } \\
\text { conformity with the prediction made. }\end{array}$ & $\bar{A}$ & Environmental Unit is formed to perform all monitoring arrangements. \\
\hline
\end{tabular}




\begin{tabular}{|l|c|l|}
\hline \multicolumn{1}{|c|}{ Criterion } & Performance & \multicolumn{1}{c|}{ Comments } \\
\hline $\begin{array}{l}\text { 6.8 The scale of any proposed monitoring arrangements } \\
\text { corresponds to the potential scale and significance of deviations } \\
\text { from expected impacts. }\end{array}$ & B & $\begin{array}{l}\text { The scale of the proposed monitoring arrangements fairly corresponds to the } \\
\text { potential scale and significance of deviations from expected impacts. }\end{array}$ \\
\hline Environmental effects of mitigation & No environmental effects of mitigation measures was investigated or identified. \\
\hline $\begin{array}{l}\text { 6.9 Investigates and describes any adverse Environmental effects of } \\
\text { mitigation measures. }\end{array}$ & F & $\begin{array}{l}\text { Besides the mention that the mitigation measures, to increase the size of the dam in } \\
\text { order to provide additional water for down stream users, might not be implemented } \\
\text { (because of un stated reasons) no consideration of potential conflict between the } \\
\text { benefits of mitigation measures and their adverse impacts exists. }\end{array}$ \\
\hline $\begin{array}{l}\text { 6.10 Considers the potential for conflict between the benefits of } \\
\text { mitigation measures and their adverse impacts. }\end{array}$ & D & \\
\hline Overall mark: &
\end{tabular}

\section{NON-TECHNICAL SUMMURY}

\section{Criterion}

7.1 There is a non-technical summary of the main finding of the study, which contains at least a brief description of the project and environment, an account of the main mitigation measures to be undertaken by the developer, and a description of any remaining or residual impacts.

7.2 The summary avoids technical terms, list of data and detailed explanation of scientific reasoning.

7.3 The summary presents the main findings of the assessment and covers all the main issues raised in the information

7.4 The summary includes a brief explanation of the overal

approach to the assessment

7.5 The summary indicates the confidence which can be placed in the results.

Overall mark

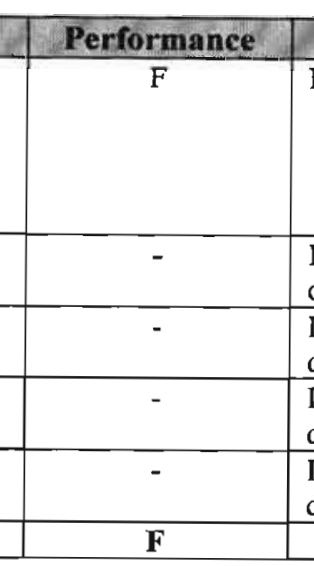

No technical summary exists.

Comments

In order to proceed with this question, the performance of section 7.1 need be different form $\mathrm{F}$.

In order to proceed with this question, the performance of section 7.1 need be different form $\mathrm{F}$.

In order to proceed with this question, the performance of section 7.1 need be different form $\mathrm{F}$.

In order to proceed with this question, the performance of section 7.1 need be different form $\mathrm{F}$.

\section{ORGANISATION AND PRESENTATION OF INFORMATION}

Criterion
\begin{tabular}{|l|c|l|}
\hline \multicolumn{2}{|c|}{ ORGANISATION AND PRESENTATION OF INFORMATION } \\
\hline Organisation of the information & Performance & \\
\hline 8.1 Logically arranges the information in sections. & A & All the information is arranged in sections. \\
\hline $\begin{array}{l}\text { 8.2 Identifies the location of information in a table or list of } \\
\text { contents. }\end{array}$ & A & $\begin{array}{l}\text { To indicate the location of the information, a full table of contents and a list of tables } \\
\text { exist. }\end{array}$ \\
\hline $\begin{array}{l}\text { 8.3 There are chapter or section summaries outlining the main } \\
\text { findings of each phase of the investigation. }\end{array}$ & D & Besides the last summary of the impacts, no section summaries exist. \\
\hline
\end{tabular}




\begin{tabular}{|c|c|c|}
\hline Criterion & Performance & 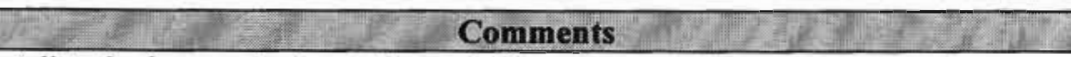 \\
\hline $\begin{array}{l}\text { 8.4 When information from external sources has been introduced, a } \\
\text { full reference to the source is included. }\end{array}$ & $\mathrm{C}$ & $\begin{array}{l}\text { A list of references is given at the end of the statement. However, besides a few } \\
\text { exceptions, the full and proper references in the text are not indicated. }\end{array}$ \\
\hline \multicolumn{3}{|l|}{ Presentation of information } \\
\hline $\begin{array}{l}\text { 8.5 Mentions the relevant EIA legislation, name of the developer, } \\
\text { name of competent authority (ies), name of organisation preparing } \\
\text { the EIS, and name address and contact number of a contact person. }\end{array}$ & B & $\begin{array}{l}\text { Besides the name and number of the contact person, all the stated requirements are } \\
\text { mentioned clearly. }\end{array}$ \\
\hline $\begin{array}{l}\text { 8.6 Include an introduction briefly describing the project, the aims } \\
\text { of the assessment, and the methods used. }\end{array}$ & A & $\begin{array}{l}\text { A brief introduction that describes the project, and aims of the assessment and the } \\
\text { methods used exists. }\end{array}$ \\
\hline $\begin{array}{l}\text { 8.7 The statement is presented as an integrated whole. Data } \\
\text { presented in appendices are fully discussed in the main body of the } \\
\text { text. }\end{array}$ & $\bar{A}$ & $\begin{array}{l}\text { The statement is presented as an integrated whole. The statement itself is prepared as } \\
\text { an integral part of the whole feasibility document, presented as an appendix. }\end{array}$ \\
\hline $\begin{array}{l}8.8 \text { Offers information and analysis to support all conclusions } \\
\text { drown. }\end{array}$ & $\mathrm{C}$ & $\begin{array}{l}\text { Although not in detailed form, some information and analysis to support all } \\
\text { conclusions drawn exists. }\end{array}$ \\
\hline $\begin{array}{l}8.9 \text { Presents information so as to be comprehensible to the non- } \\
\text { specialist. Uses maps, tables, graphical material and other devices } \\
\text { as appropriate. Avoids unnecessarily technical or obscure language. }\end{array}$ & $\mathrm{C}$ & $\begin{array}{l}\text { The presented information avoids unnecessary technical language and it is } \\
\text { comprehensible to the non-specialist. Tables are used to present information, but no } \\
\text { graphs or maps exist. }\end{array}$ \\
\hline $\begin{array}{l}8.10 \text { Discuses all the important data and results in an integrated } \\
\text { fashion. }\end{array}$ & $\bar{A}$ & All the important data and results are discussed in an integrated fashion. \\
\hline $\begin{array}{l}8.11 \text { Avoids superfluous information (i.e. information not needed } \\
\text { for the decision). }\end{array}$ & B & In most cases, superfluous information is avoided. \\
\hline $\begin{array}{l}\text { 8.12 Presents the information in a concise form with a consistent } \\
\text { terminology and logical link between different sections. }\end{array}$ & $\mathrm{C}$ & $\begin{array}{l}\text { The information is presented in a concise form with a consistent terminology and } \\
\text { logical links between different sections. But some times, the information is too } \\
\text { concise, to provide the required information. }\end{array}$ \\
\hline $\begin{array}{l}8.13 \text { Gives prominence and emphasis to sever adverse impacts, } \\
\text { substantial environmental benefits, and controversial issues. }\end{array}$ & $\mathrm{D}$ & $\begin{array}{l}\text { No noticeable emphasis to sever adverse impacts, substantial environmental benefits, } \\
\text { and controversial issues exist. }\end{array}$ \\
\hline 8.14 Defines technical terms, acronyms and initials. & $\mathrm{D}$ & $\begin{array}{l}\text { Besides few definitions inside the text, no definition of technical terms, acronyms or } \\
\text { initials exists. }\end{array}$ \\
\hline $\begin{array}{l}8.15 \text { The information is objective, and does not lobby for any } \\
\text { particular point of view. Adverse impacts are not distinguished by } \\
\text { euphemisms or platitudes. }\end{array}$ & $\mathrm{D}$ & $\begin{array}{l}\text { Though it cannot be said that adverse impacts are distinguished by euphemisms or } \\
\text { platitudes, presenting only the positive effect of the proposed project and only the } \\
\text { negative effects of the no alternative might indicate lack of objectivity of the } \\
\text { statement. }\end{array}$ \\
\hline \multicolumn{3}{|l|}{ Difficulties compiling the information } \\
\hline $\begin{array}{l}\text { 8.16 Indicates any gaps in the required data and explains the means } \\
\text { used to deal with them in the assessment. }\end{array}$ & $\mathrm{B}$ & $\begin{array}{l}\text { Lack of secondary data is indicated and the means used to deal with it is explained } \\
\text { (i.e. a field assessment of multidisciplinary team to collect the required information). }\end{array}$ \\
\hline $\begin{array}{l}8.17 \text { Acknowledges and explains any difficulties in assembling or } \\
\text { analyzing the data needed to predict impacts, and any basis for } \\
\text { questioning assumptions, data or information. }\end{array}$ & F & $\begin{array}{l}\text { No acknowledgement of any difficulties in assembling or analyzing the data needed } \\
\text { to predict impacts, nor any basis for questioning assumptions, data or information } \\
\text { exists. }\end{array}$ \\
\hline Overall mark: & $\mathbf{C}$ & \\
\hline
\end{tabular}




\section{COLLATION}

1 Description of the development

2 Description of the environment

3 Scoping, consultation, and impact identification

4 Prediction and evaluation of impacts

5 Alternatives

6 Mitigation and monitoring

7 Non-technical summary

8 Organisation and presentation of information

Overall mark (A-F): 


\section{Appendix 3: Annual report on EIA of projects for environmental clearance ${ }^{1}$ (1999- mid 2002)}

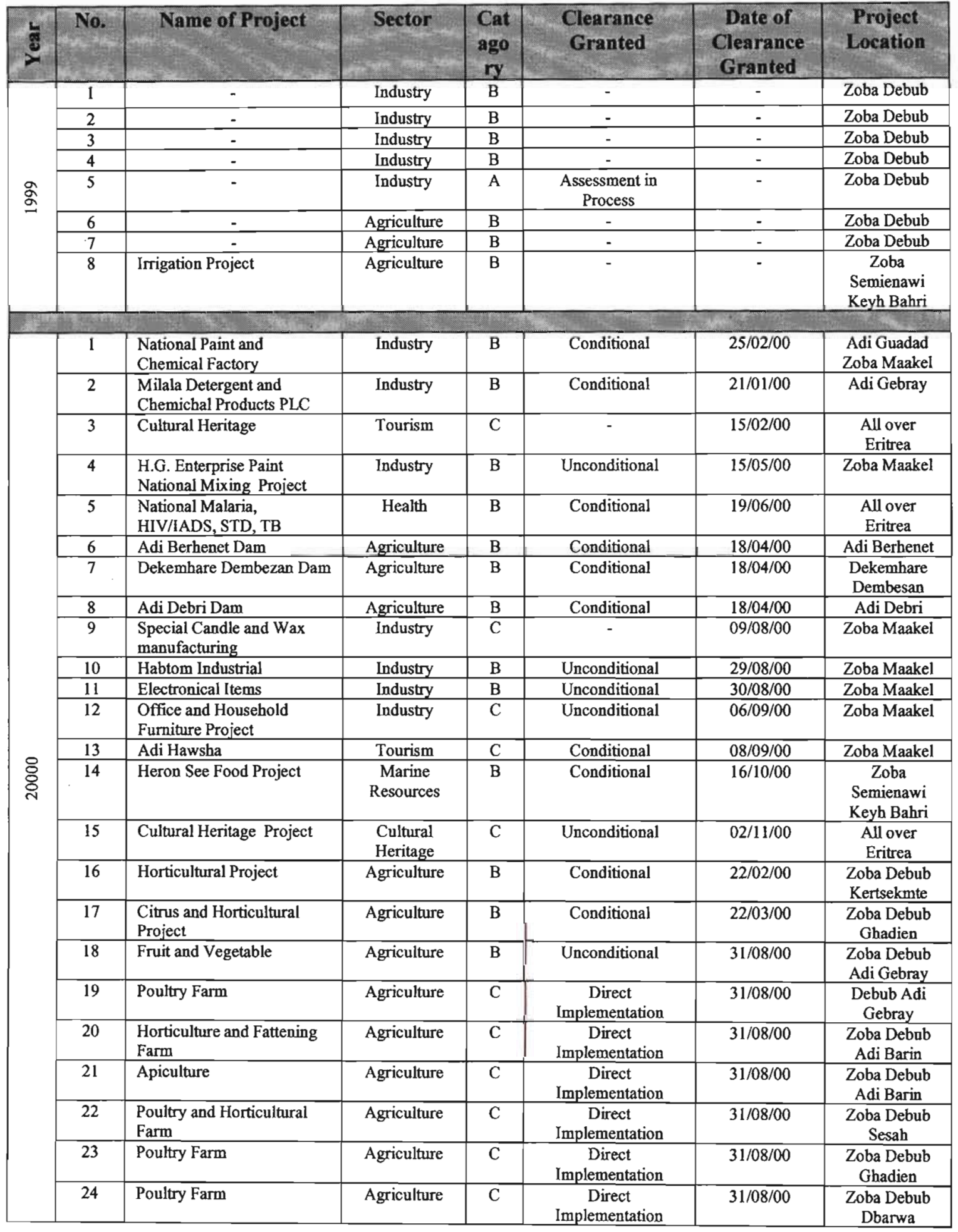

${ }^{1}$ The majority part of the report was presented in Tigrigna (Eritrean language), for the purpose of this study they are translated into English. 


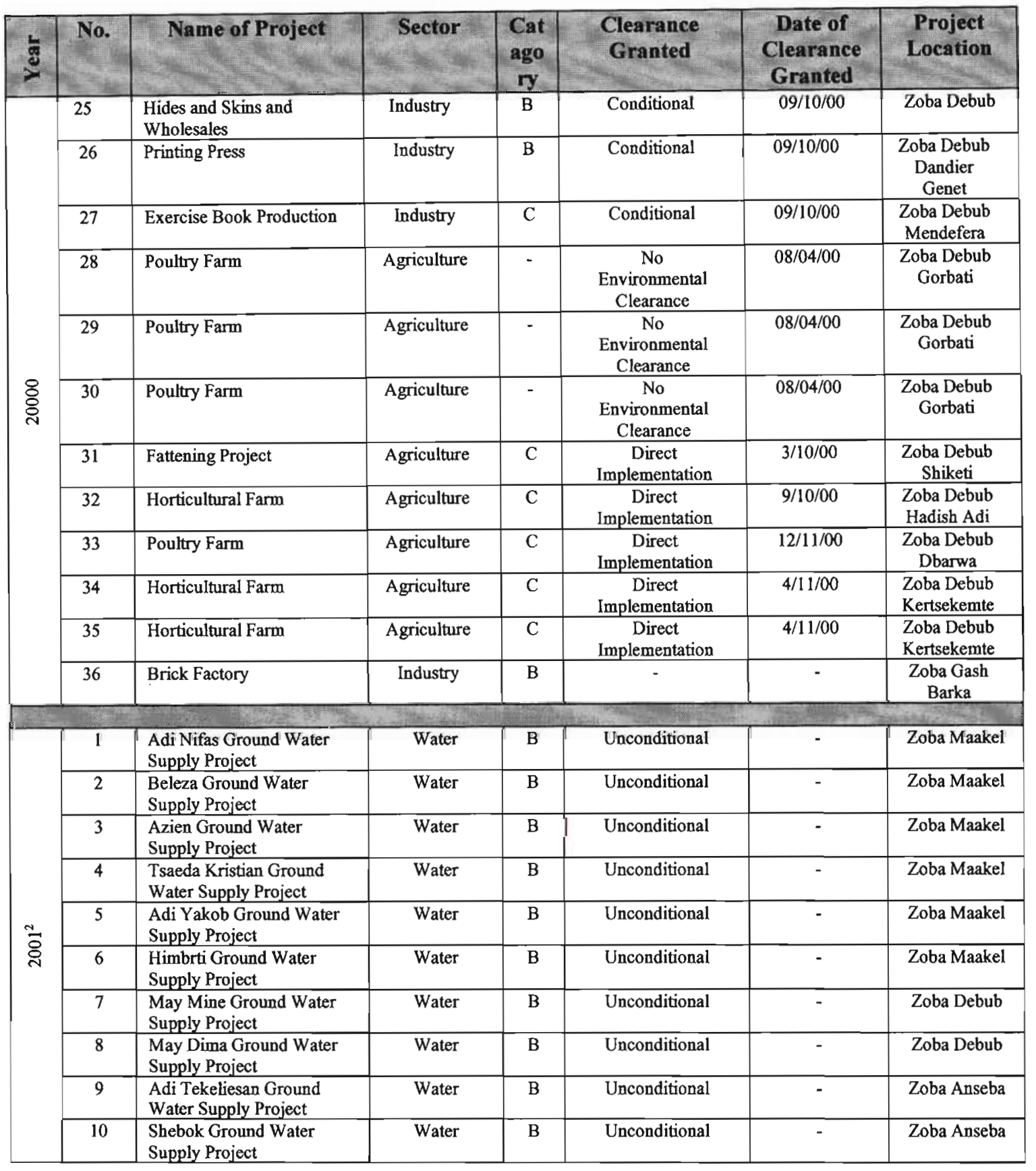

${ }^{2}$ Besides this list of projects, the report also indicated that in 2001, 58 agricultural projects in Zoba Gash Barka (8 in Akurdet, 1 in Barentu, 7 in Tesenai, 16 in Dige, 1 in Mensura, 10 in Forto, 9 in Hykota, and 1 in Gogne) were given a license after a surveying was carrier using a MoA's surveying guideline (different from NEAPG). 


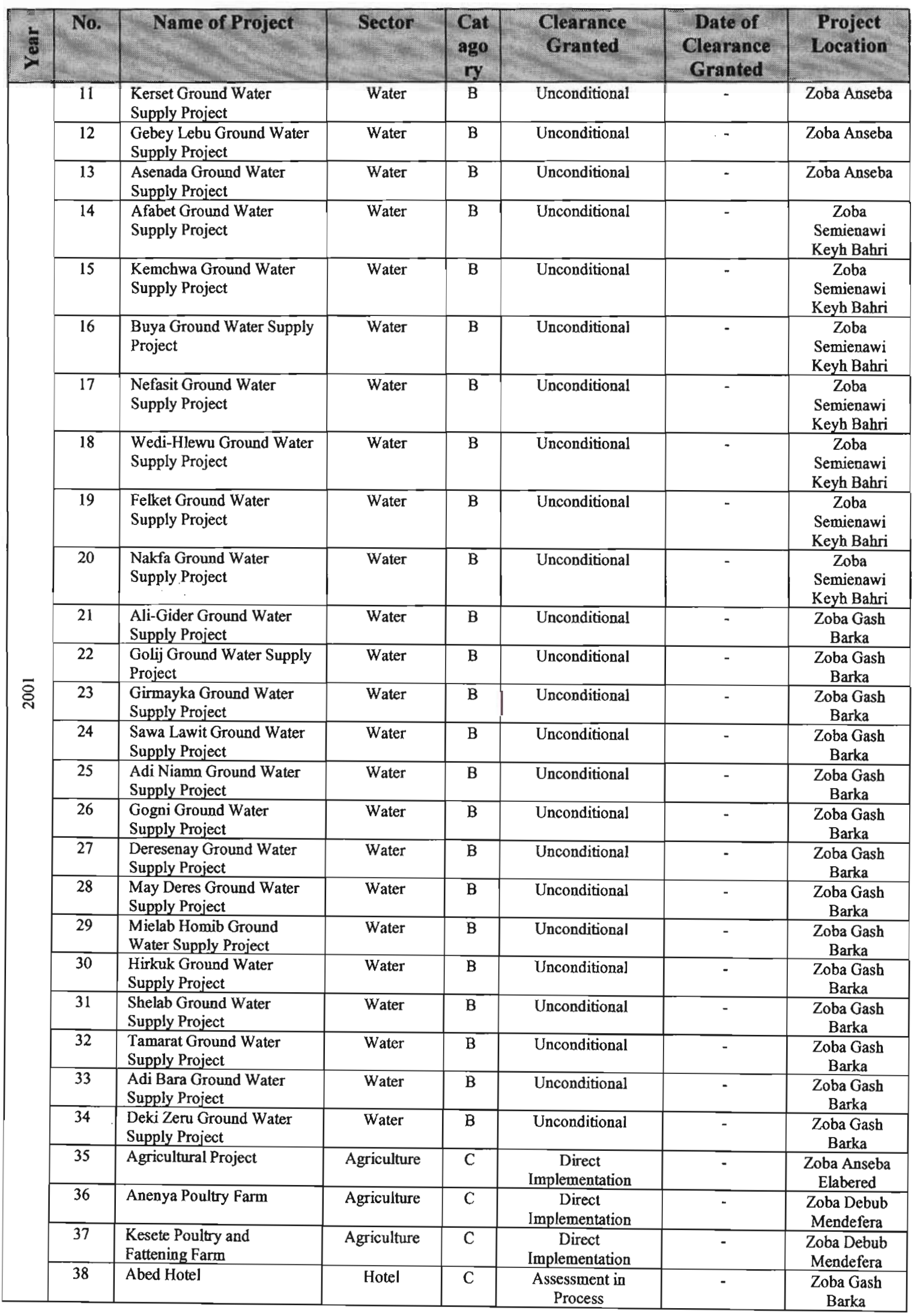




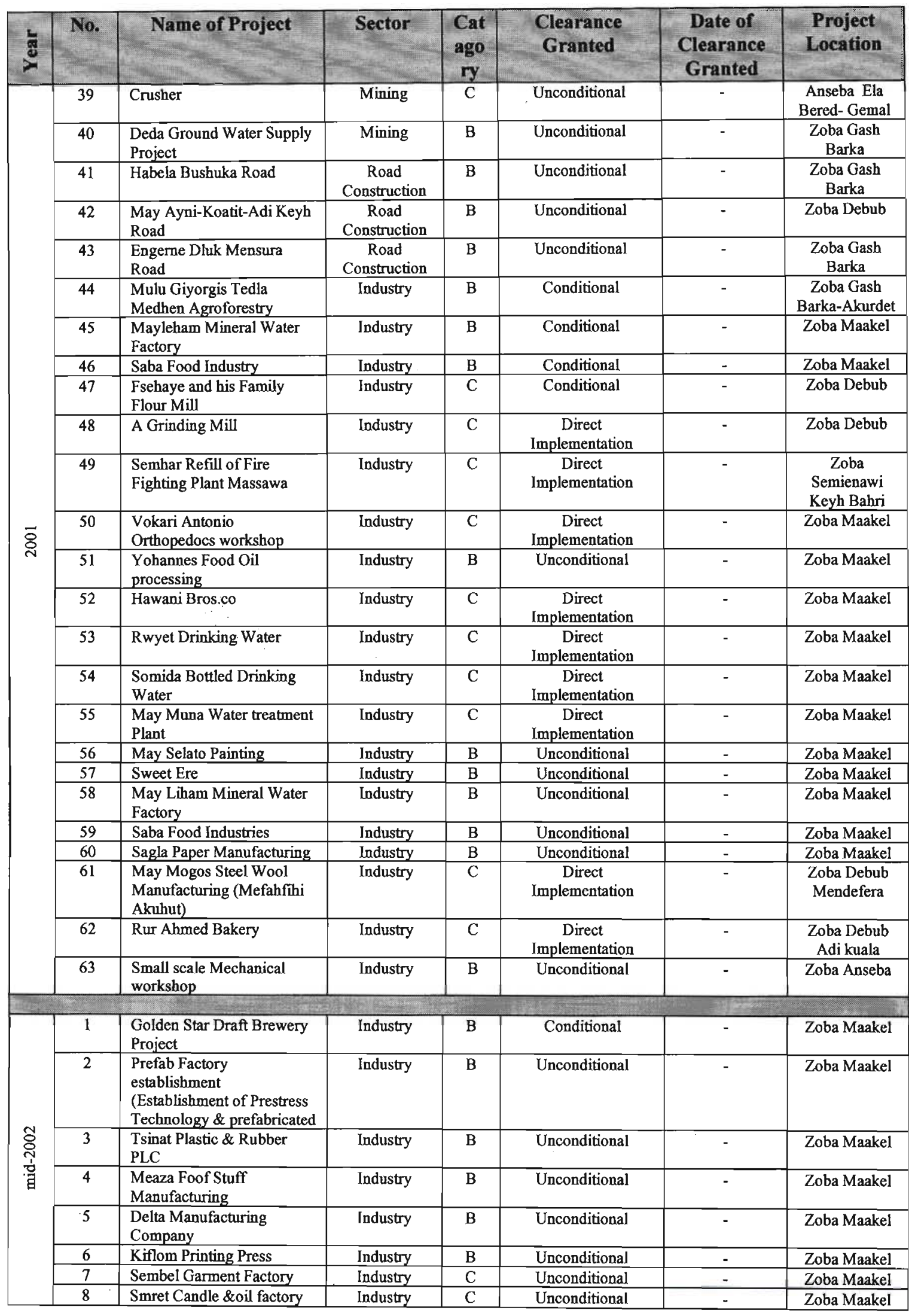




\begin{tabular}{|c|c|c|c|c|c|c|c|}
\hline है & No. & & Sector & $\begin{array}{c}\text { Cat } \\
\text { ago } \\
\text { ry }\end{array}$ & $\begin{array}{c}\text { Clearance } \\
\text { Granted }\end{array}$ & $\begin{array}{l}\text { Date of } \\
\text { Clearance } \\
\text { Granted }\end{array}$ & $\begin{array}{l}\text { Project } \\
\text { Location }\end{array}$ \\
\hline \multirow{42}{*}{$\begin{array}{l}\tilde{O} \\
\stackrel{8}{1} \\
\dot{y}\end{array}$} & 9 & $\begin{array}{l}\text { Ghidey Zerasion Machinery } \\
\text { shop \& Crasher }\end{array}$ & Industry & A & $\begin{array}{l}\text { Assessment in } \\
\text { Process }\end{array}$ & $\cdot$ & Zoba Maakel \\
\hline & 10 & $\begin{array}{l}\text { Mehari Brhan Basalt Stone } \\
\text { \&Crasher }\end{array}$ & Industry & - & $\begin{array}{l}\text { Assessment in } \\
\text { Process }\end{array}$ & - & Zoba Maakel \\
\hline & 11 & Al-Hashem Crasher & Industry & - & $\begin{array}{l}\text { Assessment in } \\
\text { Process }\end{array}$ & - & Zoba Maakel \\
\hline & 12 & $\begin{array}{l}\text { Zeweldi Cement Block } \\
\text { production }\end{array}$ & Industry & $\mathrm{B}$ & Unconditional & - & Zoba Debub \\
\hline & 13 & Maman Crasher & Industry & $\mathbf{B}$ & Conditional & - & Zoba Debub \\
\hline & 14 & $\begin{array}{l}\text { Tafere and his Sons Earth } \\
\text { Cement manufacturing }\end{array}$ & Industry & B & Unconditional & - & Zoba Debub \\
\hline & 15 & $\begin{array}{l}\text { Esku Universal Blanket } \\
\text { Manufacturing }\end{array}$ & Industry & B & Unconditional & - & Zoba Debub \\
\hline & 16 & Fishaye Andegergis Garage & Industry & $B$ & Unconditional & - & Zoba Debub \\
\hline & 17 & Habte Araya Garage & Industry & $\mathrm{B}$ & Unconditional & - & Zoba Debub \\
\hline & 18 & Issac Tekle Petrol Station & Industry & $\mathrm{B}$ & Conditional & - & Zoba Debub \\
\hline & 19 & Alhasen Alamin & $\begin{array}{l}\text { Agriculture- } \\
\text { Irrigation }\end{array}$ & - & $\begin{array}{l}\text { MoA's surveying } \\
\text { assessment form }\end{array}$ & - & $\begin{array}{c}\text { Zoba Gash } \\
\text { Barka-Akurdet }\end{array}$ \\
\hline & 20 & Ahmed Seydna Mahamed & $\begin{array}{l}\text { Agriculture- } \\
\text { Irrigation }\end{array}$ & - & $\begin{array}{l}\text { MoA's surveying } \\
\text { assessment form }\end{array}$ & - & $\begin{array}{c}\text { Zoba Gash } \\
\text { Barka } \\
\end{array}$ \\
\hline & 21 & Teklesenbet Segay & $\begin{array}{l}\text { Agriculture- } \\
\text { Irrigation }\end{array}$ & - & $\begin{array}{l}\text { MoA's surveying } \\
\text { assessment form }\end{array}$ & - & $\begin{array}{c}\text { Zoba Gash } \\
\text { Barka }\end{array}$ \\
\hline & 22 & Ibrahim Hamd & $\begin{array}{l}\text { Agriculture- } \\
\text { Irrigation }\end{array}$ & - & $\begin{array}{l}\text { MoA's surveying } \\
\text { assessment form }\end{array}$ & - & $\begin{array}{c}\text { Zoba Gash } \\
\text { Barka } \\
\end{array}$ \\
\hline & 23 & Adem Nur Kerar & $\begin{array}{l}\text { Agriculture- } \\
\text { Irrigation }\end{array}$ & - & $\begin{array}{l}\text { MoA's surveying } \\
\text { assessment form }\end{array}$ & - & $\begin{array}{c}\text { Zoba Gash } \\
\text { Barka }\end{array}$ \\
\hline & 24 & Edris Hasen Tita & $\begin{array}{l}\text { Agriculture- } \\
\text { Irrigation }\end{array}$ & - & $\begin{array}{l}\text { MoA's surveying } \\
\text { assessment form }\end{array}$ & - & $\begin{array}{c}\text { Zoba Gash } \\
\text { Barka }\end{array}$ \\
\hline & 25 & Hamd Dawd Ibrahim & $\begin{array}{l}\text { Agriculture- } \\
\text { Irrigation }\end{array}$ & - & $\begin{array}{l}\text { MoA's surveying } \\
\text { assessment form }\end{array}$ & - & $\begin{array}{c}\text { Zoba Gash } \\
\text { Barka }\end{array}$ \\
\hline & 26 & Hasen Mohamed Alhasen & $\begin{array}{l}\text { Agriculture- } \\
\text { Irrigation }\end{array}$ & - & $\begin{array}{l}\text { MoA's surveying } \\
\text { assessment form }\end{array}$ & - & $\begin{array}{c}\text { Zoba Gash } \\
\text { Barka }\end{array}$ \\
\hline & 27 & Fitwi Misgina & $\begin{array}{l}\text { Agriculture- } \\
\text { Irrigation }\end{array}$ & - & $\begin{array}{l}\text { MoA's surveying } \\
\text { assessment form }\end{array}$ & - & $\begin{array}{c}\text { Zoba Gash } \\
\text { Barka }\end{array}$ \\
\hline & 28 & Kerar Mohamed Meni & $\begin{array}{c}\text { Agriculture- } \\
\text { Irrigation }\end{array}$ & - & $\begin{array}{l}\text { MoA's surveying } \\
\text { assessment form }\end{array}$ & - & $\begin{array}{c}\text { Zoba Gash } \\
\text { Barka }\end{array}$ \\
\hline & 29 & Mohamed Ahmed Omer & $\begin{array}{l}\text { Agriculture- } \\
\text { Irrigation }\end{array}$ & - & $\begin{array}{l}\text { MoA's surveying } \\
\text { assessment form }\end{array}$ & - & $\begin{array}{c}\text { Zoba Gash } \\
\text { Barka }\end{array}$ \\
\hline & 30 & Hussein Ali Cheway & $\begin{array}{l}\text { Agriculture- } \\
\text { Irrigation }\end{array}$ & - & $\begin{array}{l}\text { MoA's surveying } \\
\text { assessment form }\end{array}$ & - & $\begin{array}{c}\text { Zoba Gash } \\
\text { Barka }\end{array}$ \\
\hline & 31 & Abed Techlemeriam & $\begin{array}{l}\text { Agriculture- } \\
\text { Irrigation }\end{array}$ & - & $\begin{array}{l}\text { MoA's surveying } \\
\text { assessment form }\end{array}$ & - & $\begin{array}{c}\text { Zoba Gash } \\
\text { Barka }\end{array}$ \\
\hline & 32 & Gash Agro Industry & Agriculture & $\mathrm{B}$ & Unconditional & - & $\begin{array}{c}\text { Zoba Gash } \\
\text { Barka }\end{array}$ \\
\hline & 33 & ECDF Water Well Drilling & $\begin{array}{c}\text { Water } \\
\text { Resource }\end{array}$ & $\mathrm{B}$ & Unconditional & - & Zoba Debub \\
\hline & 34 & ECDF Water Well Drilling & $\begin{array}{c}\text { Water } \\
\text { Resource }\end{array}$ & B & Unconditional & - & Zoba Debub \\
\hline & 35 & Jelaleksa Lead Mining & Mining & $\mathrm{C}$ & Conditional & - & Zoba Anseba \\
\hline & 36 & Bet Gemil Lead Mining & Mining & $\mathrm{C}$ & Conditional & - & Zoba Anseba \\
\hline & 37 & Lalmba Lead Mining & Mining & $\mathrm{C}$ & Conditional & - & Zoba Anseba \\
\hline & 38 & Megarh Lead Mining & Mining & $\mathrm{C}$ & Conditional & - & Zoba Anseba \\
\hline & 39 & Gufa Lead Mining & Mining & $\mathrm{C}$ & Conditional & - & Zoba Anseba \\
\hline & 40 & Kebet Lamtet Lead Mining & Mining & $\mathrm{C}$ & Conditional & - & Zoba Anseba \\
\hline & 41 & Hbub Lead Mining & Mining & $\mathrm{C}$ & Conditional & - & Zoba Anseba \\
\hline & 42 & Adi Angur Lead Mining & Mining & $\mathrm{C}$ & Conditional & - & Zoba Anseba \\
\hline & 43 & Abak Lead Mining & Mining & $\mathrm{C}$ & Conditional & - & Zoba Anseba \\
\hline & 44 & Begugubet Lead Mining & Mining & $\mathrm{C}$ & Conditional & - & Zoba Anseba \\
\hline & 45 & Halibay Lead Mining & Mining & $\mathrm{C}$ & Conditional & - & Zoba Anseba \\
\hline & 46 & Kusheten Lead Mining & Mining & $\mathrm{C}$ & Conditional & - & Zoba Anseba \\
\hline & 47 & Kusheten Lead Mining & Mining & $\mathrm{C}$ & Conditional & - & Zoba Anseba \\
\hline & 48 & Buluh Lead Mining & Mining & $\mathrm{C}$ & Conditional & - & Zoba Anseba \\
\hline & 49 & Beguenkmetri Sand Mining & Mining & $\mathrm{C}$ & Conditional & - & Zoba Anseba \\
\hline & 50 & Begu Sand Mining & Mining & $\mathrm{C}$ & Conditional & - & Zoba Anseba \\
\hline
\end{tabular}




\begin{tabular}{|c|c|c|c|c|c|c|c|}
\hline 농 & No. & Name of Project & Sector & $\begin{array}{c}\text { Cat } \\
\text { ago } \\
\text { ry } \\
\end{array}$ & $\begin{array}{l}\text { Clearance } \\
\text { Granted }\end{array}$ & $\begin{array}{l}\text { Date of } \\
\text { Clearance } \\
\text { Granted }\end{array}$ & $\begin{array}{l}\text { Project } \\
\text { Location }\end{array}$ \\
\hline \multirow{17}{*}{ 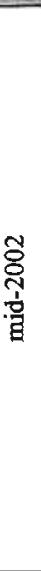 } & 51 & Begu Sand Mining & Mining & $\mathrm{C}$ & Conditional & - & Zoba Anseba \\
\hline & 52 & Fredgi Sand Mining & Mining & $\mathrm{C}$ & Conditional & - & Zoba Anseba \\
\hline & 53 & Kusheten Sand Mining & Mining & $\mathrm{C}$ & Conditional & - & Zoba Anseba \\
\hline & 54 & Kusheten Sand Mining & Mining & $\mathrm{C}$ & Conditional & - & Zoba Anseba \\
\hline & 55 & Kusheten Sand Mining & Mining & $\mathrm{C}$ & Conditional & - & Zoba Anseba \\
\hline & 56 & Kusheten Sand Mining & Mining & $\mathrm{C}$ & Conditional & - & Zoba Anseba \\
\hline & 57 & Bluh Sand Mining & Mining & $\mathrm{C}$ & Conditional & - & Zoba Anseba \\
\hline & 58 & Terenka Sand Mining & Mining & $\mathrm{C}$ & Conditional & - & Zoba Anseba \\
\hline & 59 & Rubankedi Sand Mining & Mining & $\mathrm{C}$ & Conditional & & Zoba Anseba \\
\hline & 60 & Bet Gemil Sand Mining & Mining & $\mathrm{C}$ & Conditional & - & Zoba Anseba \\
\hline & 61 & Keroruba Sand Mining & Mining & $\mathrm{C}$ & Conditional & - & Zoba Anseba \\
\hline & 62 & Wedi Cheway Sand Mining & Mining & $\mathrm{C}$ & Conditional & - & Zoba Anseba \\
\hline & 63 & Gufa Sand Mining & Mining & $\mathrm{C}$ & Conditional & - & Zoba Anseba \\
\hline & 64 & Mentel Sand Mining & Mining & $\mathrm{C}$ & Conditional & - & Zoba Anseba \\
\hline & 65 & Mentel Sand Mining & Mining & $\mathrm{C}$ & Conditional & - & Zoba Anseba \\
\hline & 66 & Ruba Ahferom Sand Mining & Mining & $\mathrm{C}$ & Conditional & - & Zoba Anseba \\
\hline & 67 & Gufa Sand Mining & Mining & $\mathrm{C}$ & Conditional & - & Zoba Anseba \\
\hline
\end{tabular}

